\title{
GENETIC INVESTIGATIONS IN CHRONIC PANCREATITIS AND PANCREATIC CANCER
}

\author{
Ph.D. Thesis
}

Anita Balázs, M.D.

Supervisors:

Prof. Péter Hegyi, M.D., Ph.D., D.Sc. ${ }^{1,2}$

Prof. Miklós Sahin-Tóth, M.D., Ph.D. ${ }^{3}$

\author{
${ }^{1}$ First Department of Medicine \\ Faculty of Medicine \\ University of Szeged
}

${ }^{2}$ MTA-SZTE Lendület Translational Gastroenterology Research Group

\author{
${ }^{2}$ Department of Molecular and Cell Biology \\ Boston University
}

Henry M. Goldman School of Dental Medicine

Szeged

2015. 


\section{TABLE OF CONTENTS}

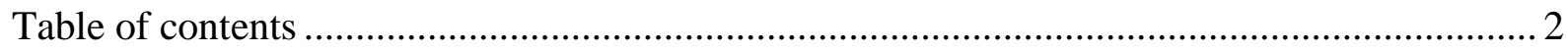

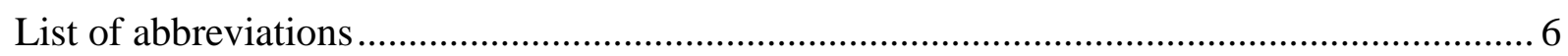

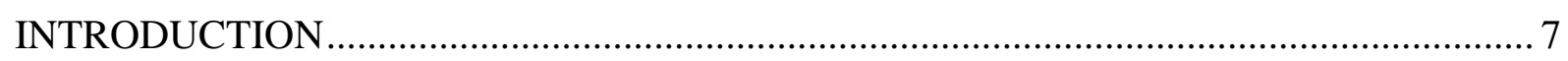

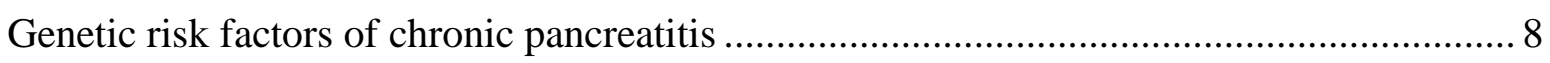

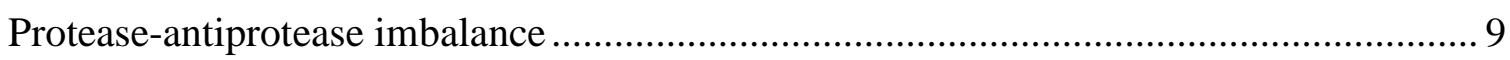

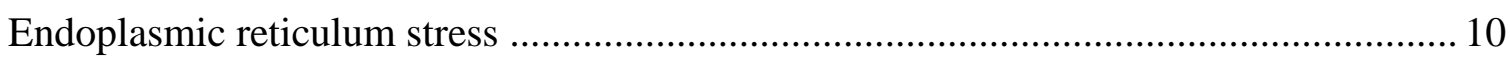

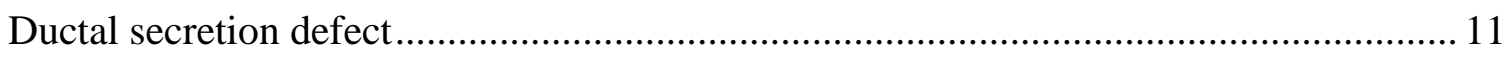

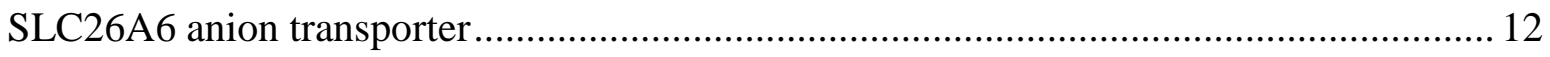

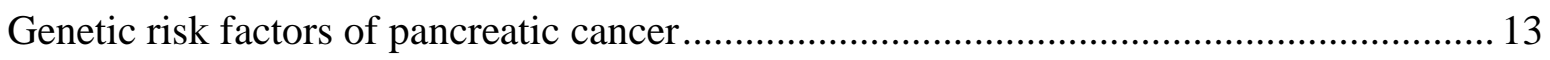

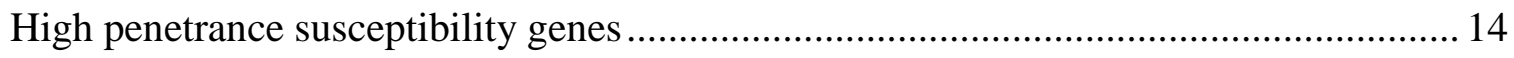

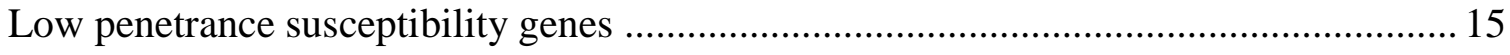

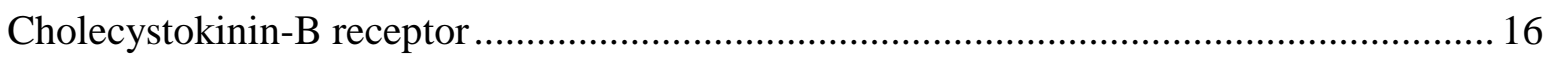

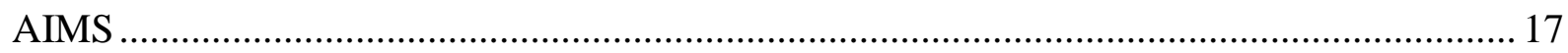

PATIENTS AND METHODS OF GENETIC ANALYSIS OF SLC26A6 IN CHRONIC

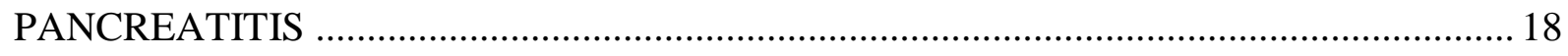

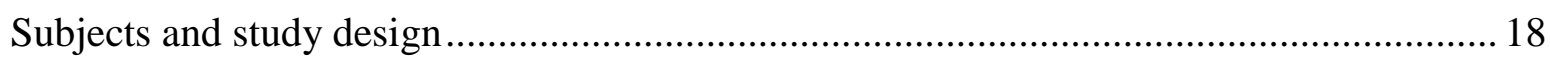

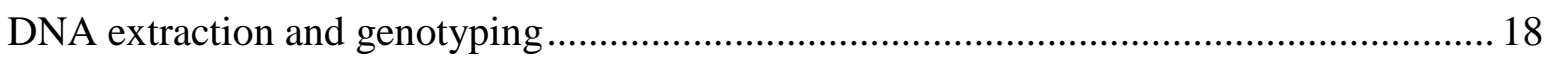

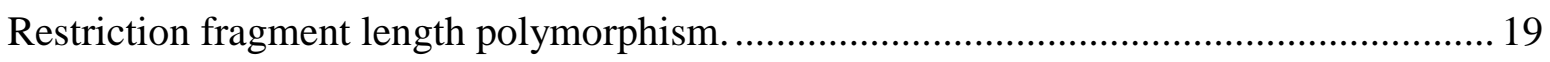

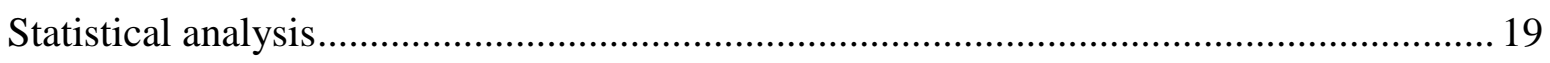

PATIENTS AND METHODS OF GENETIC ANALYSIS OF CCKBR VARIANT IN

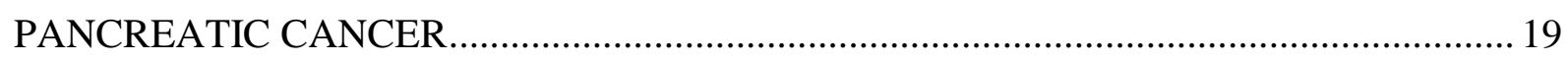

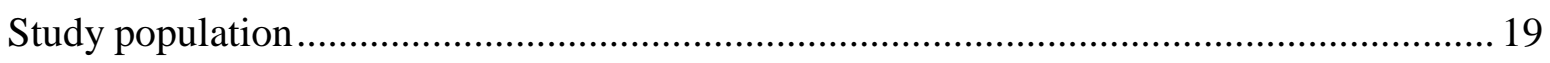

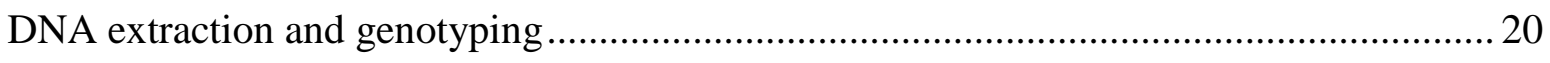

Construction of expression plasmids harboring CCKBR minigenes ................................ 20

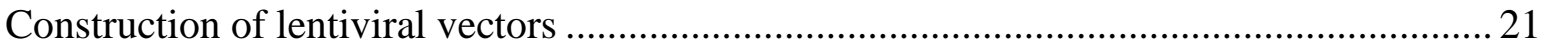




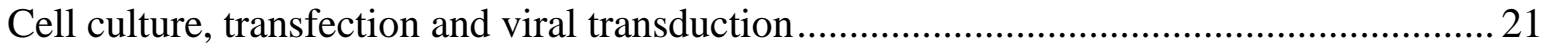

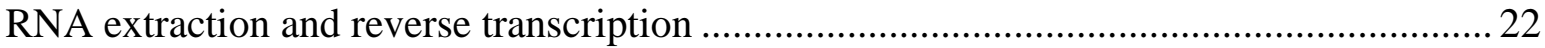

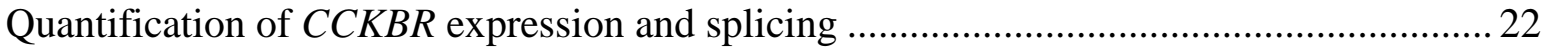

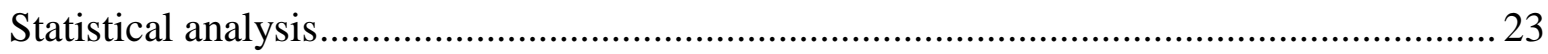

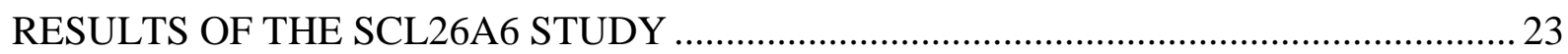

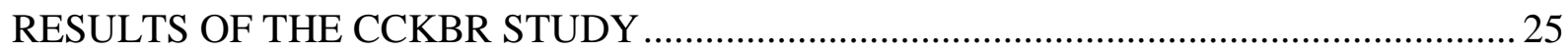

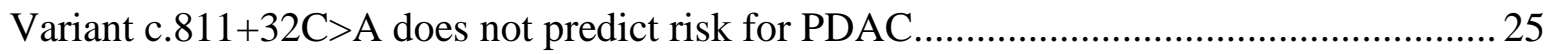

Variant c.811+32C>A does not predict survival in PDAC …......................................... 25

Variant c.811+32C>A does not affect splicing of intron 4 in $C C K B R$................................26

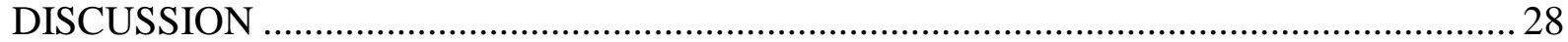

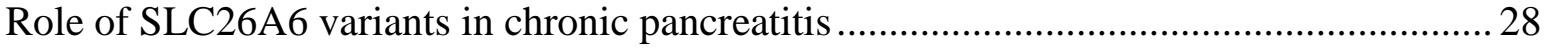

Role of $C C K B R$ variant c. $811+32 \mathrm{C}>\mathrm{A}$ in pancreatic cancer...........................................29

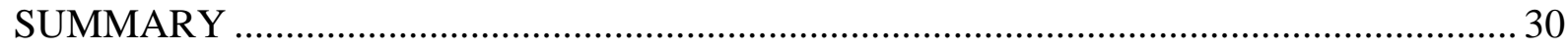

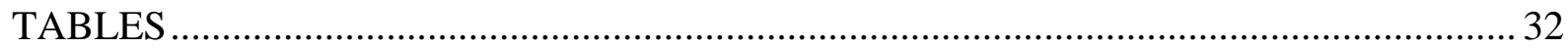

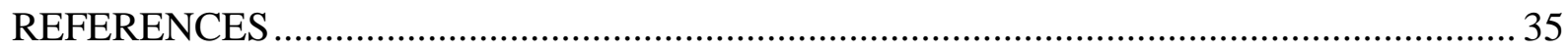

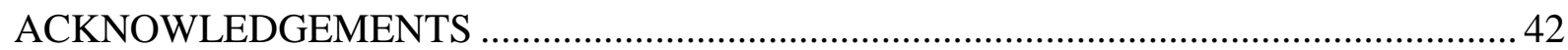




\section{Publications related to the subject of the thesis:}

I) Anita Balázs Balázs Csaba Németh Balázs Ördög Eszter Hegyi István Hritz László Czakó József Czimmer MD, Szilárd Gódi Adrienn Csiszkó Zoltán Rakonczay Jr. Andrea Párniczky Ferenc Izbéki Adrienn Halász Zsuzsanna Kahán Péter Hegyi Miklós Sahin-Tóth “A COMMON CCK-B RECEPTOR INTRONIC VARIANT IN PANCREATIC ADENOCARCINOMA IN A HUNGARIAN COHORT"

Pancreas (2015 in press) IF: 2.96

II.) Anita Balázs, Claudia Ruffert, Eszter Hegyi, István Hritz, László Czakó, Tamás Takács, Zoltán Szepes, Balázs Csaba Németh, Judit Gervain, Ferenc Izbéki, Adrienn Halász, Dezső Kelemen, Richárd Szmola, János Novák, Stefan Crai, Anita Illés, Áron Vincze, Zsolt Molnár, Márta Varga, Barnabás Bod, Gyula Farkas Jr, János Sümegi, Attila Szepes, Zsolt Dubravcsik, Natália Lásztity, Andrea Párniczky, József Hamvas, Csilla Andorka, Gábor Veres, Zsolt Szentkereszty, Zoltán Rakonczay Jr, József Maléth, Miklós Sahin-Tóth, Jonas Rosendahl, Péter Hegyi "GENETIC ANALYSIS OF THE BICARBONATE SECRETING ANION EXCHANGER SLC26A6 IN CHRONIC PANCREATITIS"

Pancreatology (2015 in press) IF: 2.84

Publications not related to the subject of the thesis:

I.) Anita Balázs, Péter Hegyi "CYSTIC FIBROSIS-STYLE CHANGES IN THE EARLY PHASE OF PANCREATITIS"

Clinics and Research in Hepatology and Gastroenterology (2015)

doi:10.1016/j.clinre.2015.05.020 IF: 1.64

II.) József Maléth, Anita Balázs, Zsolt Balla, Balázs Kui, Máté Katona, Linda Judák, István Németh, Petra Pallagi, Lajos Vince Kemény, Zoltán Rakonczay Jr, Viktória Venglovecz, Imr Földesi, Zoltán Pető, Áron Somorácz, Katalin Borka, Ditta Perdomo, Gergely Lukacs, Mike A. Gray, Sylvio Monterisi, Manuela Zaccolo, Matthias Sendler, Julia Mayerle, Jens Kühn, Markus M. Lerch, Miklós Sahin-Tóth, Péter Hegyi. "ALCOHOL DISRUPTS LEVELS AND FUNCTION OF THE CYSTIC FIBROSIS TRANSMEMBRANE CONDUCTANCE REGULATOR TO PROMOTE DEVELOPMENT OF PANCREATITIS. "

Gastroenterology (2014) S0016-5085(14)01336-5. IF: 16.72

III.) József Maléth, Tamara Madácsy, Petra Pallagi, Anita Balázs, Viktoria Venglovecz, Zoltán Rakonczay, Péter Hegyi "PANCREATIC EPITHELIAL FLUID AND BICARBONATE SECRETION IS SIGNIFICANTLY ELEVATED IN THE ABSENCE OF PHERIPHERAL SEROTONIN"

Gut (2015) doi: 10.1136/gutjnl-2015-309776 IF: 14.66 
IV.) Eszter Hegyi, Andrea Geisz, Miklós Sahin-Tóth, Monique Derikx, Balázs Csaba Neméth, Anita Balázs, Istvan Hritz, Ferenc Izbéki, Adrienn Halász, Andrea Párniczky, Tamás Takács, Dezső Kelemen, Patrícia Sarlós, Laszló Czakó, Péter Hegyi "SPINK1 PROMOTER VARIANTS IN CHRONIC PANCREATITIS"

Pancreas (2015 in press) IF: $\mathbf{2 . 9 6}$

Number of full publications: $6 \quad$ (3 first author)

Cumulative impact factor: $\quad \mathbf{4 1 . 7 8}$ 


\section{LIST OF ABBREVIATIONS}

ATM

BRCA2

$C C K B R$

CCKBRi4sv

CEL

CDKN2A

$\mathrm{CF}$

CFTR

CPA1

$\mathrm{CP}$

CTRC

PDAC

PRSS1

SPINK1

ER

FAMMM

GAPDH

GWAS

KRAS

$M M R$

MSH2

hMLH1

PALB2

PanIN

SLC26

SMAD4

STAS

STK11

TP53

OR

OS ataxia teleangiectasia mutated

breast cancer 2 , early onset

cholecystokinin-B receptor

intron 4-containing splice variant of CCK-B receptor

carboxyl ester lipase

cyclin-dependent kinase inhibitor $2 \mathrm{~A}$

cystic fibrosis

cystic fibrosis transmembrane conductance regulator

carboxypeptidase A1

chronic pancreatitis

chymotrypsin $\mathrm{C}$

pancreatic ductal adenocarcinoma

protease serine 1 , human cationic trypsinogen

serine protease inhibitor Kazal type 1

endoplasmic reticulum

familial atypical multiple-mole melanoma

glyceraldehyde-3-phosphate dehydrogenase

genome-wide association studies

Kirsten rat sarcoma viral oncogene homolog

mismatch repair genes

DNA mismatch repair protein

MutL homolog 1

partner and localizer of $B R C A 2$

pancreatic intraepithelial neoplasia

solute-linked carrier 26

mothers against DPP homolog 4

sulphate transporter and anti-sigma antagonist

serine/threonine kinase 11

tumor protein P53

odds ratio

overall survival 


\section{INTRODUCTION}

Genetic risk factors are important determinants of disease susceptibility and prognosis in chronic pancreatitis (CP) and pancreatic ductal adenocarcinoma (PDAC). The pathogenesis of these disorders is complex; in the majority of patients the disease develops through the interaction of environmental and genetic risk factors. Hereditary forms represent a minority of patients, where solely a genetic etiology is apparent. To date, several highly penetrant susceptibility genes have been identified in hereditary pancreatitis and familial pancreatic cancer syndromes, while low penetrance genetic risk factors often accumulate and interact with lifestyle and environment in sporadic or idiopathic cases.

A genetic background for $\mathrm{CP}$ was first described in a pedigree with an autosomal dominant inheritance pattern in $1952^{1}$. In 1996 Whitcomb et al. identified the protease serine 1 $(P R S S 1)^{2}$ gene encoding the human cationic trypsinogen as the first gene associated with $\mathrm{CP}^{2}$. Using candidate gene approaches several pancreatitis associated variants have been discovered in genes encoding serine protease inhibitor Kazal type 1 (SPINK1) $)^{3}$, chymotrypsin $\mathrm{C}(C T R C)^{4}$, cystic fibrosis transmembrane conductance regulator $(C F T R)^{5}$, carboxypeptidase A1 $(\mathrm{CPA} 1)^{6}$ and carboxyl ester lipase $(C E L)^{7}$, while genome-wide association studies identified numerous other susceptibility loci. Despite these recent advances, many patients with idiopathic $\mathrm{CP}$ do not carry mutations in any of the known susceptibility genes, suggesting the involvement of other yet unidentified genes.

Chronic pancreatitis is an established risk factor for pancreatic cancer. Indeed, hereditary CP patients harboring the p.R122H mutation in the PRSS1 gene are at 50\% lifetime risk for developing cancer ${ }^{8}$. It has been reported that common variants are shared between $\mathrm{CP}$ and PDAC, suggesting the idea that these conditions not only have common environmental but also common genetic risk factors ${ }^{9}$. About $5 \%$ of PDAC cases are familial, involving highly penetrant susceptibility genes, such as breast cancer 2, early onset (BRCA2), ataxia teleangiectasia mutated $(A T M)$, and partner and localizer of BRCA2 $(P A L B 2)^{10}$. The remaining $95 \%$ of cases considered to be 'sporadic' have a significant germline genetic component as well, and are estimated to represent up to $30 \%$ of pancreatic cancer susceptibility $^{11}$. Such common variants were first identified in the AB0 blood group gene ${ }^{12}$. To date, five genome-wide association studies (GWAS) have described multiple susceptibility loci associated with the risk of pancreatic cancer. ${ }^{13-17}$ However, estimates of heritability suggest a large number of loci remain to be discovered. 
In the field of pancreas genetics there is a clear need to further explore the complex genetic background. Functional analysis of the disease-associated variants provides a better understanding of the molecular pathogenesis and may open up new treatment possibilities. The other challenge is to understand what variations mean for an individual patient and how to apply this knowledge for treatment decisions. Although in its infancy, there is a growing body of evidence suggesting that individualized therapies that are based upon the specific genetic alterations of an individual patient will soon be a reality.

In this thesis genetic investigations regarding chronic pancreatitis and pancreatic cancer have been reviewed together with the description of the author's experimental data in order to gain a deeper comprehension of the pathophysiology of pancreatic diseases.

\section{Genetic risk factors of chronic pancreatitis}

Chronic pancreatitis (CP) is an irreversible, progressive inflammatory disease of the pancreas, characterized by morphological changes of the gland, exocrine and/or endocrine insufficiency and chronic abdominal pain. The prevalence of CP is about 50/100.000. Patients experience substantial impairment in health-related quality of life ${ }^{18}$, have an increased risk for developing pancreatic cancer, and face a markedly decreased life expectancy ${ }^{19}$. CP is most commonly associated with excessive alcohol consumption but other factors such as smoking, metabolic disturbances, anatomic abnormalities, autoimmunity and genetic variations have also been implicated. In a substantial proportion of patients the cause of the disease remains obscure; thus, up to $30 \%$ of all cases are classified as having idiopathic CP. Whether or not the disease becomes manifest depends on the individual combination of genetic predisposition and exogenous insults, particularly alcohol intake and smoking. 


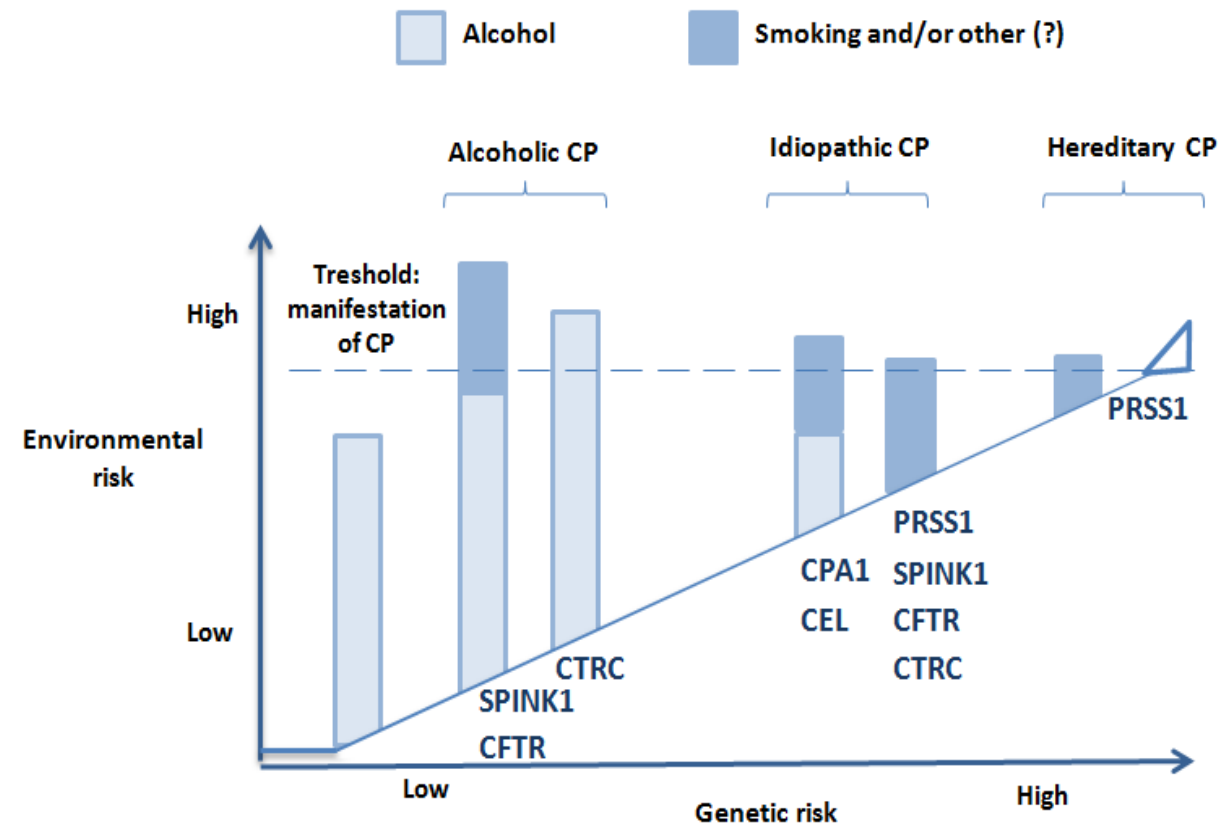

Figure 1.

Model of interaction between genetic susceptibility and environmental risk factors in chronic pancreatitis

The fact that the majority of individuals with high alcohol intake does not develop alcoholic CP suggest a genetic basis for susceptibility as well, such as variations in SPINK1, CTRC, and CFTR genes ${ }^{20}$. In idiopathic CP the genetic risk is more apparent. Comprehensive screenings of the major risk genes in larger cohorts revealed that $30-50 \%$ of idiopathic CP patients carry one or more known disease associated mutations ${ }^{21,22}$. In hereditary pancreatitis heterozygous mutations of PRSSI are causative. There have been major discoveries about the mechanism of action of $\mathrm{CP}$ associated mutations, involving premature activation of digestive enzymes, endoplasmic reticulum stress and diminished ductal bicarbonate secretion.

\section{Protease-antiprotease imbalance}

Tissue autodigestion in pancreatitis is a century-old paradigm. This pathogenic concept has been supported by several lines of genetic evidence, indicating that trypsin plays a key role in triggering an activation cascade of the digestive zymogens. Mutations in PRSS1 cause increased autoactivation of mutant trypsinogens by directly increasing trypsinogen autoactivation or by altering the CTRC-dependent activation and/or degradation of cationic trypsinogen $^{23}$. CTRC is a pancreatic serine protease which regulates autoactivation of cationic 
trypsinogen by selectively cleaving regulatory sites within the activation peptide and the calcium binding loop. CP-associated mutations of CTRC cause impaired activity and/or decreased secretion, resulting in diminished trypsin-degrading activity ${ }^{4}$. Consistent with the trypsin-paradigm, a protective, loss-of-function variant of PRSS2 encoding human anionic trypsinogen has been identified ${ }^{24}$. The SPINK1 gene encodes the pancreatic secretory trypsin inhibitor, which is believed to play a part in protecting the pancreas against premature trypsinogen activation. The p.N34S mutation is the most frequent and best studied SPINK1 variant, which is clearly a risk factor for $\mathrm{CP}$, although the mechanism remains unclear ${ }^{25}$. It is plausible that intronic mutations in linkage disequilibrium with p.N34S may be responsible for the clinical effect. Taken together, gain-of-function mutations in PRSS1, or loss-offunction mutations in the trypsinogen-regulatory protease CTRC and protease inhibitor SPINK1 result in elevated intrapancreatic trypsin activity, leading to self-digestion of the gland.

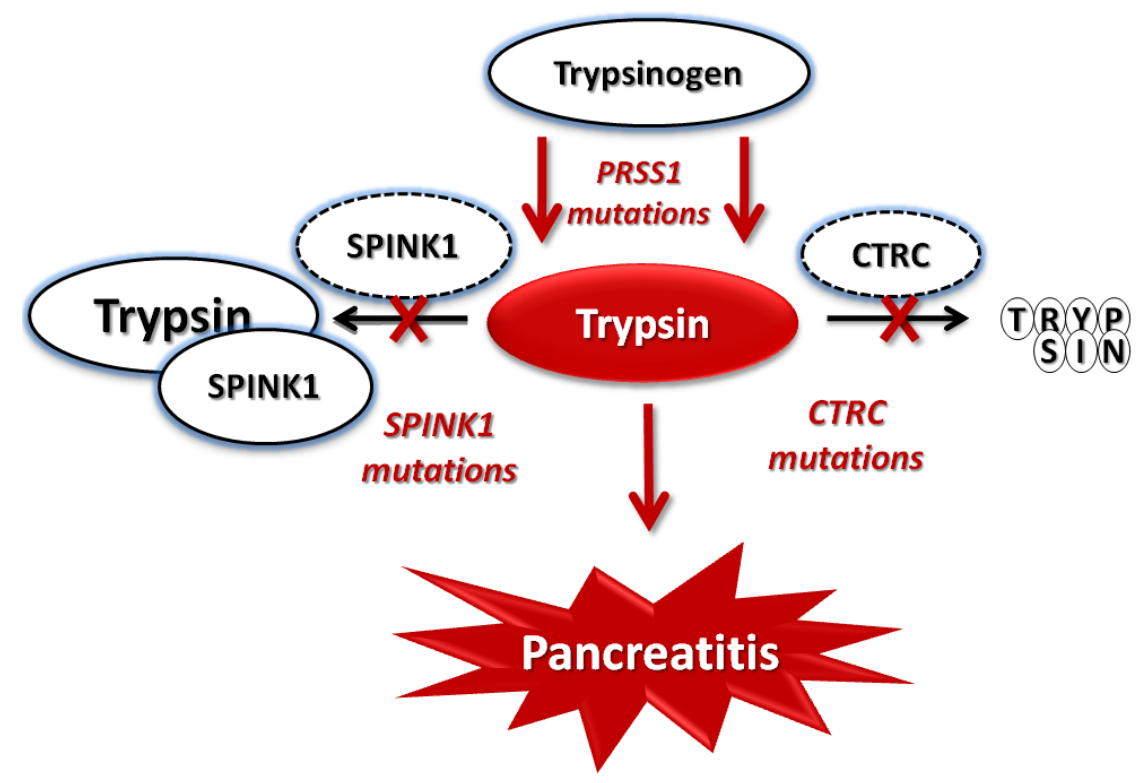

\section{Figure 2.}

Trypsin-central paradigm of pancreatitis.

\section{Endoplasmic reticulum stress}

The endoplasmic reticulum (ER) is a membrane-enclosed organelle responsible for the synthesis, folding, modification, and quality control of numerous secretory and membrane 
proteins. The ER responds to the accumulation of unfolded proteins in its lumen (ER stress) by activating intracellular signal transduction pathways; cumulatively called the unfolded protein response (UPR). UPR increases the ER protein-folding capacity, reduces global protein synthesis, and enhances ER-associated degradation of misfolded proteins. Pancreatic acinar cells are particularly vulnerable to ER dysfunction, since they secrete enormous amount of proteins. First evidence that protein misfolding may be associated with $\mathrm{CP}$ came to light by investigation of several CP-associated SPINK1 missense mutants, that exhibited a

protein secretion defect ${ }^{25}$. Next, a hereditary CP associated PRSS1 variant, namely p.R116C was found to induce misfolding and consequent ER stress, due to an unpaired cysteine residue $^{26}$. A similar phenotype was observed for PRSS1 variant p.C139S. Certain CTRC mutations also exhibited secretion defect and ER stress, that was proportional to the loss of secretion $^{27}$. Mutations in CPAl were found to associate with $\mathrm{CP}$, and the mechanism by which these variants confer increased pancreatitis risk was found involve misfolding-induced ER stress. ${ }^{6}$ In a more recent study a carboxyl ester lipase hybrid allele (CEL-HYB) originating from a crossover between $C E L$ and its neighboring pseudogene, CELP was found to increase susceptibility to idiopathic and alcoholic $\mathrm{CP}$ as well. Functional investigations revealed intracellular retention and impaired secretion. ${ }^{7}$ Besides genetic evidence, ER stress was also observed in experimental models of pancreatitis, such as in the cerulein hyperstimulation model or the arginine-induced experimental acute pancreatitis model. ${ }^{28}$

\section{Ductal secretion defect}

Fluid and $\mathrm{HCO}_{3}{ }^{-}$secretion is a vital function of pancreatic ductal epithelium and is fundamental for the integrity of the tissue. The human pancreas secretes 1-2 liters of alkaline, isotonic juice per day, which contains concentrations of bicarbonate that may exceed $140 \mathrm{mM}^{29}$. This bicarbonate rich fluid flushes out digestive enzymes from the ductal tree, facilitates solubilization of macromolecules, neutralizes the protons secreted by acinar cells, prevents premature activation of trypsinogen and neutralizes gastric acid in the duodenum providing an optimal $\mathrm{pH}$ environment for digestive enzymes. One of the functional consequences of $\mathrm{CP}$ is the reduction in secretin-stimulated bicarbonate content in pancreatic juice ${ }^{30}$. Impaired $\mathrm{HCO}_{3}{ }^{-}$secretion disrupts the physiological interaction between acinar and duct cells, resulting in decreased intraluminal $\mathrm{pH}$, premature trypsinogen activation, impaired acinar secretion, obstruction of the lumen with protein plugs and finally destruction of the parenchyma. ${ }^{31}$. Several pancreatitis associated toxic factors, such as ethanol ${ }^{32}$, bile acids ${ }^{33}$, trypsin $^{34}$ and cigarette smoke extract ${ }^{35}$ displayed inhibitory effects on bicarbonate secretion 
and influenced the activity of the CFTR chloride channel. Not only functional inhibition, but also genetic defects of CFTR can increase the risk for pancreatitis. Association of CFTR mutations and the development of $\mathrm{CP}^{5,36}$, and recurrent acute pancreatitis ${ }^{38}$ has been reported. Genetic defects in the CFTR gene result in a wide disease spectrum (classic cystic fibrosis (CF), non-classic CF, CF-related diseases), which is dependent on organ-specific protein requirements, the amount of functional protein, - which is influenced by the genotype -, as well as genetic modifiers and environmental factors. CFTR variants found in CP patients are in most cases 'mild' variants with residual CFTR function, and it is yet unknown why heterozygote carriers are at increased disease risk. Heterozygous CF-causing severe and mild CFTR variants increase the risk 2.9 and 4.5 -fold respectively ${ }^{22}$. These observations indicate that insufficient electrolyte transport is pathogenic for $\mathrm{CP}$

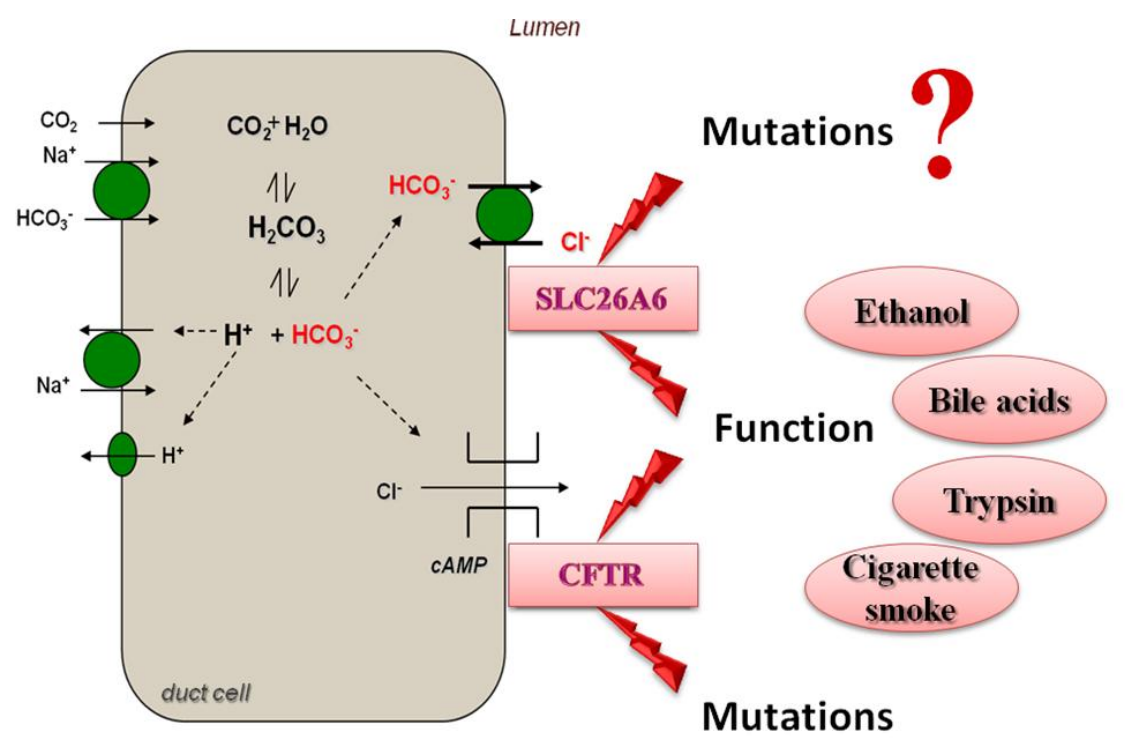

Figure 3.

Model of pancreatic ductal secretion.

\section{SLC26A6 anion transporter}

Pancreatic bicarbonate secretion is not only dependent on CFTR but also on the solute-linked carrier 26 (SLC26) anion transporters, localized in the apical membrane of the ductal cells. SLC26 isoforms constitute a conserved family of anion transporters with 10 distinct members. All SLC26 isoforms - except for SLC26A5 (prestin) - are versatile anion exchangers mediating apical chloride/base exchange in epithelial tissues. Several diseases have been linked to mutations in members of the family, including diastrophic dysplasias (SLC26A2), congenital chloride diarrhea (SLC26A3), Pendred's syndrome (SLC26A4), hearing loss 
(SLC26A5) and asthma (SLC26A9) $)^{39,40}$. The SLC26A6 anion exchanger is expressed in the apical membrane of pancreatic ducts, intestinal epithelium and kidney proximal tubule ${ }^{40}$. It mediates multiple anion exchange modes, including, $\mathrm{Cl}^{-} / \mathrm{HCO}_{3}{ }^{-}$exchange, $\mathrm{Cl}^{-} /$formate exchange and $\mathrm{Cl}^{\%}$ \%oxalate exchange. Earlier studies revealed a direct molecular interaction between CFTR and two SLC26 exchangers, namely A3 and A6, which results in mutual upregulation of their transport activity ${ }^{41}$. This process is mediated by binding of the regulatory (R) domain of CFTR to the highly conserved STAS (sulphate transporter and anti-sigma antagonist) domain of SLC26 and this interaction is required for activation of both SLC26 transporters and CFTR. Notably, CF causing CFTR mutations that retain normal or substantial $\mathrm{Cl}^{-}$conductance exhibited a severe defect in $\mathrm{CFTR}$ dependent $\mathrm{Cl}^{-} / \mathrm{HCO}_{3}{ }^{-}$exchange activity. This indicates that impairment of the coupled bicarbonate transport mechanism is sufficient to damage pancreatic function even in the presence of $\mathrm{CFTR}^{-}$channel activity ${ }^{42}$. On the basis of its localization in the apical membrane of the pancreatic duct and its function as $\mathrm{Cl}^{-}$ $/ \mathrm{HCO}_{3}{ }^{-}$exchanger, SLC26A6 has been proposed to be a major contributor to the apical $\mathrm{HCO}_{3}{ }^{-}$ secretion in the pancreatic duct ${ }^{43}$

\section{Genetic risk factors of pancreatic cancer}

Carcinoma of the exocrine pancreas is a genetic disease that is caused by inherited and acquired mutations in specific cancer-associated genes. It has the highest mortality rate of all malignancies. There is no effective screening available and advanced disease is commonly present at initial diagnosis. ${ }^{44}$ The incidence of the disease is $8 / 100,000$, and it is the fourth leading cause of cancer-related death among both men and women. ${ }^{45}$ The majority of these tumors (85 percent) are adenocarcinomas arising from the ductal epithelium. Established risk factors are cigarette smoking, chronic inflammation of the pancreas, diabetes mellitus and increased body mass. ${ }^{46}$ Chronic pancreatitis and PDAC share common environmental risk factors, such as smoking and heavy alcohol consumption and share some common genetic susceptibility factors as well. Cumulative risk for pancreatic cancer in CP reaches $1.8 \%$ at 10 years and $4 \%$ at 20 years, independent of the type of pancreatitis. ${ }^{47}$ Hereditary pancreatitis is associated with a markedly increased, more than 50\% lifetime risk for pancreatic cancer, although it accounts for a very small fraction of pancreatic cancer cases. The signaling mechanisms that underlie the transition from $\mathrm{CP}$ to invasive cancer involve inflammation induced transdifferentiation and oncogenic stimulation, resulting in metaplastic duct lesions or other precancerous lesions known as pancreatic intraepithelial neoplasia (PanIN). Eventually, PanIN can further progress to PDAC once cells acquire additional transforming mutations. ${ }^{48}$ 
Sequencing of pancreatic adenocarcinoma tissue samples revealed that multiple combinations of genetic mutations are commonly present that can be divided into three broad categories: mutational activation of oncogenes such as KRAS; inactivation of tumor suppressor genes such as TP53, p16/CDKN2A, and SMAD4; inactivation of genome maintenance genes, such as $h M L H 1$ and $M S H 2$, which control the repair of DNA damage. ${ }^{49}$ Although most of these genetic aberrations represent somatic mutations, others are present in the germline of kindreds who carry a familial predisposition to pancreatic cancer. Advances in our understanding of the genes involved in the molecular pathogenesis of pancreatic cancer have provided insight into the progression of normal pancreatic ductal cells to noninvasive precursor lesions and to invasive carcinoma; and important implications for the development of chemoprevention and early detection strategies.

\section{High penetrance susceptibility genes}

Pancreatic cancer aggregates in some families; an estimated 5-10\% of individuals with pancreatic cancer have a family history of the disease. There are two broad categories of hereditary risk for pancreatic cancer: defined syndromes in which patients are at risk for a number of malignancies, including pancreatic cancer; and familial pancreatic cancer. Several high-penetrance germline mutations are involved in these cases, such as ${ }^{50}$ :

- BRCA and PALB2 - hereditary breast and ovarian cancer syndrome: Germline mutations in BRCA1 and especially BRCA2 are associated with an increased risk of pancreatic cancer. BRCA2 mutations are found in as many as $12-17 \%$ of patients with familial pancreatic cancer

- Germline mutations in STK11 - Peutz-Jeghers syndrome. In individuals with PJS, the lifetime risk may be as high as $36 \%$.

- Mutations in CDKN2A - Familial atypical multiple-mole melanoma (FAMMM) syndrome, a disorder associated with multiple nevi, cutaneous and ocular malignant melanomas, as well as pancreatic cancers.

- Ataxia-telangiectasia mutated (ATM) - Ataxia-telangiectasia is an autosomal recessive disorder associated with defective DNA repair mechanisms associated with an increased risk of pancreatic cancer

- Mismatch repair genes (MMR) - Lynch syndrome. Individuals with Lynch syndrome are also at increased risk of cancer of the ovary, stomach, pancreas, small bowel, hepatobiliary 
system, transitional cell cancer of the renal pelvis and ureter, brain (glioma), and sebaceous neoplasms

- PRSS1 mutations - hereditary pancreatitis and pancreatic cancer

However, combined, these known genetic factors account for less than $20 \%$ of the observed familial aggregation, suggesting that other as yet unidentified susceptibility genes may exist.

\section{Low penetrance susceptibility genes}

In sporadic cases of pancreatic cancer more common genetic variants are implicated that represent a minor risk for the disease. Epidemiologic evidence suggested that people with blood group 0 may have a lower risk of pancreatic cancer than those with groups A or B. Later risk variants in the $\mathrm{AB} 0$ blood group gene have been identified. ${ }^{5,6}$ To date, five GWAS studies have described multiple susceptibility loci associated with the risk of pancreatic cancer. ${ }^{13-17}$ Several of these loci harbor plausible candidate genes that have been implicated in pancreas development, pancreatic beta-cell function and predisposition to diabetes. The effect size of these susceptibility loci is generally small, with odds ratios (ORs) usually not higher than 1.2 or not lower than 0.8 . When the cumulative association of risk alleles with pancreatic cancer was evaluated, it was found that compared to individuals with the most prevalent number $(\mathrm{n}=10)$ of risk alleles in controls, those with $\leq 6$ risk alleles had an OR of $0.55(95 \%$ CI $0.44-0.68)$ and those with $\geq 14$ risk alleles had an OR of 2.24 (95\% CI 1.80-2.80) for pancreatic cancer ${ }^{52}$.

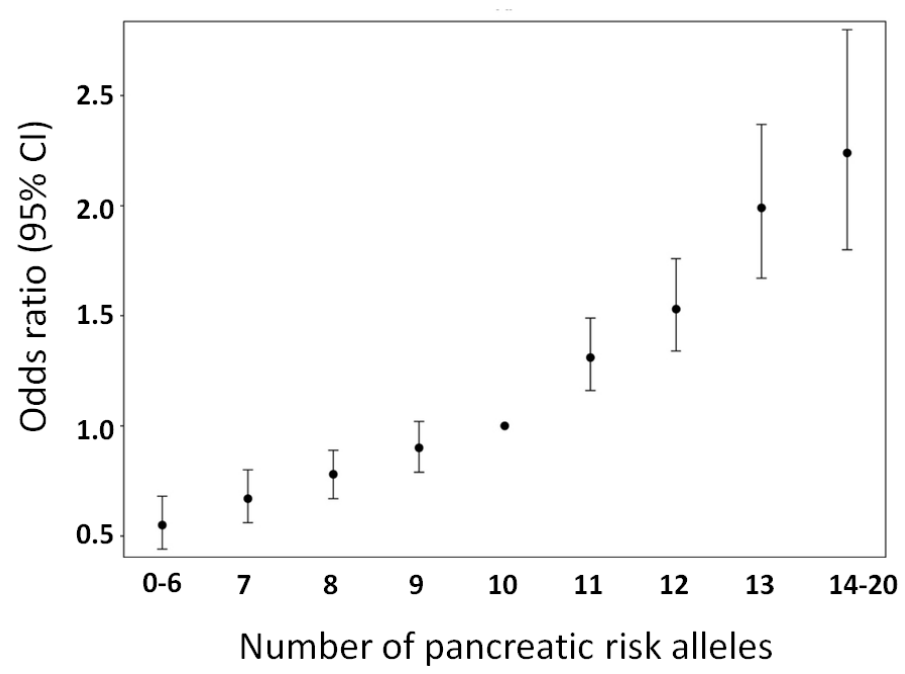

Figure 4. ${ }^{52}$

Cumulative association of risk alleles with pancreatic cancer 


\section{Cholecystokinin-B receptor}

The gastrin/CCK-B receptor is a member of the G protein-coupled receptor superfamily, physiologically expressed in the human pancreas. ${ }^{53}$ Binding of gastrin or CCK triggers activation of multiple signal transduction pathways that relay mitogenic signals to the nucleus and promote cell proliferation. Numerous studies have shown that CCK-B receptor plays a significant role in carcinogenesis and tumor progression. ${ }^{54,55}$ An alternatively spliced mRNA form of the receptor generated by retention of intron 4 (designated CCK-BRi4sv for intron 4containing splice variant; also referred to as CCK-C receptor) was reported in various tumours ${ }^{56}$, including pancreatic cancer. ${ }^{57}$ The resulting CCK-BRi4sv receptor protein exhibits constitutive (agonist-independent) activation of cell proliferation pathways. ${ }^{58}$ Smith et al. (2012) reported a common single nucleotide polymorphism (SNP) in the cholecystokinin-B receptor gene $(C C K B R)$ as a risk factor for PDAC, which has not been observed in prior GWAS studies. ${ }^{59}$ The authors showed in a small cohort (51 cases and 39 controls) that variant c. $811+32 \mathrm{C}>\mathrm{A}$ (rs1800843) located in intron 4 of $C C K B R$ increased PDAC risk and was also associated with poorer survival. In a more recent follow-up study, Smith et al. (2014) replicated their results in a larger North-American multi-center cohort (931 cases and 59 controls) and confirmed both increased PDAC risk (odds ratio 2.28, CC versus AC plus AA genotypes) and shorter survival (hazard ratio 1.56 ) associated with variant $\mathrm{c} .811+32 \mathrm{C}>\mathrm{A} .{ }^{60}$ Using immunohistochemistry, Smith et al. (2012) found that tumors with variant c. $811+32 \mathrm{C}>\mathrm{A}$ expressed CCK-BRi4sv receptor protein, suggesting that the variant might be directly responsible for intron retention. The authors speculated that binding of the splicing factor SRp55 might be reduced by the intronic variant resulting in enhanced retention of intron $4^{12,13}$. 


\section{AIMS}

I. On the basis of its localization in the apical membrane of the pancreatic duct and its function as a $\mathrm{Cl}^{-} / \mathrm{HCO}_{3}{ }^{-}$exchanger, SLC26A6 has been proposed to be a major contributor to the apical $\mathrm{HCO}_{3}{ }^{-}$secretion in the pancreatic duct. However, the role of genetic variations in SLC26A6 has remained unexplored in CP. Therefore we aimed to investigate SLC26A6 gene variants in chronic pancreatitis.

Specific aims: in this study, we aimed to sequence the entire coding region of SLC26A6 in 100 non-alcoholic CP cases. We aimed to further investigate the identified variants in Hungarian and German cohorts of non-alcoholic and alcoholic CP.

II. There are few known risk factors in pancreatic adenocarcinoma and a better understanding of the molecular pathogenesis is urgently needed. Therefore, we aimed to re-evaluate the role of $C C K B R$ variant $c .811+32 \mathrm{C}>\mathrm{A}$ as a novel genetic prognostic marker.

Specific aims: in this study we had three objectives: (1) to replicate the association between variant c. $811+32 \mathrm{C}>\mathrm{A}$ and the risk for developing pancreatic cancer in an independent population, (2) to evaluate the impact of the variant on patient survival and (3) to examine the functional effect of the variant on pre-mRNA splicing. 


\section{PATIENTS AND METHODS OF GENETIC ANALYSIS OF SLC26A6 IN CHRONIC PANCREATITIS}

\section{Subjects and study design}

The study protocol was approved by the national ethical review committee ETT-TUKEB (22254-1/2012). The study population has been collected and characterized by members of the Hungarian Pancreatic Study Group (see the list of coauthors). Therefore, characterization of study cohort which can be found in the manuscript is other coauthors scientific achievement. All patients gave written informed consent for genetic analysis. The study included CP patients originating from Hungary $(\mathrm{n}=106)$ and Germany $(\mathrm{n}=361)$. Clinicopathological information on individual patients including symptoms, diagnostic criteria and etiology were collected from medical records and questioners completed by the patients. Diagnosis of CP was based on at least two of the following criteria: constant or recurrent abdominal pain, calcifications on sonography or CT, ductal irregularities on ERCP or MRCP examination, EUS based diagnosis of $\mathrm{CP}$ and histologically confirmed $\mathrm{CP}$. According to etiology, patients were divided into alcoholic CP and non-alcoholic CP groups. Alcoholic CP was defined by consumption of more than $80 \mathrm{~g} / \mathrm{d}$ (man) ethanol or more than $60 \mathrm{~g} / \mathrm{d}$ (women) for at least two years. 99 Hungarian and 171 German control subjects were recruited from adult volunteers who considered themselves generally healthy, from inpatients who had no history of pancreatic disease and from blood donors.

\section{DNA extraction and genotyping}

Genomic DNA was isolated from whole blood using QIAamp DNA Blood mini kit (Qiagen, Hilden, Germany). In a discovery cohort of 60 non-alcoholic Hungarian CP patients the entire coding sequence and adjacent intronic sequences were amplified and sequenced. Primers were designed according to the published sequence of the human SLC26A6 gene (GenBank: NM_022911.2) (Table 1). Our analysis did not include the non-functional alternative splice variant SLC26A6d ${ }^{61}$, which retains an unspliced intron, resulting in a different carboxy terminus lacking the STAS domain. PCR was performed in a total volume of $30 \mu 1$, which contained 0.5 U HotStarTaq DNA Polymerase (Qiagen, Hilden, Germany), $1.5 \mathrm{mM} \mathrm{Mg} 2 \mathrm{Cl}$, $0.2 \mathrm{mM}$ dNTP, $0.5 \mu \mathrm{M}$ primer and 10-50 ng genomic DNA. Amplification was performed under the following cycle conditions: $95^{\circ} \mathrm{C}$ for $15 \mathrm{~min}$ to activate the enzyme, followed by 40 
cycles of $30 \mathrm{~s}$ denaturation at $94{ }^{\circ} \mathrm{C}, 30 \mathrm{~s}$ at specific annealing temperatures and $1 \mathrm{~min}$ extension at $72{ }^{\circ} \mathrm{C}$, with a final extension of $5 \mathrm{~min}$. Prior to sequencing PCR products were visualized by agarose gel electrophoresis.

\section{Restriction fragment length polymorphism.}

Genotyping of the p.V206M and c.1191C>A (p.P397=) variants in the Hungarian cohort was carried out by restriction fragment length polymorphism analysis. PCR was performed with primer sets 7 and 16, (see Table1) and the products were digested with NlaIII (Thermo Scientific, Vilnius, Lithuania) and BmrI (New England Biolabs, Ipswich, MA USA) restriction enzymes, respectively.

\section{Statistical analysis}

Quantitative variables were described as mean $\pm \mathrm{SD}$. We tested the significance of the differences between allele frequencies in cases and controls by Fisher's exact test and calculated $p$-values and odds ratios using GraphPad Prism v6.0a (San Diego, CA USA).

\section{PATIENTS AND METHODS OF GENETIC ANALYSIS OF CCKBR VARIANT IN PANCREATIC CANCER}

\section{Study population}

The study protocol has been approved by the Regional and Institutional Committee of Science and Research Ethics. The study population has been collected and characterized by members of the Hungarian Pancreatic Study Group (see the list of coauthors). Therefore, characterization of study cohort which can be found in the manuscript is other coauthors scientific achievement. All participants gave written informed consent for genetic analysis. 122 cases with a confirmed diagnosis of PDAC were recruited from the Hungarian National Pancreas Registry. For each patient, information about gender, age at diagnosis, method of diagnosis and date of death or date of last follow-up was collected. Two patients had synchronous or metachronous cancer suggestive of inherited cancer syndromes. Other cases were sporadic; no patients fulfilled the criteria for familial pancreatic cancer (two or more first degree relatives with pancreatic cancer). 106 control subjects were recruited from adult volunteers who considered themselves generally healthy and from inpatients, who had no history of pancreatic diseases. Tumor stage and survival of patients is described in Table 3. 


\section{DNA extraction and genotyping}

Genomic DNA was isolated from $300 \mu$ l EDTA-blood using QIAamp DNA Blood mini kit (Qiagen, Hilden, Germany). Primers were designed according to the genomic sequence of CCKBR on chromosome 11 (GenBank NC_000011.10) (see primer sequences in Table 4). PCR was performed in a total volume of $30 \mu \mathrm{l}$, which contained $0.5 \mathrm{U}$ HotStarTaq DNA Polymerase (Qiagen), $1.5 \mathrm{mM} \mathrm{MgCl} 2,0.2 \mathrm{mM}$ dNTP, $0.5 \mu \mathrm{M}$ of each primer and 10-50 ng genomic DNA. Amplification was performed under the following cycle conditions: $95{ }^{\circ} \mathrm{C}$ for $15 \mathrm{~min}$ to activate the enzyme, followed by 40 cycles of $30 \mathrm{~s}$ denaturation at $94{ }^{\circ} \mathrm{C}, 30 \mathrm{~s}$ annealing at $58{ }^{\circ} \mathrm{C}$ and $1 \mathrm{~min}$ extension at $72{ }^{\circ} \mathrm{C}$, with a final extension of $5 \mathrm{~min}$. Prior to sequencing PCR products were purified with QIAquickPCR Purification Kit (Qiagen). Nucleotide sequence analysis was carried out in a commercial laboratory (Delta Bio 2000 Ltd., Szeged, Hungary) using a 3500 Genetic Analyser (Applied Biosystems) automatic dyeterminator sequencing machine. The reverse PCR primer was used as sequencing primer. Chromatograms were analyzed with ChromasPro software (Technelysium, South Brisbane, Australia).

\section{Construction of expression plasmids harboring CCKBR minigenes}

We designed $C C K B R$ minigenes that contain intron 4 placed in the appropriate context of the full length coding DNA. CCKBR coding DNA (GenBank NM_176875.3) was custom synthesized (GenScript) and cloned into the pcDNA3.1(-) plasmid using XhoI and EcoRI restriction sites. To create $C C K B R$ minigenes, a 584 nucleotide long fragment containing intron 4 with or without the $c .811+32 \mathrm{C}>\mathrm{A}$ variant was custom synthesized and cloned into the pcDNA3.1(-) CCKBR plasmid using BsrGI and BamHI restriction sites. 
CCKBR CDNA

\begin{tabular}{|l|l|l|l|l|}
\hline 1 & 2 & 3 & 4 & 5 \\
\hline
\end{tabular}

Minigene wild type

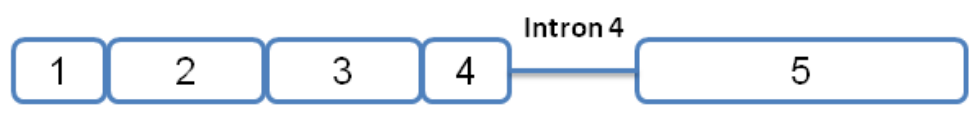

Minigene $c .811+32 \mathrm{C}>\mathrm{A}$

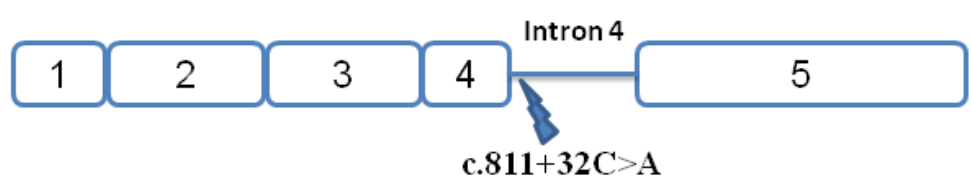

$250 \mathrm{bp}$

Figure 6. Minigene constructs used to analyze the effect of the c.811+32C $>$ A variant on premRNA splicing. Intron 4 was placed in the appropriate context of the CCKBR cDNA. Numbers indicate exons.

\section{Construction of lentiviral vectors}

The pWPI lentivirus vector plasmid and the packaging plasmids (psPAX2 and pMD2.G) were obtained from Didier Trono's laboratory (http://tronolab.epfl.ch/; Ecole Polytechnique Federale de Lausanne, Lausanne, Switzerland) through Addgene (Addgene plasmids 12254, 12260, and 12259). First, CCKBR minigene templates were PCR amplified with Phusion Flash High-Fidelity PCR Master Mix (Thermo Scientific) using the following primers 5'GCTTAATTAACCATGGAGCTGCTAAAGCTGAACC-3' containing PacI restriction site and 5' phosphorilated 5'-CTCAGCCAGGGCCCAGTGTG-3'. CCKBR minigene inserts were then subcloned into pWPI plasmid between PmeI and PacI restriction sites. The lentivirus production in HEK 293 T packaging cells was performed as described previously ${ }^{62}$. Briefly, 293T cells were co-transfected with the pWPI expression plasmids, the packaging plasmid psPAX2 and the envelope vector pMD2.G. Transfection medium was changed after $16 \mathrm{~h}$, and the lentivirus-containing medium was subsequently harvested after 48 hours and frozen at $-80^{\circ} \mathrm{C}$. Viral preparations were titrated on HEK $293 \mathrm{~T}$ cells.

\section{Cell culture, transfection and viral transduction}

Human embrionic kidney (HEK) 293T cells were cultured in 6-well plates in Dulbecco's Modified Eagle Medium (DMEM) (Sigma, Budapest, Hungary) supplemented with $10 \%$ fetal bovine serum, $4 \mathrm{mM}$ glutamine, and $1 \%$ penicillin/streptomycin at $37{ }^{\circ} \mathrm{C}$ in a humified atmosphere containing 5\% $\mathrm{CO}_{2}$. Transfections of HEK $293 \mathrm{~T}$ cells were performed at $70-80 \%$ 
confluence using $2 \mu \mathrm{g}$ plasmid DNA and $10 \mu \mathrm{L}$ Lipofectamine 2000 (Life Technologies, Carlsbad, CA, USA) in 2 ml Opti-MEM Reduced Serum Medium (Life Technologies). After $4 \mathrm{~h}$ of incubation, cells were washed and the transfection medium was replaced with $2 \mathrm{ml}$ DMEM. Cells were harvested $24 \mathrm{~h}$ after this medium change. Capan-1 pancreatic adenocarcinoma cells were maintained in RPMI-1640 Medium (Sigma) supplemented with $15 \%$ fetal bovine serum $4 \mathrm{mM}$ glutamine, and $1 \%$ penicillin/streptomycin at $37^{\circ} \mathrm{C}$. To establish stable cell-lines a total number of $10^{5}$ cells were plated in 6-well plates and transduced with viral supernatant at multiplicity of infections (MOIs) of four. Expression analysis was performed at first, second and third passages.

\section{RNA extraction and reverse transcription}

Total RNA was isolated from transfected cells using RNeasy Mini Kit (Qiagen). To avoid plasmid and genomic DNA contamination, an additional on-column DNase digestion step was applied with RNase-Free DNAse (Qiagen). Two $\mu \mathrm{g}$ RNA was reverse transcribed using High Capacity cDNA Reverse Transcription Kit (Applied Biosystems, Foster City, CA, USA) in the presence of RNase inhibitor RNasin Plus (Promega, Fitchburg, WI, USA).

\section{Quantification of $C C K B R$ expression and splicing}

Real-time PCR reactions were performed with Maxima SYBR Green/ROX qPCR Master Mix (2X) (Fermentas) on an ABI PRISM 7000 Sequence Detection System (Applied Biosystems) platform with the following conditions: $10 \mathrm{~min}$ initial denaturation at $95{ }^{\circ} \mathrm{C}$, followed by 40 two-step cycles: $15 \mathrm{~s}$ at $95{ }^{\circ} \mathrm{C}$ and $1 \mathrm{~min}$ at $60{ }^{\circ} \mathrm{C}$. Primer sequences are given in Table 3 . Threshold cycle (CT) values were determined using the 7000 Sequence Detection System Software V.1.2.3. Relative expression was calculated using the comparative CT method ( $\triangle \triangle \mathrm{CT}$ method). Expression level of $C C K B R$ was first normalized to the glyceraldehyde-3phosphate dehydrogenase $(G A P D H)$ internal control gene $(\triangle \mathrm{CT})$ and then to expression levels measured in cells transfected with empty vector $(\Delta \Delta \mathrm{CT})$. Results were expressed as fold changes calculated with the formula $2^{-\Delta \Delta C T}$. Relative expression of splice variants was studied by using two different primer sets, one amplifying both the spliced and unspliced forms of $C C K B R$ and the other amplifying the intron 4-retaining splice variant (CCKB-Ri4sv) only. For absolute quantification of total $C C K B R$ and $C C K$-BRi4sv expression, we generated external calibration curves using serial dilutions of minigene plasmid templates. Using the calibration curves, copy numbers of total CCKBR and unspliced CCK-BRi4sv were determined and 
expressed as percent of total (spliced plus unspliced) CCKBR expression. All reactions were performed in duplicates.

\section{Statistical analysis}

Quantitative variables were described as mean \pm SE. Observed genotype frequencies in the study population were compared to the expected Hardy-Weinberg equilibrium. To test the association between pancreatic cancer and genotype/allele frequencies we used two-tailed Fisher's exact test. Additional odds ratios (OR) with 95\% confidence interval (CI) were estimated. Overall survival (OS) was defined as the time interval between diagnosis and death (uncensored observation) or the last date when the patient was still known to be alive (censored observation). Survival curves were calculated for OS of patients according to Kaplan-Meier. Two-sided log rank test was used to compare the difference between survival of pancreatic cancer patients harboring the A-allele (A/A or $\mathrm{A} / \mathrm{C})$ with survival of those patients with the $\mathrm{C} / \mathrm{C}$ genotype. Median survival time was calculated using data from all patients; median follow-up time was computed with censored observations. All the analyses were performed with GraphPad Prism (San Diego, CA, USA). For sample size calculation we used Quanto v.1.2.4. ${ }^{63}$.

\section{RESULTS OF THE SCL26A6 STUDY}

In the Hungarian discovery cohort we included 55 adult and five pediatric patients with nonalcoholic CP. No genetic testing was performed previously in the adult group. The pediatric patients were tested for PRSS1, CTRC, SPINK1 and CFTR mutations and no pathogenic variants were found. We sequenced 21 exons of $S L C 26 A 6^{64}$. We found four common variants: a missense variant c.616G>A (p.V206M; rs 13324142) in exon 6 and three intronic variants: c.23+71_103del in intron 1 (rs72201074); c.183-4C>A in intron 2 (rs34368826); and c.1134+32C >A in intron 9 ( $r$ s3821876) in complete linkage disequilibrium, indicating a conserved haplotype. 


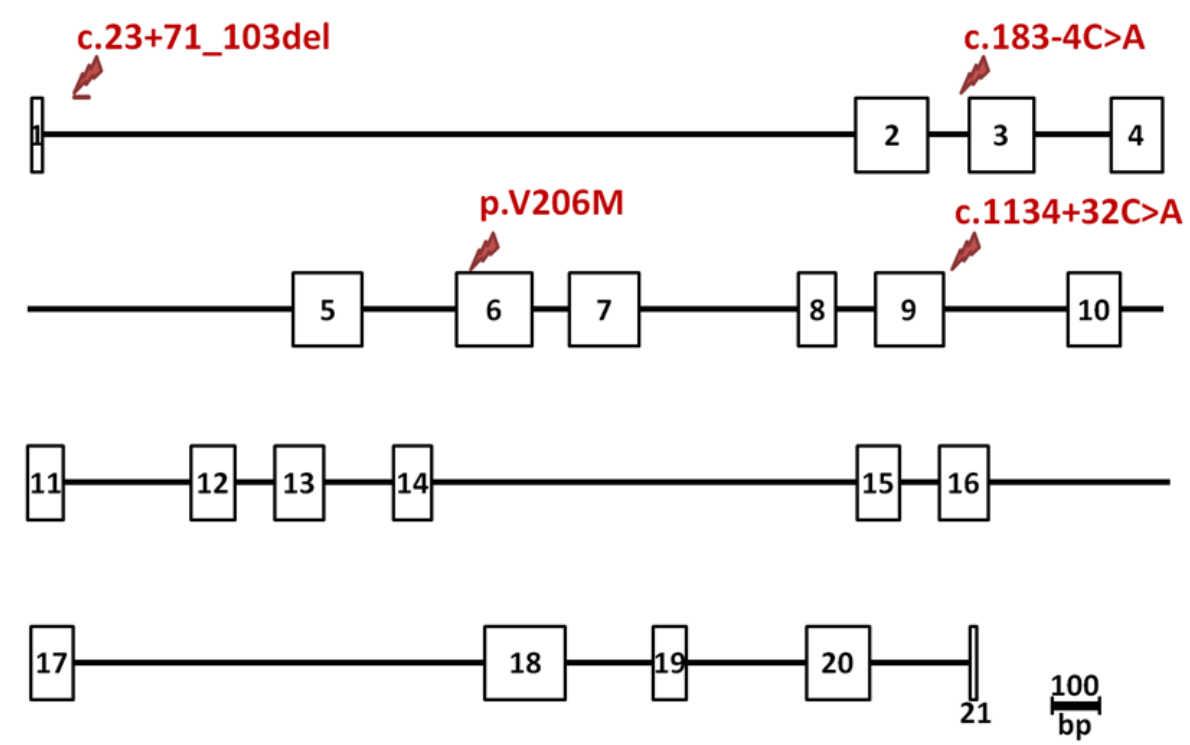

Figure 5. Schematic overview of the human SLC26A6 gene. Squares represent exons. The p.V206M associated haplotype is indicated by red arrows.

One homozygous and heterozygous patients were identified with the haplotype (allele frequency $15.8 \%$ ). One patient carried a synonymous mutation c.1191C>A (p.P397=) in exon 10 (rs369278809). Subsequently, we determined the distribution of the p.V206M associated haplotype in the Hungarian cohort by genotyping the p.V206M variant in 46 subjects with alcoholic CP and 99 control subjects. When genotype-frequencies were compared, the distribution of the p.V206M variant did not show a statistically significant difference between patients and controls. The Hungarian cohorts were also genotyped for the c.1191C>A (p.P397=) variant but beyond the single case identified by sequencing no additional carriers were found.

We performed a replication study in a German cohort consisting of 202 subjects with nonalcoholic CP, 159 subjects with alcoholic CP and 171 controls. In 40 non-alcoholic CP cases the coding region was sequenced and the p.V206M associated haplotype was detected in five patients (three heterozygous and two homozygous). Additionally, two intronic variants c.1248+9_20del and c.-10C>T (rs150438742) were detected in single cases. In agreement with our findings in the Hungarian cohort, the distribution of the p.V206M variant did not show a statistically significant difference between cases with alcoholic or non-alcoholic etiology and controls (Table 2a and b). 


\section{RESULTS OF THE CCKBR STUDY}

\section{Variant c.811+32C $>$ A does not predict risk for PDAC}

First, we attempted to replicate the published association between variant $\mathrm{c} .811+32 \mathrm{C}>\mathrm{A}$ in intron 4 of $C C K B R$ and the risk for developing pancreatic cancer. To this end, we sequenced this region of $C C K B R$ in our Hungarian cohort and detected variant c. $811+32 \mathrm{C}>\mathrm{A}$ in 35 heterozygous and 5 homozygous cases (allele frequency 18.4\%), and in 32 heterozygous and 3 homozygous controls (allele frequency 17.9\%). Similarly to allele frequencies, genotype frequencies did not show a statistically significant difference between cases and controls either (Table 5). Genotype frequencies in cases and controls were found to conform to the Hardy-Weinberg equilibrium. Additionally, we identified two variants in exon 5: c.955C>T (p.R319W, rs113168010) in one control subject and c.956G>A (p.R319Q, rs1805001) in a single patient.

A

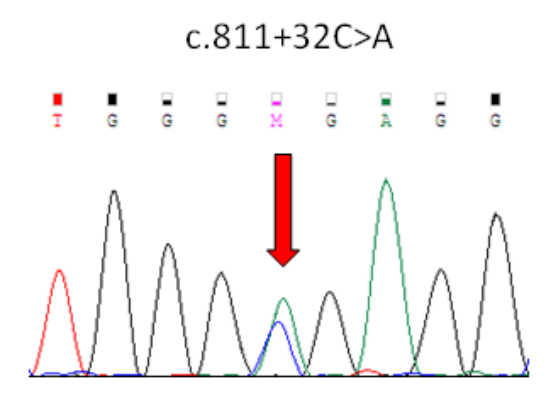

B

c.956G>A, p.R319Q

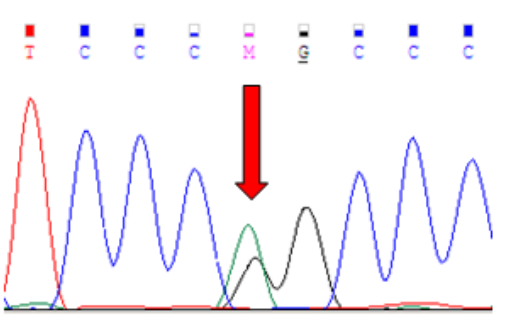

C c.955C>T, p.R319W

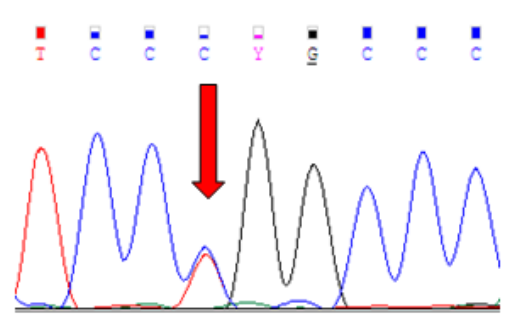

Figure 7. Sequence electropherograms of $C C K B R$ gene variants found in our cohort.

\section{Variant c.811+32C $>$ A does not predict survival in PDAC}

To address the hypothesis that variant c. $811+32 \mathrm{C}>\mathrm{A}$ may have a prognostic relevance, we analyzed this variant in relation to patient survival. Median follow-up time was 334 days, $12.3 \%$ of the observations were censored. Median survival of cases with $\mathrm{A} / \mathrm{C}$ and $\mathrm{A} / \mathrm{A}$ genotypes was not significantly different from those with the CC genotype (257 days and 266 days, respectively; $\mathrm{p}=0.45$ ), indicating that this variant does not modify survival of PDAC patients. 


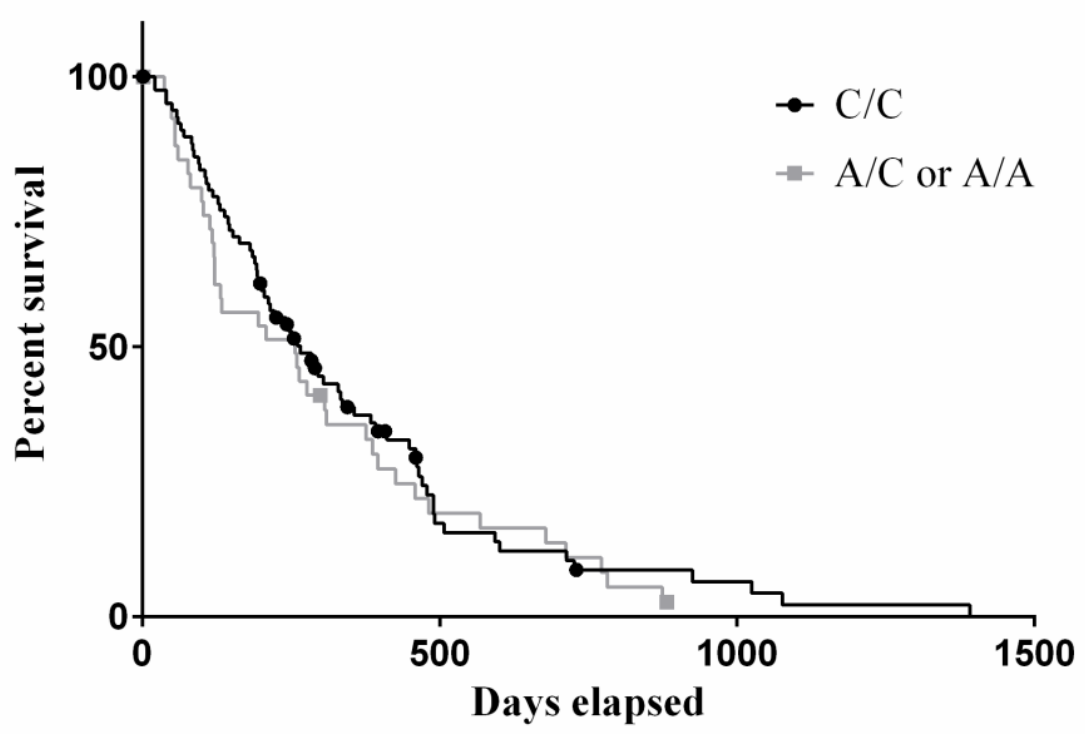

\section{Figure 8.}

\section{Kaplan-Meier survival curves according to genotype.}

Censored cases are shown as dots and squares.

\section{Variant c.811+32C $>\mathrm{A}$ does not affect splicing of intron 4 in $C C K B R$}

To determine whether variant $c .811+32 \mathrm{C}>\mathrm{A}$ has an effect on pre-mRNA splicing; we have tested two different cell lines. HEK 293T cells were transfected with expression plasmids carrying $C C K B R$ minigenes with or without the intron 4 variant and examined mRNA expression. CCKBR expression in transfected HEK 293T cells was about six orders of magnitude higher than endogenously expressed levels (Figure 8A). Interestingly, CCKBR mRNA was expressed at 1.5-fold higher levels when cells were transfected with introncontaining minigenes compared to cells transfected with the intronless CCKBR cDNA construct. This phenomenon is in agreement with published observations that the presence of introns can enhance gene expression. ${ }^{65,66}$ For absolute quantification of different splice-forms, we generated calibration curves using minigene plasmids as template. We found that expression of the CCK-BRi4sv intron 4-retaining splice variant corresponded to about $10 \%$ of total $C C K B R$ mRNA and was not different between cells transfected with minigenes with or 
without the c.811+32C $>$ A variant (Figure $8 \mathrm{C}$ ). Since splicing factors can be differently expressed in carcinoma cells, we have analyzed CCKBR splicing in Capan-1 pancreatic adenocarcinoma cells as well. In line with the data on HEK 293 T cells, splicing was not affected by the variant c. $811+32 \mathrm{C}>\mathrm{A}$ (Figure $8 \mathrm{~B}, 8 \mathrm{D}$ ).

A

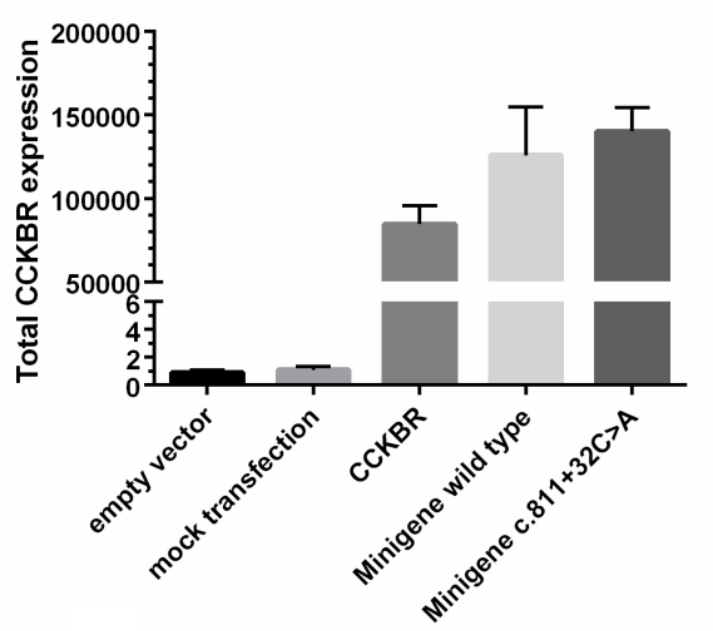

C

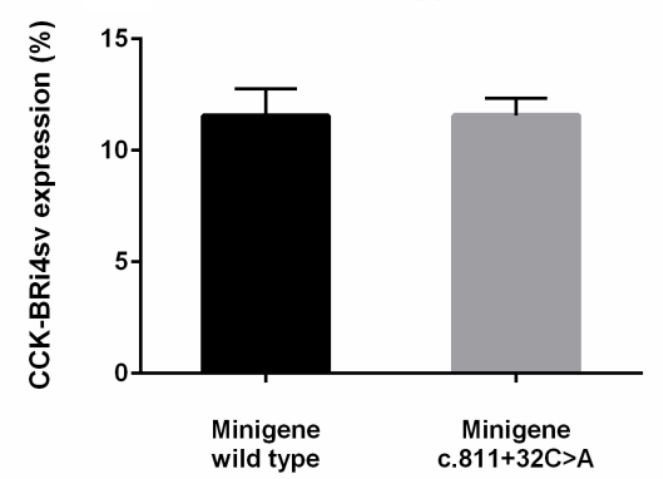

B
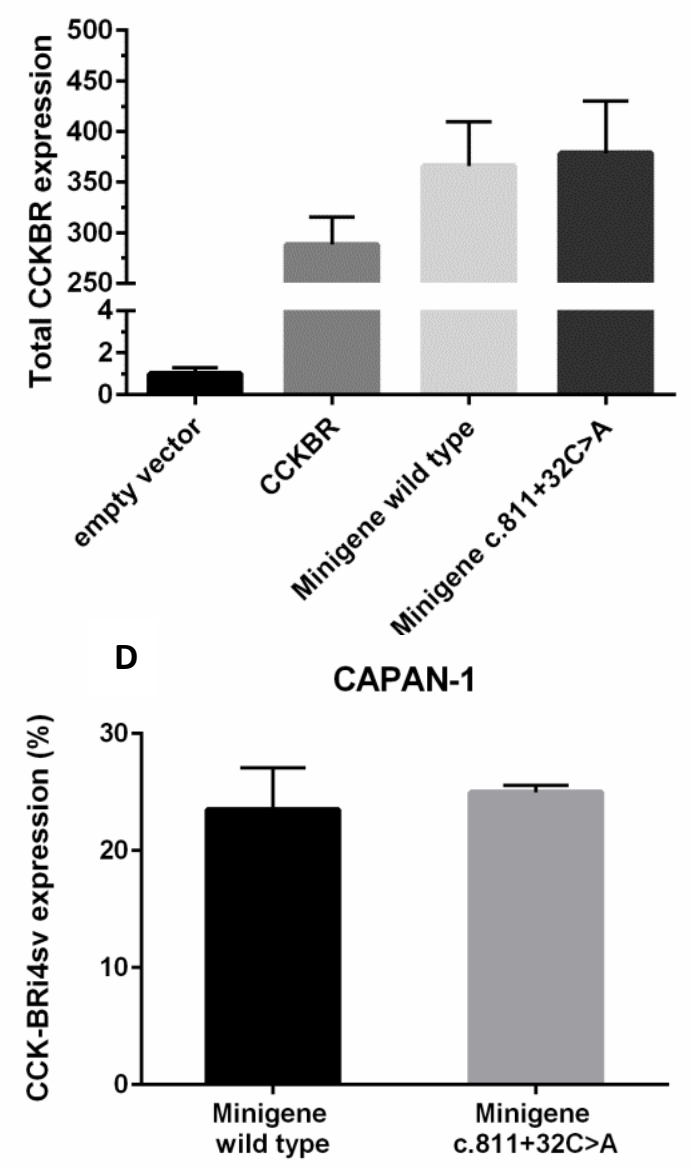

Figure 9. Functional analysis of the effect of variant c. $811+32 \mathrm{C}>\mathrm{A}$ on pre-mRNA splicing (A) Expression of CCKBR mRNA in transfected HEK 293T cells and transduced Capan-1 cells (B) with the indicated constructs. (C) Expression of the intron-retaining splice variant relative to the total amount of $C C K B R$ mRNA. Results are from three independent transfections with seven parallels each. 


\section{DISCUSSION}

\section{Role of SLC26A6 variants in chronic pancreatitis}

Pancreatic ductal $\mathrm{HCO}_{3}{ }^{-}$secretion is essential for the maintenance of tissue integrity, and is impaired in CP. In the present study we investigated the association of SLC26A6 variants with $\mathrm{CP}$, based on the crucial role of this candidate gene in the maintenance of ductal fluid and bicarbonate secretion. However, the SLC26A6 variants we identified did not alter the risk for development of either alcoholic or non-alcoholic CP. Smoking represents an independent risk factor for the development of $\mathrm{CP}^{67}$, possibly by impairing $\mathrm{HCO}_{3}{ }^{-}$transport ${ }^{6869}$ Therefore, we compared the occurrence of the p.V206M variant in patients where data on smoking habits were available. It is conceivable, that mutations of the SLC26A6 anion transporter could influence the effects of smoking, however, we did not find a significant difference between genotype frequencies of smokers and non-smokers (data not shown). Previously, Amato et al. (2012) examined SLC26 anion transporter and epithelial $\mathrm{Na}^{+}$channel genes in 39 patients with CFTR related disorders, and found no association. ${ }^{70}$ They described the SLC26A6 variants which we also identified as the p.V206M associated haplotype, however, they did not report linkage of these variants.

Studies on native pancreatic ducts isolated from Slc26a $6^{-1-}$ mice have been controversial regarding the effect on ductal fluid and bicarbonate secretion ${ }^{71,72}$. Our group investigated two acute pancreatitis models in Slc26a $6^{-1-}$ mice, and we did not detect a difference in disease severity compared to the wild type animals (unpublished observations).

On the other hand, Slc26a6 $6^{--}$mice exhibit a high incidence of oxalate nephrolithiasis ${ }^{73}$, due to defective intestinal oxalate secretion and urinary excretion ${ }^{74}$. In an attempt to identify association with nephrolithiasis, SLC26A6 variants were screened in familiar hyperoxaluria and primary hyperparathyroidism, but none of the variants increased disease risk ${ }^{75,76}$ Notably, the authors also reported co-segregation of 3 intronic variations with p.V206M. Functional analysis of the p.V206M mutation in Xenopus oocyte expression studies revealed a 30\% decrease of oxalate transport activity. However, the variant did not influence oxalate excretion in heterozygous carrier subjects ${ }^{75}$. Surmising that heterozygosity would result in a $15 \%$ reduction in transport, this defect may not be sufficient to alter oxalate homeostasis. 
The STAS domain of SLC26A6 plays a key role in the functional interaction with CFTR $^{41}$. The p.V206M mutation is located outside the STAS domain, and therefore, most likely does not have a substantial effect on bicarbonate transport.

In conclusion, in this study we tested the hypothesis that pancreatitis-associated mutations may be located in the $S L C 26 A 6$ gene encoding a pancreatic $\mathrm{Cl}^{-} / \mathrm{HCO}_{3}{ }^{-}$transporter, which interacts with CFTR. We did not find association between genetic variants of SLC26A6 and CP.

\section{Role of $C C K B R$ variant $\mathrm{c} .811+32 \mathrm{C}>\mathrm{A}$ in pancreatic cancer}

Identification of pancreatic cancer susceptibility genes is of outmost importance to define high-risk populations who may benefit from early detection by screening tests. Based on its role in pancreatic carcinogenesis and regulation of tumor growth $C C K B R$ is a promising candidate for a susceptibility gene. Indeed, several somatic mutations were identified in colorectal and gastric cancers that alter receptor activity, sensitization and localization. ${ }^{77,78}$ Some of these mutations are located in the third intracellular loop of the receptor, which plays a critical role in signal transduction. The same loop is altered by the tumor associated $C C K$ $B R i 4 s v$ splice variant, which retains intron 4 and codes for an insertion of 69 additional amino acid residues that enhances receptor activity. ${ }^{58}$ The molecular basis for this alternative splicing has been explained by aberrant expression of certain auxiliary splicing factors in carcinoma cells that are necessary for the spliceosome assembly. ${ }^{79}$ Alternatively, Smith et al. (2012, 2014) proposed that the c.811+32C > A intronic variant in CCKBR can induce retention of intron 4 and thereby increase risk for the development of PDAC and also lead to poorer survival in carriers $[12,13]$. In contrast, here we demonstrated that variant c. $811+32 \mathrm{C}>\mathrm{A}$ has no effect on CCKBR mRNA splicing, and it is not associated with increased risk for pancreatic cancer, nor with shorter survival in PDAC. Although we had more than $85 \%$ statistical power to replicate the previously described odds ratio of 2.28 , we detected no enrichment of the variant in our PDAC cohort. The reasons for the discrepancy between our results and those of Smith et al. $(2012,2014)$ are not readily apparent but may be related to ethnic and geographic variability of the frequency of the c.811+32C>A variant and the admixed nature of the US cohort. Association studies in ethnically admixed populations are potentially vulnerable to spurious association due to the ethnic variability of the SNP frequency studied. Indeed, data retrieved from the 1000 Genome Project database (www.1000genomes.org) show that the allele frequency of variant c. $811+32 \mathrm{C}>\mathrm{A}$ is $18.4 \%$ in 
subjects of European origin, whereas it is $2 \%$ in subjects of Asian descent and $23 \%$ in subjects of African descent. We also note that the control group in the study by Smith et al. (2014) was unusually small (59 subjects), which might result in the incorrect determination of control genotype frequencies. Indeed, the reported minor allele frequency $(11.8 \%)$ for this control cohort is appreciably smaller than the incidence found in our controls (17.9\%) which compares well with the 1000 Genomes data.

In conclusion, data presented here argue that intronic variant c. $811+32 \mathrm{C}>\mathrm{A}$ in $C C K B R$ is not associated with PDAC risk or survival in a Hungarian cohort and does not alter splicing of the $C C K B R$ pre-mRNA. Despite the fact that our study was not designed to detect a potentially small effect of variant c. $811+32 \mathrm{C}>\mathrm{A}$ on cancer risk and we did not take into account age and tumor stage at diagnosis when analyzing survival, our findings are convincingly selfconsistent. Therefore, we propose that variant c. $811+32 \mathrm{C}>\mathrm{A}$ is functionally harmless and it should be considered a common polymorphism with no clinical significance. Finally, our results highlight the necessity for replication studies and the importance of functional testing of new genetic risk markers.

\section{SUMMARY}

Background: Genetic risk factors are important determinants of disease susceptibility and prognosis in chronic pancreatitis (CP) and pancreatic ductal adenocarcinoma (PDAC). In this thesis two genetic investigations were conducted to gain a deeper comprehension of the pathophysiology of these diseases.

I. Pancreatic ductal $\mathrm{HCO}_{3}^{-}$secretion is critically dependent on the cystic fibrosis transmembrane conductance regulator chloride channel (CFTR) and the solute-linked carrier 26 member 6 anion transporter (SLC26A6). Deterioration of $\mathrm{HCO}_{3}{ }^{-}$secretion is observed in $\mathrm{CP}$, and CFTR mutations increase CP risk. Therefore, SLC26A6 is a reasonable candidate for a CP susceptibility gene, which has not been investigated in CP patients so far.

II. Single nucleotide polymorphism c. $811+32 \mathrm{C}>\mathrm{A}$ in intron 4 of the cholecystokinin-B receptor gene $(C C K B R)$ was previously reported to correlate with higher PDAC risk and poorer survival. The variant was suggested to induce retention of intron 4 , resulting in a new spliceform with enhanced receptor activity. Our objective was to validate the c.811+32C>A variant as an emerging biomarker for pancreatic cancer risk and prognosis. 


\section{Patients and methods}

I. As a first screening cohort, 106 subjects with $\mathrm{CP}$ and 99 control subjects with no pancreatic disease were recruited from the Hungarian National Pancreas Registry. In 60 nonalcoholic CP cases the entire SLC26A6 coding region was sequenced. In the Hungarian cohort variants c.616G >A (p.V206M) and c.1191C>A (p.P397=) were further genotyped by restriction fragment length polymorphism analysis. In a German replication cohort all exons were sequenced in 40 non-alcoholic CP cases and variant c.616G>A (p.V206M) was further analyzed by sequencing in $321 \mathrm{CP}$ cases and 171 controls.

II. We genotyped variant c. $811+32 \mathrm{C}>\mathrm{A}$ in 122 pancreatic adenocarcinoma cases and 106 controls by sequencing and examined its association with cancer risk and patient survival. To test the functional effect of variant c. $811+32 \mathrm{C}>\mathrm{A}$ on pre-mRNA splicing, we transfected HEK 293T cells and Capan-1 cells with CCKBR minigenes.

\section{Results}

I. Sequencing of the entire coding region revealed four common variants: intronic variants c.23+78_110del, c.183-4C>A, c.1134+32C>A, and missense variant c.616G>A (p.V206M) which were found in linkage disequilibrium indicating a conserved haplotype. The distribution of the haplotype did not show a significant difference between patients and controls in the two cohorts. A synonymous variant c.1191C>A (p.P397=) and two intronic variants c.1248+9_20del and c.-10C>T were detected in single cases.

II. The allele frequency of the variant was similar between patients and controls $(17.9 \%$ and $18.4 \%$, respectively). Survival analysis showed no significant difference between median survival of patients with the $\mathrm{C} / \mathrm{C}$ genotype (266 days) and patients with the $\mathrm{A} / \mathrm{C}$ or $\mathrm{A} / \mathrm{A}$ genotypes (257 days). $C C K B R$ minigenes with or without variant c. $811+32 \mathrm{C}>\mathrm{A}$ exhibited no difference in expression of the intron-retaining splice variant.

\section{Conclusion}

I. Our data show that SLC26A6 variants do not alter the risk for the development of CP.

II: These data indicate that variant c. $811+32 \mathrm{C}>\mathrm{A}$ in $C C K B R$ does not have a significant impact on pancreatic cancer risk or survival. 


\section{TABLES}

Table 1. Oligonucleotide primers and conditions used for PCR amplification and sequencing of the coding exons and the exon-intron junctions in the SLC26A6 gene.

\begin{tabular}{|c|c|c|c|c|}
\hline Exon & $\begin{array}{l}\text { Primer } \\
\text { name }\end{array}$ & Sequence $\left(5^{\prime} \rightarrow 3^{\prime}\right)$ & $\begin{array}{c}\text { PCR } \\
\text { product } \\
\text { (bp) }\end{array}$ & $\begin{array}{c}\text { Annealing } \\
\text { temperature }\left({ }^{\circ} \mathrm{C}\right)\end{array}$ \\
\hline \multirow{2}{*}{ Exon 1} & Primer 01. F & TCCGGAGCGTAGCGGCCT & \multirow{2}{*}{289} & \multirow{2}{*}{$58.7-60$} \\
\hline & Primer $01 . \mathrm{R}$ & GCACAGCCCAAGGGACTGG & & \\
\hline \multirow{2}{*}{ Exon 2-3 } & Primer 02. F & GATGCCTTCACTGTGTCTCTC & \multirow{2}{*}{522} & \multirow{2}{*}{$53.5-59.7$} \\
\hline & Primer $02 . \mathrm{R}$ & CTGGGTTAGGTGCCATAGTTC & & \\
\hline \multirow{2}{*}{ Exon 4} & Primer 03. F & ATCGTTTCAAGATCTGCTCTCC & \multirow{2}{*}{214} & \multirow{2}{*}{$53-59.7$} \\
\hline & Primer 03. R & CCATGATGGATGTGGGCAT & & \\
\hline \multirow{2}{*}{ Exon 5} & Primer $04 . \mathrm{F}$ & AGTGTCСTCTCCTCTTCAGAC & \multirow{2}{*}{217} & \multirow{2}{*}{$53-58.1$} \\
\hline & Primer 04. R & CATACTCCTGACTGTTCCACAC & & \\
\hline \multirow{2}{*}{ Exon 6-7 } & Primer $05 . \mathrm{F}$ & CTGCGCTCCTCATTAGCAACC & \multirow{2}{*}{538} & \multirow{2}{*}{65.1} \\
\hline & Primer 05. R & TACAGGAGGCTGCCCACGTGG & & \\
\hline \multirow{2}{*}{ Exon 8-9 } & Primer 06. F & CTCACCTCACAGTGGTTTATGT & \multirow{2}{*}{704} & \multirow{2}{*}{$52-60$} \\
\hline & Primer 06. R & GATGCCTCCGATAAGGTTACTG & & \\
\hline \multirow{2}{*}{$\begin{array}{c}\text { Exon } 10- \\
11\end{array}$} & Primer 07. F & TACAGTGGAACAGTGACCAGC & \multirow{2}{*}{424} & \multirow{2}{*}{$57-60.2$} \\
\hline & Primer 07. R & CTCGCCTGAACCTAGACTGG & & \\
\hline \multirow{2}{*}{$\begin{array}{c}\text { Exon } 12- \\
13\end{array}$} & Primer 08. F & GAGGAGGGTTGTCAGCATC & \multirow{2}{*}{401} & \multirow{2}{*}{$56.2-60.6$} \\
\hline & Primer 08. R & CCCTGTGGTACTCTCTCACTA & & \\
\hline \multirow{2}{*}{$\begin{array}{c}\text { Exon } 12- \\
13\end{array}$} & Primer 09. F & GGGACTTCAGGCTCCTTC & \multirow{2}{*}{219} & \multirow{2}{*}{$53-56.2$} \\
\hline & Primer 09. R & CGAATCCACAAAGGCTCATTC & & \\
\hline \multirow{2}{*}{ Exon 14} & Primer $10 . \mathrm{F}$ & GCAGGCACTGGGCACACTAGG & \multirow{2}{*}{235} & \multirow{2}{*}{$60-65.1$} \\
\hline & Primer $10 . \mathrm{R}$ & GACCTGCTAGGGGAGTGAAGC & & \\
\hline Exon 15- & Primer 11. F & ATTCCCTGTCTTCCCTGGTGTA & 235 & $53-606$ \\
\hline 16 & Primer 11. R & CATCGGCGCAACACCCT & & 00.0 \\
\hline Fxon 17 & Primer 12. F & TCCTGTCTTTGCACACCTATG & 400 & \\
\hline Exon $1 /$ & Primer $12 . \mathrm{R}$ & GAGTGCTCTCAGGGCAAATTA & 409 & $34.0-01$ \\
\hline Exon 18 & Primer 13. F & CCСAAACCCTCAAAGCTC & 207 & $56-61$ \\
\hline & Primer $13 . \mathrm{R}$ & AAAGTATCCTACССТCTTCCC & 201 & \\
\hline Fxon 19 & Primer 14. F & GGAGTTGAGTTCCTAGAGGTTC & 321 & \\
\hline Exon 19 & Primer $14 . \mathrm{R}$ & CATGGCCACCAGGAAAGA & 321 & 53 \\
\hline Exon 20 & Primer 15. F & TCTTTGGATAAAGCTGTTCTAGGG & 200 & -586 \\
\hline LXOH 20 & Primer $15 . \mathrm{R}$ & GGGACTCCTGGGTAGCA & & 31 \\
\hline Fxon 21 & Primer $16 \mathrm{~F}$ & TCAATGAGACAGCCAGAGATGC & 620 & $57-61$ \\
\hline Exon 21 & Primer $16 \mathrm{R}$ & CATTCAACAGCTTCACCACCAC & 020 & $5 /-01$ \\
\hline
\end{tabular}


Table 2. Distribution of the p.V206M SLC26A6 variant (genotypes in Table 3A and allele frequencies in Table 3B) in non-alcoholic and alcoholic chronic pancreatitis patients and control subjects from Hungary and Germany. Calculations were performed for a recessive model (GG+GA vs. AA) and a dominant model (GG vs. GA+AA) using two-sided Fisher Exact test. $P$-values are displayed for the dominant model (no significant $p$-value was obtained for the recessive model).

\section{Table 2A}

\section{Country}

Hungary

Non-alcoholic CP $(\mathrm{n}=60)$

Alcoholic CP

$(\mathrm{n}=46)$

Controls $(\mathrm{n}=99)$

Germany

Non-alcoholic CP $(\mathrm{n}=202)$

Alcoholic CP

$(\mathrm{n}=159)$

Controls

$(\mathrm{n}=171)$

\section{Genotype}

GA

GG

$43(71.6 \%)$

$36(78.2 \%) \quad 9(19.5 \%)$

$73(73.7 \%)$

$24(24.2 \%)$

$2(2 \%)$

$159(78.7 \%) \quad 36(17.8 \%)$

$7(3.4 \%)$

0.57

$128(80.5 \%) \quad 28(17.6 \%)$

$129(75.4 \%)$

$32(18.7 \%)$

$3(1.9 \%) \quad 0.27$

$10(5.9 \%)$

$0.74(0.44-1.26)$

n.a. n.a.

\section{Table 2B}

Country

Hungary

Non-alcoholic CP

$(\mathrm{n}=120)$

Alcoholic CP (n=92)

Controls

$(\mathrm{n}=198)$

Germany

Non-alcoholic CP

$(\mathrm{n}=404)$

Alcoholic CP

$(\mathrm{n}=318)$

Controls

$(n=342)$
Allele

G

$102(85 \%)$

$81(88 \%)$

$170(85.9 \%)$

$354(87.6 \%)$

$284(89.3 \%)$

$290(84.8 \%)$

$$
\text { A }
$$

$18(15 \%)$

0.83

0.61

$11(12 \%)$

$28(14.1 \%)$

n.a.

0.26

$0.79(0.52-1.20)$

$0.67(0.42-1.06)$

0.09

n.a.

n.a.

$1.07(0.56-2.03)$

$0.82(0.39-1.74)$

n.a.

OR (95\% CI)

V- $\quad$ OR $(95 \% \mathrm{CI})$

$1.11(0.54-2.28)$

$.78(0.34-1.26)$

n.a.

0.87 (0.54-1.41) 
Table 3. Tumor stage and survival of patients

\begin{tabular}{|c|c|c|}
\hline & no. of cases & $\begin{array}{l}\text { median } \\
\text { days }\end{array}$ \\
\hline $\begin{array}{l}\text { localized } \\
\text { locally }\end{array}$ & 9 & $480 \pm 312$ \\
\hline advanced & 78 & $321 \pm 267$ \\
\hline metastasized & 29 & $222 \pm 204$ \\
\hline unknown & 5 & \\
\hline
\end{tabular}

Table 4. Oligonucleotide primers used in this study.

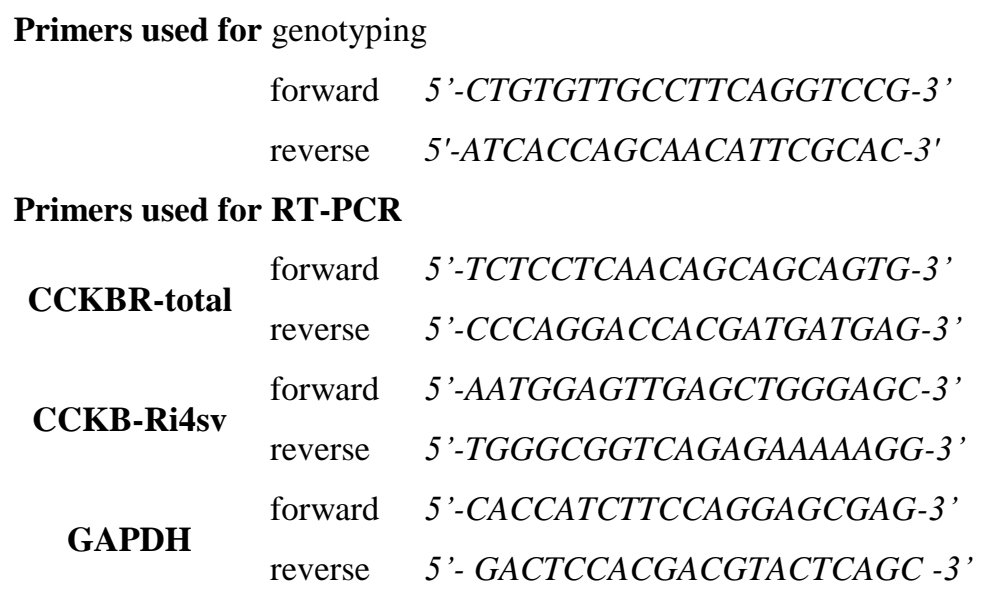

Table 5. Genotype and allele frequencies of variant c. $811+32 \mathrm{C}>\mathrm{A}$ in PDAC patients and controls. OR, odds ratio; CI, confidence interval.

$\begin{array}{ccccc} & \text { PDAC cases } & \text { Controls } & \text { genotypic OR (95\% CI) } & \text { p value } \\ \mathbf{C C} & 82 / 122 & 71 / 106 & \text { Reference } & - \\ \mathbf{A C} & 35 / 122 & 32 / 106 & 0.947(0.5328-1.683) & 0.884 \\ \mathbf{A A} & 5 / 122 & 3 / 106 & 1.443(0.339-6.255) & 0.7271 \\ \mathbf{A C + A A} & 40 / 122 & 35 / 106 & 0.9895(0.5686-1.722) & 1 \\ & & & \text { allelic OR (95\% CI) } & \\ \text { Minor allele } & 18.4 \% & 17.9 \% & 1.01(0.58-1.76) & 1 \\ \text { frequency } & & & \end{array}$




\section{REFERENCES}

1. Comfort, M. W. \& Steinberg, A. G. Pedigree of a family with hereditary chronic relapsing pancreatitis. Gastroenterology 21, 54-63 (1952).

2. Whitcomb, D. C. et al. Hereditary pancreatitis is caused by a mutation in the cationic trypsinogen gene. Nat. Genet. 14, 141-145 (1996).

3. Witt, H. et al. Mutations in the gene encoding the serine protease inhibitor, Kazal type 1 are associated with chronic pancreatitis. Nat. Genet. 25, 213-216 (2000).

4. Rosendahl, J. et al. Chymotrypsin C (CTRC) variants that diminish activity or secretion are associated with chronic pancreatitis. Nat. Genet. 40, 78-82 (2008).

5. Cohn, J. A. et al. Relation between mutations of the cystic fibrosis gene and idiopathic pancreatitis. N. Engl. J. Med. 339, 653-658 (1998).

6. Witt, H. et al. Variants in CPA1 are strongly associated with early onset chronic pancreatitis. Nat. Genet. 45, 1216-1220 (2013).

7. Fjeld, K. et al. A recombined allele of the lipase gene CEL and its pseudogene CELP confers susceptibility to chronic pancreatitis. Nat. Genet. 47, 518-522 (2015).

8. Howes, N. et al. Clinical and genetic characteristics of hereditary pancreatitis in Europe. Clin. Gastroenterol. Hepatol. 2, 252-261 (2004).

9. Malats, N. et al. Genetic variants associated with PDAC also contribute to chronic pancreatitis susceptibility. Pancreatology 15, S16 (2015).

10. Bartsch, D. K., Gress, T. M. \& Langer, P. Familial pancreatic cancer--current knowledge. Nat. Rev. Gastroenterol. Hepatol. 9, 445-453 (2012).

11. Lu, Y. et al. Most common 'sporadic' cancers have a significant germline genetic component. Hum. Mol. Genet. 23, 6112-6118 (2014).

12. Marcus, D. M. The ABO and Lewis blood-group system. Immunochemistry, genetics and relation to human disease. N. Engl. J. Med. 280, 994-1006 (1969). 
13. Amundadottir, L. et al. Genome-wide association study identifies variants in the ABO locus associated with susceptibility to pancreatic cancer. Nat. Genet. 41, 986-990 (2009).

14. Low, S.-K. et al. Genome-Wide Association Study of Pancreatic Cancer in Japanese Population. PLOS ONE 5, e11824 (2010).

15. Wu, C. et al. Genome-wide association study identifies five loci associated with susceptibility to pancreatic cancer in Chinese populations. Nat. Genet. 44, 62-66 (2012).

16. Petersen, G. M. et al. A genome-wide association study identifies pancreatic cancer susceptibility loci on chromosomes 13q22.1, 1q32.1 and 5p15.33. Nat. Genet. 42, 224-228 (2010).

17. Wolpin, B. M. et al. Genome-wide association study identifies multiple susceptibility loci for pancreatic cancer. Nat. Genet. 46, 994-1000 (2014).

18. Wehler, M. et al. Factors associated with health-related quality of life in chronic pancreatitis. Am. J. Gastroenterol. 99, 138-146 (2004).

19. Thuluvath, P. J., Imperio, D., Nair, S. \& Cameron, J. L. Chronic pancreatitis. Long-term pain relief with or without surgery, cancer risk, and mortality. J. Clin. Gastroenterol. 36, 159-165 (2003).

20. da Costa, M. Z. G. et al. Genetic Risk for Alcoholic Chronic Pancreatitis. Int. J. Environ. Res. Public. Health 8, 2747-2757 (2011).

21. Keiles, S. \& Kammesheidt, A. Identification of CFTR, PRSS1, and SPINK1 mutations in 381 patients with pancreatitis. Pancreas 33, 221-227 (2006).

22. Rosendahl, J. et al. CFTR, SPINK1, CTRC and PRSS1 variants in chronic pancreatitis: is the role of mutated CFTR overestimated? Gut 62, 582-592 (2013).

23. Németh, B. C. \& Sahin-Tóth, M. Human cationic trypsinogen (PRSS1) variants and chronic pancreatitis. Am. J. Physiol. - Gastrointest. Liver Physiol. 306, G466-G473 (2014).

24. Witt, H. et al. A degradation-sensitive anionic trypsinogen (PRSS2) variant protects against chronic pancreatitis. Nat. Genet. 38, 668-673 (2006).

25. Király, O., Wartmann, T. \& Sahin-Tóth, M. Missense mutations in pancreatic secretory trypsin inhibitor (SPINK1) cause intracellular retention and degradation. Gut 56, 1433-1438 (2007). 
26. Kereszturi, É. et al. Hereditary pancreatitis caused by mutation induced misfolding of human cationic trypsinogen - a novel disease mechanism. Hum. Mutat. 30, 575-582 (2009).

27. Beer, S. et al. Comprehensive functional analysis of chymotrypsin C (CTRC) variants reveals distinct loss-of-function mechanisms associated with pancreatitis risk. Gut 62, 1616-1624 (2013).

28. Sah, R. P. et al. Endoplasmic reticulum stress is chronically activated in chronic pancreatitis. J. Biol. Chem. 289, 27551-27561 (2014).

29. Domschke, S. et al. Inhibition by somatostatin of secretin-stimulated pancreatic secretion in man: a study with pure pancreatic juice. Scand. J. Gastroenterol. 12, 59-63 (1977).

30. Denyer, M. E. \& Cotton, P. B. Pure pancreatic juice studies in normal subjects and patients with chronic pancreatitis. Gut 20, 89-97 (1979).

31. Hegyi, P. \& Petersen, O. H. The exocrine pancreas: the acinar-ductal tango in physiology and pathophysiology. Rev. Physiol. Biochem. Pharmacol. 165, 1-30 (2013).

32. Maléth, J. et al. Alcohol disrupts levels and function of the cystic fibrosis transmembrane conductance regulator to promote development of pancreatitis. Gastroenterology 148, 427439.e16 (2015).

33. Venglovecz, V. et al. Effects of bile acids on pancreatic ductal bicarbonate secretion in guinea pig. Gut 57, 1102-1112 (2008).

34. Pallagi, P. et al. Trypsin reduces pancreatic ductal bicarbonate secretion by inhibiting CFTR $\mathrm{Cl}^{-}$ channels and luminal anion exchangers. Gastroenterology 141, 2228-2239.e6 (2011).

35. Raju, S. V. et al. Cigarette smoke induces systemic defects in cystic fibrosis transmembrane conductance regulator function. Am. J. Respir. Crit. Care Med. 188, 1321-1330 (2013).

36. LaRusch, J. et al. Mechanisms of CFTR Functional Variants That Impair Regulated Bicarbonate Permeation and Increase Risk for Pancreatitis but Not for Cystic Fibrosis. PLoS Genet. 10, (2014).

37. Bishop, M. D. et al. The cystic fibrosis transmembrane conductance regulator gene and ion channel function in patients with idiopathic pancreatitis. Hum. Genet. 118, 372-381 (2005). 
38. Cavestro, G. M. et al. Connections between genetics and clinical data: Role of MCP-1, CFTR, and SPINK-1 in the setting of acute, acute recurrent, and chronic pancreatitis. Am. J. Gastroenterol. 105, 199-206 (2010).

39. Anagnostopoulou, P. et al. SLC26A9-mediated chloride secretion prevents mucus obstruction in airway inflammation. J. Clin. Invest. 122, 3629-3634 (2012).

40. Mount, D. B. \& Romero, M. F. The SLC26 gene family of multifunctional anion exchangers. Pflüg. Arch. Eur. J. Physiol. 447, 710-721 (2004).

41. Ko, S. B. H. et al. Gating of CFTR by the STAS domain of SLC26 transporters. Nat. Cell Biol. 6, 343350 (2004).

42. Choi, J. Y. et al. Aberrant CFTR-dependent HCO3- transport inmutations associated with cystic fibrosis. Nature 410, 94-97 (2001).

43. Steward, M. C. \& Ishiguro, H. Molecular and cellular regulation of pancreatic duct cell function. Curr. Opin. Gastroenterol. 25, 447-453 (2009).

44. Hidalgo, M. Pancreatic Cancer. N. Engl. J. Med. 362, 1605-1617 (2010).

45. Yadav, D., Timmons, L., Benson, J. T., Dierkhising, R. A. \& Chari, S. T. Incidence, prevalence, and survival of chronic pancreatitis: a population-based study. Am. J. Gastroenterol. 106, 2192-2199 (2011).

46. Lowenfels, A. B. \& Maisonneuve, P. Epidemiology and risk factors for pancreatic cancer. Best Pract. Res. Clin. Gastroenterol. 20, 197-209 (2006).

47. Ekbom, A. et al. Pancreatitis and pancreatic cancer: a population-based study. J. Natl. Cancer Inst. 86, 625-627 (1994).

48. Liou, G.-Y. et al. Macrophage-secreted cytokines drive pancreatic acinar-to-ductal metaplasia through NF-KB and MMPs. J. Cell Biol. 202, 563-577 (2013).

49. Abramson, M. A., Jazag, A., van der Zee, J. A. \& Whang, E. E. The Molecular Biology of Pancreatic Cancer. Gastrointest. Cancer Res. GCR 1, S7-S12 (2007).

50. Saiki, Y. \& Horii, A. Molecular pathology of pancreatic cancer. Pathol. Int. 64, 10-19 (2014). 
51. Wolpin, B. M. et al. ABO Blood Group and the Risk of Pancreatic Cancer. J. Natl. Cancer Inst. 101, 424-431 (2009).

52. Wolpin, B. M. et al. Genome-wide association study identifies multiple susceptibility loci for pancreatic cancer. Nat. Genet. 46, 994-1000 (2014).

53. Rozengurt, E. \& Walsh, J. H. Gastrin, CCK, signaling, and cancer. Annu. Rev. Physiol. 63, 49-76 (2001).

54. Aly, A., Shulkes, A. \& Baldwin, G. S. Gastrins, cholecystokinins and gastrointestinal cancer. Biochim. Biophys. Acta 1704, 1-10 (2004).

55. Smith, J. P. \& Solomon, T. E. Cholecystokinin and pancreatic cancer: the chicken or the egg? Am. J. Physiol. Gastrointest. Liver Physiol. 306, G91-G101 (2014).

56. Körner, M., Waser, B., Reubi, J. C. \& Miller, L. J. CCK(2) receptor splice variant with intron 4 retention in human gastrointestinal and lung tumours. J. Cell. Mol. Med. 14, 933-943 (2010).

57. Smith, J. P. et al. Characterization of the CCK-C (cancer) receptor in human pancreatic cancer. Int. J. Mol. Med. 10, 689-694 (2002).

58. Hellmich, M. R. et al. Human colorectal cancers express a constitutively active cholecystokininB/gastrin receptor that stimulates cell growth. J. Biol. Chem. 275, 32122-32128 (2000).

59. Smith, J. P. et al. A single nucleotide polymorphism of the cholecystokinin-B receptor predicts risk for pancreatic cancer. Cancer Biol. Ther. 13, 164-174 (2012).

60. Smith, J. P. et al. Distribution of Cholecystokinin-B Receptor Genotype Between Patients With Pancreatic Cancer and Controls and Its Impact on Survival. Pancreas (2014). doi:10.1097/MPA.0000000000000263

61. Lohi, H. et al. Isoforms of SLC26A6 mediate anion transport and have functional PDZ interaction domains. Am. J. Physiol. - Cell Physiol. 284, C769-C779 (2003).

62. Dawson, K. et al. MicroRNA29: a mechanistic contributor and potential biomarker in atrial fibrillation. Circulation 127, 1466-1475, 1475e1-28 (2013). 
63. García-Closas, M. \& Lubin, J. H. Power and sample size calculations in case-control studies of gene-environment interactions: comments on different approaches. Am. J. Epidemiol. 149, 689692 (1999).

64. Waldegger, S. et al. Cloning and characterization of SLC26A6, a novel member of the solute carrier 26 gene family. Genomics 72, 43-50 (2001).

65. Wiegand, H. L., Lu, S. \& Cullen, B. R. Exon junction complexes mediate the enhancing effect of splicing on mRNA expression. Proc. Natl. Acad. Sci. 100, 11327-11332 (2003).

66. Kereszturi, E., Kiraly, O. \& Sahin-Toth, M. Minigene analysis of intronic variants in common SPINK1 haplotypes associated with chronic pancreatitis. Gut 58, 545-549 (2009).

67. Maisonneuve, P. et al. Cigarette smoking accelerates progression of alcoholic chronic pancreatitis. Gut 54, 510-514 (2005).

68. Kadiyala, V. et al. Cigarette smoking impairs pancreatic duct cell bicarbonate secretion. JOP J. Pancreas 14, 31-38 (2013).

69. Kreindler, J. L., Jackson, A. D., Kemp, P. A., Bridges, R. J. \& Danahay, H. Inhibition of chloride secretion in human bronchial epithelial cells by cigarette smoke extract. Am. J. Physiol. Lung Cell. Mol. Physiol. 288, L894-902 (2005).

70. Amato, F. et al. Extensive Molecular Analysis of Patients Bearing CFTR-Related Disorders. J. Mol. Diagn. 14, 81-89 (2012).

71. Wang, Y. et al. Slc26a6 regulates CFTR activity in vivo to determine pancreatic duct HCO3secretion: relevance to cystic fibrosis. EMBO J. 25, 5049-5057 (2006).

72. Song, Y., Ishiguro, H., Yamamoto, A., Jin, C. X. \& Kondo, T. Effects of Slc26a6 deletion and CFTR inhibition on HCO3- secretion by mouse pancreatic duct. J. Med. Investig. JMI 56 Suppl, 332-335 (2009).

73. Jiang, Z. et al. Calcium oxalate urolithiasis in mice lacking anion transporter Slc26a6. Nat. Genet. 38, 474-478 (2006). 
74. Freel, R. W., Hatch, M., Green, M. \& Soleimani, M. Ileal oxalate absorption and urinary oxalate excretion are enhanced in Slc26a6 null mice. Am. J. Physiol. Gastrointest. Liver Physiol. 290, G719-728 (2006).

75. Monico, C. G. et al. Phenotypic and Functional Analysis of Human SLC26A6 Variants in Patients With Familial Hyperoxaluria and Calcium Oxalate Nephrolithiasis. Am. J. Kidney Dis. Off. J. Natl. Kidney Found. 52, 1096-1103 (2008).

76. Corbetta, S. et al. Analysis of the $206 \mathrm{M}$ polymorphic variant of the SLC26A6 gene encoding a Cloxalate transporter in patients with primary hyperparathyroidism. Eur. J. Endocrinol. Eur. Fed. Endocr. Soc. 160, 283-288 (2009).

77. Willard, M. D. et al. Somatic Mutations in CCK2R Alter Receptor Activity that Promote Oncogenic Phenotypes. Mol. Cancer Res. MCR 10, 739-749 (2012).

78. Schmitz, F. et al. CCK-B/gastrin receptors in human colorectal cancer. Eur. J. Clin. Invest. 31, 812820 (2001).

79. Ding, W.-Q., Kuntz, S. M. \& Miller, L. J. A misspliced form of the cholecystokinin-B/gastrin receptor in pancreatic carcinoma: role of reduced sellular U2AF35 and a suboptimal 3'-splicing site leading to retention of the fourth intron. Cancer Res. 62, 947-952 (2002). 


\section{ACKNOWLEDGEMENTS}

I would like to express my most sincere gratitude to my mentors Professor Péter Hegyi at the First Department of Medicine, University of Szeged and Professor Miklós Sahin-Tóth at the Department of Molecular and Cell Biology, Boston University Medical Center for their guidance and support. These great scientists have served as role models for me. Without their outstanding supervision, this Ph.D. thesis would not have been possible. I would like to thank Dr. Viktoria Venglovecz and Prof. Dr. Zoltán Rakonczay Jr., the primary investigators of the cell physiology research lab their valuable insights and fruitful discussions. I am grateful to Prof. Dr. György Ábrahám and Prof. Dr. Tibor Wittmann, the current and former head of the First Department of Medicine, who gave me opportunity to work their Department. I would also like to thank my colleagues and friends, Dr. Eszter Hegyi, Dr. Balázs Kui, Dr. József Maléth, Dr Balázs Németh, Dr. Petra Pallagi, Tamara Madácsy, Zsolt Balla, Éva Kunstár, Dr. Andrea Geisz, Dr. Andrea Schnúr, Dr. Dorottya Laczkó, Dr. Eszter Kormányos, Máté Katona, Dr. Eszter Végh for all the help, encouragement and the great times we had, without them I would have been lost. This work would not have been possible to accomplish without the assistance and work of Edit Magyarné Pálfi, Tünde Pritz, Rea Fritz, Miklósné Árva, Zoltánné Fuksz, Imre Ignáth and Andrea Szentesi. I am deeply grateful to Professor Jonas Rosendahl, Leipzig University, Leipzig, Germany and his research team for the outstanding collaboration. We gratefully acknowledge the financial support we got from the Hungarian National Development Agency grants (TÁMOP-4.2.2.A-11/1/KONV-2012-0035, TÁMOP-4.2.2-A11/1/KONV-2012-0052, TÁMOP-4.2.2.A-11/1/KONV-2012-0073), the Hungarian Scientific Research Fund (OTKA NF105758, NF100677, K101521, K109756, PD105948), the Hungarian Academy of Sciences (BO/00531/11/5, BO/00632/14/5), co-financed by the European Social Fund in the framework of TÁMOP 4.2.4.A/2-11-1-2012-0001 and TÁMOP4.2.4.A2- 710-SZJÖ-TOK-13-0017 'National Excellence Program' and the MTA-SZTE Momentum Grant (LP2014-10/2014), the Deutsche Forschungsgemeinschaft (DFG) grants RO 3929/1-1 \& RO 3939/2-1 (to J.R.), and a grant of the Colora Stiftung gGmbH (to J.R.). Functional studies in the laboratory of MST were supported by NIH grants R01DK058088, R01DK082412, and R01DK095753.

Lastly, I owe warm thanks to my beloved Cornelius, who taught me a great deal of the things of the world and encouraged me to devote myself to my passion.

"You can't wait for inspiration. You have to go after it with a club." - Jack London 


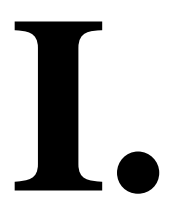


Original article

\title{
Genetic analysis of the bicarbonate secreting anion exchanger SLC26A6 in chronic pancreatitis
}

\author{
Anita Balázs a , Claudia Ruffert ${ }^{\mathrm{b}}$, Eszter Hegyi ${ }^{\mathrm{a}, \mathrm{c}}$, István Hritz ${ }^{\mathrm{a}}$, László Czakó a
} Tamás Takács a , Zoltán Szepes ${ }^{a}$, Balázs Csaba Németh ${ }^{\mathrm{d}}$, Judit Gervain ${ }^{\mathrm{e}}$, Ferenc Izbéki ${ }^{\mathrm{e}}$, Adrienn Halász ${ }^{\mathrm{e}}$, Dezső Kelemen ${ }^{\mathrm{f}}$, Richárd Szmola ${ }^{\mathrm{g}}$, János Novák ${ }^{\mathrm{h}}$, Stefan Crai ${ }^{\mathrm{h}}$, Anita Illés ${ }^{\mathrm{i}}$, Áron Vincze ${ }^{\mathrm{i}}$, Zsolt Molnár ${ }^{\mathrm{j}}$, Márta Varga ${ }^{\mathrm{k}}$, Barnabás Bod ${ }^{\mathrm{l}}$, Gyula Farkas Jr. ${ }^{\mathrm{m}}$, János Sümegi ${ }^{\mathrm{n}}$, Attila Szepes ${ }^{\circ}$, Zsolt Dubravcsik ${ }^{\mathrm{O}}$, Natália Lásztity ${ }^{\mathrm{p}}$, Andrea Párniczky ${ }^{\mathrm{p}}$, József Hamvas ${ }^{\mathrm{q}}$, Csilla Andorka ${ }^{\mathrm{r}}$, Gábor Veres ${ }^{\mathrm{r}}$, Zsolt Szentkereszty ${ }^{\mathrm{s}}$, Zoltán Rakonczay Jr. a, József Maléth a , Miklós Sahin-Tóth ${ }^{\mathrm{d}, 1}$, Jonas Rosendahl ${ }^{\mathrm{b}, 1}$, Péter Hegyi ${ }^{a, t, *, 1}$, on behalf of the Hungarian Pancreatic Study Group

${ }^{a}$ First Department of Medicine, University of Szeged, Szeged, Hungary

${ }^{\mathrm{b}}$ Department of Internal Medicine, Neurology and Dermatology, Division of Gastroenterology and Rheumatology, University of Leipzig, Leipzig, Germany

c 2nd Department of Pediatrics, Comenius University Medical School, University Children's Hospital, Bratislava, Slovakia

${ }^{d}$ Department of Molecular and Cell Biology, Boston University Henry M. Goldman School of Dental Medicine, Boston, MA 02118, USA

e Szent György University Teaching Hospital of County Fejér, Székesfehérvár, Hungary

${ }^{\mathrm{f}}$ Department of Surgery, University of Pécs, Hungary

${ }^{\mathrm{g}}$ Department of Interventional Gastroenterology, National Institute of Oncology, Budapest, Hungary

h Pándy Kálmán County Hopsital, Gyula, Hungary

i First Department of Medicine, University of Pécs, Hungary

${ }^{\mathrm{j}}$ Department of Anestesiology and Intensive Care, University of Szeged, Szeged, Hungary

${ }^{\mathrm{k}}$ Dr. Réthy Pál Hospital, Békéscsaba, Hungary

${ }^{1}$ Dr. Bugyi István Hospital, Szentes, Hungary

${ }^{\mathrm{m}}$ Department of Surgery, University of Szeged, Hungary

n B-A-Z County Hopspital and University Teaching Hospital, Miskolc, Hungary

${ }^{\circ}$ Department of Gastroenterology, Bács-Kiskun County Hospital, Kecskemét, Hungary

${ }^{\mathrm{p}}$ Heim Pál Children's Hospital, Budapest, Hungary

${ }^{\mathrm{q}}$ Bajcsy-Zsilinszky Hospital, Budapest, Hungary

${ }^{\mathrm{r}} 1$ 1st Department of Pediatrics, Semmelweis University, Faculty of Medicine, Budapest, Hungary

${ }^{\mathrm{s}}$ Institute of Surgery, University of Debrecen, Clinical Center, Debrecen Hungary

${ }^{\mathrm{t}}$ MTA-SZTE Translational Gastroenterology Research Group, Szeged, Hungary

\section{A R T I C L E I N F O}

\section{Article history:}

Available online xxx

\section{Keywords:}

Candidate gene analysis

$\mathrm{Cl}^{-}-\mathrm{HCO}_{3}^{-}$exchanger

Pancreatic duct

Chronic pancreatitis

Genetic risk factor

Bicarbonate secretion

\begin{abstract}
A B S T R A C T
Background: Pancreatic ductal $\mathrm{HCO}_{3}^{-}$secretion is critically dependent on the cystic fibrosis transmembrane conductance regulator chloride channel (CFTR) and the solute-linked carrier 26 member 6 anion transporter (SLC26A6). Deterioration of $\mathrm{HCO}_{3}^{-}$secretion is observed in chronic pancreatitis (CP), and CFTR mutations increase CP risk. Therefore, SLC26A6 is a reasonable candidate for a CP susceptibility gene, which has not been investigated in $\mathrm{CP}$ patients so far.

Methods: As a first screening cohort, 106 subjects with CP and 99 control subjects with no pancreatic disease were recruited from the Hungarian National Pancreas Registry. In 60 non-alcoholic CP cases the entire SLC26A6 coding region was sequenced. In the Hungarian cohort variants c.616G > A (p.V206M) and c.1191C > A (p.P397=) were further genotyped by restriction fragment length polymorphism analysis. In a German replication cohort all exons were sequenced in 40 non-alcoholic CP cases and variant c.616G > A (p.V206M) was further analyzed by sequencing in 321 CP cases and 171 controls.
\end{abstract}

\footnotetext{
* Corresponding author. First Department of Medicine, University of Szeged, Koranyi fasor 8-10, H-6720, Szeged, Hungary. Tel.: +36 62545 200; fax: +36 62545 185.

E-mail address: hegyi.peter@med.u-szeged.hu (P. Hegyi).

1 Contributed equally.
} 
Results: Sequencing of the entire coding region revealed four common variants: intronic variants c.23 + 78_110del, c.183-4C > A, c.1134 + 32C > A, and missense variant c.616G > A (p.V206M) which were found in linkage disequilibrium indicating a conserved haplotype. The distribution of the haplotype did not show a significant difference between patients and controls in the two cohorts. A synonymous variant c.1191C > A (p.P397=) and two intronic variants c.1248 + 9_20del and c.-10C > T were detected in single cases.

Conclusion: Our data show that SLC26A6 variants do not alter the risk for the development of CP.

Copyright $\odot$ 2015, IAP and EPC. Published by Elsevier India, a division of Reed Elsevier India Pvt. Ltd. All rights reserved.

\section{Introduction}

Chronic pancreatitis (CP) is an intractable inflammatory disease of the pancreas, leading to progressive and irreversible destruction of the parenchyma. In the majority of patients the etiology is complex, the disease results from the interaction of multiple risk factors. CP is most commonly associated with excessive alcohol consumption but other factors such as smoking, metabolic disturbances, anatomic abnormalities, autoimmunity and genetic variations have also been implicated. Discoveries of association of $\mathrm{CP}$ with PRSS1 [1], SPINK1 [2] and CTRC [3] gene mutations suggest a central role for trypsin in the development of $\mathrm{CP}$, while association with CFTR [4] variants highlight the importance of ductal changes contributing to disease development.

Fluid and $\mathrm{HCO}_{3}^{-}$secretion is a vital function of pancreatic ductal epithelium and is fundamental for the integrity of the tissue. The human pancreas secretes 1-2 L of alkaline, isotonic juice per day, which contains concentrations of bicarbonate that may exceed $140 \mathrm{mM}$ [5]. This bicarbonate rich fluid flushes out digestive enzymes from the ductal tree, facilitates solubilization of macromolecules, neutralizes the protons secreted by acinar cells, prevents premature activation of trypsinogen and neutralizes gastric acid in the duodenum providing an optimal $\mathrm{pH}$ environment for digestive enzymes.

One of the functional consequences of $\mathrm{CP}$ is the reduction in secretin-stimulated bicarbonate content in pancreatic juice [6]. On the other hand, in cystic fibrosis $(\mathrm{CF})$, pancreatic $\mathrm{HCO}_{3}^{-}$secretion is impaired. Impaired $\mathrm{HCO}_{3}^{-}$secretion disrupts the physiological interaction between acinar and duct cells, resulting in decreased intraluminal $\mathrm{pH}$, premature trypsinogen activation, impaired acinar secretion, obstruction of the lumen with protein plugs and finally destruction of the parenchyma [7]. Several pancreatitis associated toxic factors, such as ethanol [8], bile acids [9], trypsin [10] and cigarette smoke extract [11] displayed inhibitory effects on bicarbonate secretion and influenced the activity of the cystic fibrosis transmembrane conductance regulator chloride channel (CFTR). Not only functional inhibition, but also genetic defects of CFTR can increase the risk for pancreatitis. Association of CFTR mutations and the development of $\mathrm{CP}[4,12,13]$, and recurrent acute pancreatitis [14] has been reported. CF-causing severe and mild CFTR variants increase the risk 2.9 and 4.5 -fold respectively [15]. These observations indicate that insufficient electrolyte transport is pathogenic for CP (Fig. 1).

Pancreatic bicarbonate secretion is not only dependent on CFTR but also on the solute-linked carrier 26 (SLC26) anion transporters, localized in the apical membrane of the ductal cells. SLC26 isoforms constitute a conserved family of anion transporters with 10 distinct members. All SLC26 isoforms - except for SLC26A5 (prestin) - are versatile anion exchangers mediating apical chloride/base exchange in epithelial tissues. Several diseases have been linked to mutations in members of the family, including diastrophic dysplasias (SLC26A2), congenital chloride diarrhea (SLC26A3), Pendred's syndrome (SLC26A4), hearing loss (SLC26A5) and asthma (SLC26A9) [16,17].

The SLC26A6 anion exchanger is expressed in the apical membrane of pancreatic ducts, intestinal epithelium and kidney proximal tubule [17]. It mediates multiple anion exchange modes, including, $\mathrm{Cl}^{-} / \mathrm{HCO}_{3}^{-}$exchange, $\mathrm{Cl}^{-} /$formate exchange and $\mathrm{Cl}^{-}$/oxalate exchange. Earlier studies revealed a direct molecular interaction between CFTR and two SLC26 exchangers, namely A3 and A6, which results in mutual upregulation of their transport activity [18]. This process is mediated by binding of the regulatory ( $R$ ) domain of CFTR to the highly conserved STAS (sulphate transporter and anti-sigma antagonist) domain of SLC26 and this interaction is required for activation of both SLC26 transporters and CFTR. Notably, CF causing CFTR mutations that retain normal or substantial $\mathrm{Cl}^{-}$conductance exhibited a severe defect in CFTR dependent $\mathrm{Cl}^{-} / \mathrm{HCO}_{3}^{-}$exchange activity. This indicates that impairement of the coupled bicarbonate transport mechanism is sufficient to damage pancreatic function even in the presence of CFTR $\mathrm{Cl}^{-}$channel activity [19]. On the basis of its localization in the apical membrane of the pancreatic duct and its function as a $\mathrm{Cl}^{-} / \mathrm{HCO}_{3}^{-}$exchanger, SLC26A6 has been proposed to be a major contributor to the apical $\mathrm{HCO}_{3}^{-}$secretion in the pancreatic duct [20]. However, the role of genetic variations in SLC26A6 has remained unexplored in $\mathrm{CP}$.

In this study, we sequenced the entire coding region of SLC26A6 in 100 non-alcoholic CP cases. The identified variants were further investigated in Hungarian and German cohorts of non-alcoholic and alcoholic CP.

\section{Methods}

Subjects and study design

The study protocol was approved by the national ethical review committee ETT-TUKEB (22254-1/2012). All patients gave written informed consent for genetic analysis. The study included CP patients originating from Hungary $(n=106)$ and Germany $(n=361)$. Clinico-pathological information on individual patients including symptoms, diagnostic criteria and etiology were collected from medical records and questioners completed by the patients. Diagnosis of CP was based on at least two of the following criteria: constant or recurrent abdominal pain, calcifications on sonography or CT, ductal irregularities on ERCP or MRCP examination, EUS based diagnosis of $\mathrm{CP}$ and histologically confirmed $\mathrm{CP}$. According to etiology, patients were divided into alcoholic $\mathrm{CP}$ and non-alcoholic $\mathrm{CP}$ groups. Alcoholic CP was defined by consumption of more than $80 \mathrm{~g} / \mathrm{d}$ (man) ethanol or more than $60 \mathrm{~g} / \mathrm{d}$ (women) for at least two years. 99 Hungarian and 171 German control subjects were recruited from adult volunteers who considered themselves generally healthy, from inpatients who had no history of pancreatic disease and from blood donors (Table 1). 


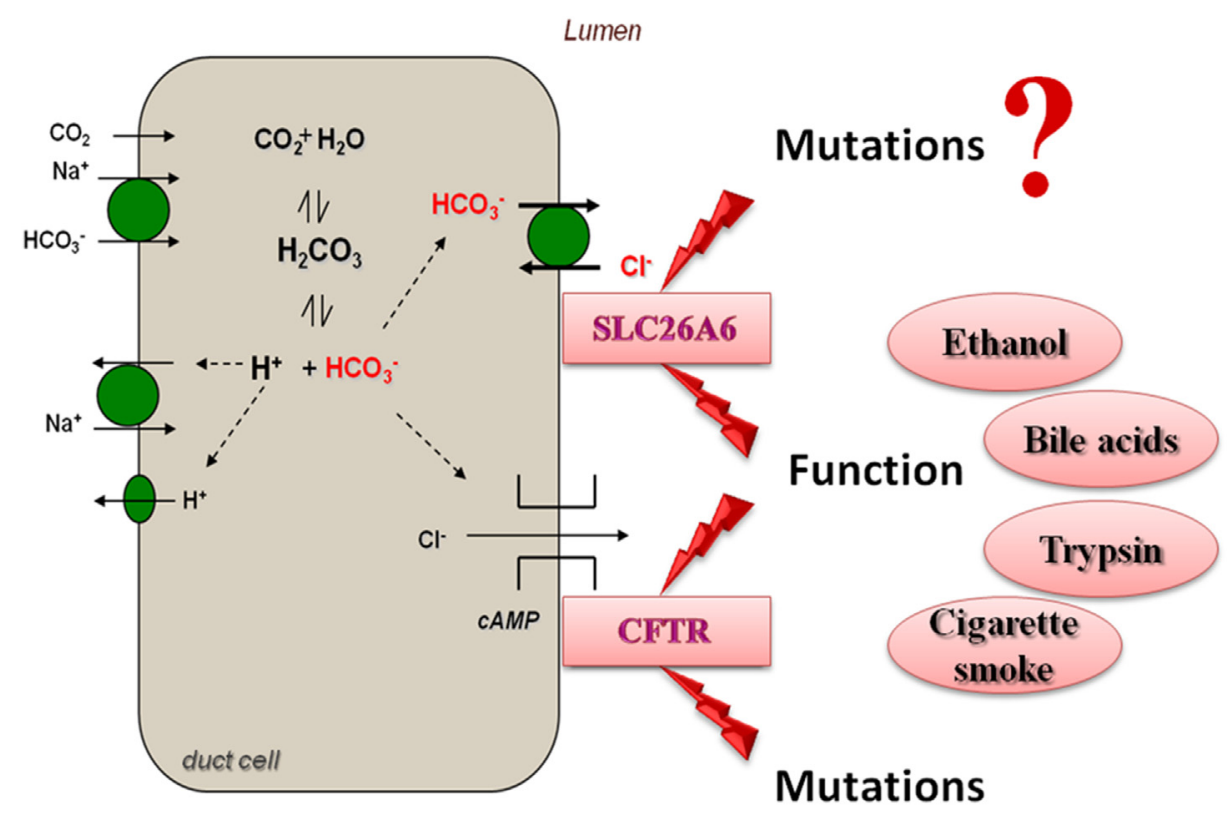

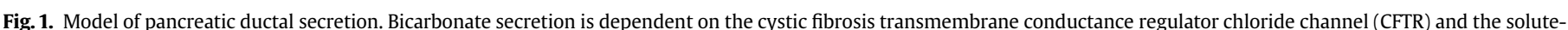

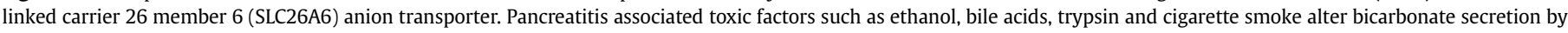

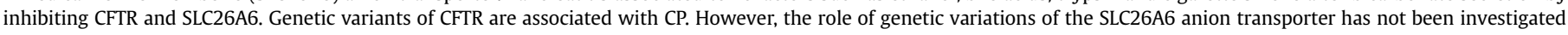
yet.

\section{Polymerase chain reaction and DNA sequencing}

Genomic DNA was isolated from whole blood using QIAamp DNA Blood mini kit (Qiagen, Hilden, Germany). In a discovery cohort of 60 non-alcoholic Hungarian CP patients and in 40 nonalcoholic German CP patients the entire coding sequence and adjacent intronic sequences were amplified and sequenced. Primers were designed according to the published sequence of the human SLC26A6 gene (GenBank: NM_022911.2) (Table 2). Our analysis did not include the non-functional alternative splice variant SLC26A6d [21], which retains an unspliced intron, resulting in a different carboxy terminus lacking the STAS domain. PCR was performed in a total volume of $30 \mu \mathrm{l}$, which contained $0.5 \mathrm{U}$ HotStarTaq DNA Polymerase (Qiagen, Hilden, Germany), $1.5 \mathrm{mM} \mathrm{Mg}_{2} \mathrm{Cl}$, $0.2 \mathrm{mM}$ dNTP, $0.5 \mu \mathrm{M}$ primer and $10-50 \mathrm{ng}$ genomic DNA. Amplification was performed under the following cycle conditions: $95^{\circ} \mathrm{C}$ for $15 \mathrm{~min}$ to activate the enzyme, followed by 40 cycles of $30 \mathrm{~s}$ denaturation at $94{ }^{\circ} \mathrm{C}, 30 \mathrm{~s}$ at specific annealing temperatures and $1 \mathrm{~min}$ extension at $72{ }^{\circ} \mathrm{C}$, with a final extension of $5 \mathrm{~min}$. Prior to sequencing PCR products were visualized by agarose gel electrophoresis. In the German cohort variant c.616G > A (p.V206M) was further analyzed by sequencing.

\section{Restriction fragment length polymorphism}

Genotyping of the p.V206M and c.1191C > A (p.P397=) variants in the Hungarian cohort was carried out by restriction fragment length polymorphism analysis. PCR was performed with primer sets 7 and 16, (see Table 1) and the products were digested with NlaIII (Thermo Scientific, Vilnius, Lithuania) and BmrI (New England Biolabs, Ipswich, MA USA) restriction enzymes, respectively.

\section{Statistical analysis}

Quantitative variables were described as mean \pm SD. We tested the significance of the differences between allele frequencies in cases and controls by Fisher's exact test and calculated $p$-values and odds ratios using GraphPad Prism v6.0a (San Diego, CA USA).

\section{Results}

In the Hungarian discovery cohort we included 55 adult and five pediatric patients with non-alcoholic CP. No genetic testing was performed previously in the adult group. The pediatric patients were tested for PRSS1, CTRC, SPINK1 and CFTR mutations and no

Table 1

Demographic data of cases and controls.

\begin{tabular}{|c|c|c|c|c|}
\hline & \multicolumn{2}{|l|}{ Hungary } & \multicolumn{2}{|l|}{ Germany } \\
\hline & alcoholic CP $(n=46)$ & non-alcoholic $\mathrm{CP}(\mathrm{n}=60)$ & alcoholic CP $(\mathrm{n}=159)$ & non-alcoholic CP $(\mathrm{n}=202)$ \\
\hline Age of onset range & $19-74$ & $3-85$ & $18-73$ & $3-75$ \\
\hline Median age of onset \pm SD & $45.1 \pm 10.9$ & $44.7 \pm 17.8$ & $41.6 \pm 11.2$ & $33.2 \pm 16.7$ \\
\hline Male & 41 & 35 & 137 & 100 \\
\hline \multirow[t]{2}{*}{ Female } & 5 & 25 & 22 & 102 \\
\hline & & Controls $(\mathrm{n}=99)$ & & Controls $(n=171)$ \\
\hline Age & & $53.2 \pm 17.7$ & & $63.8 \pm 2.9$ \\
\hline Male & & 43 & & 83 \\
\hline female & & 53 & & 88 \\
\hline
\end{tabular}


Table 2

Oligonucleotide primers and conditions used for PCR amplification and sequencing of the coding exons and the exon-intron junctions in the SLC26A6 gene.

\begin{tabular}{|c|c|c|c|c|}
\hline Exon & Primer name & Sequence $\left(5^{\prime} \rightarrow 3^{\prime}\right)$ & PCR product (bp) & Annealing temperature $\left({ }^{\circ} \mathrm{C}\right)$ \\
\hline \multirow[t]{2}{*}{ Exon 1} & Primer 01. F & TCCGGAGCGTAGCGGCCT & 289 & $58.7-60$ \\
\hline & Primer 01. R & GCACAGCCCAAGGGACTGG & & \\
\hline \multirow[t]{2}{*}{ Exon $2-3$} & Primer 02. F & GATGCCTTCACTGTGTCTCTC & 522 & $53.5-59.7$ \\
\hline & Primer 02. R & CTGGGTTAGGTGCCATAGTTC & & \\
\hline \multirow[t]{2}{*}{ Exon 4} & Primer 03. F & ATCGTTTCAAGATCTGCTCTCC & 214 & $53-59.7$ \\
\hline & Primer 03. R & CCATGATGGATGTGGGCAT & & \\
\hline \multirow[t]{2}{*}{ Exon 5} & Primer 04. F & AGTGTCCTCTCСTCTTCAGAC & 217 & $53-58.1$ \\
\hline & Primer 04. R & САТАСТССТGACTGTTCСАСАС & & \\
\hline \multirow[t]{2}{*}{ Exon 6-7 } & Primer 05. F & CTGCGCTCCTCATTAGCAACC & 538 & 65.1 \\
\hline & Primer 05. R & TACAGGAGGCTGCCCACGTGG & & \\
\hline \multirow[t]{2}{*}{ Exon 8-9 } & Primer 06. F & СTCACCTCACAGTGGTTTATGT & 704 & $52-60$ \\
\hline & Primer 06. $\mathrm{R}$ & GATGCCTCCGATAAGGTTACTG & & \\
\hline \multirow[t]{2}{*}{ Exon $10-11$} & Primer 07. F & TACAGTGGAACAGTGACCAGC & 424 & $57-60.2$ \\
\hline & Primer 07. $\mathrm{R}$ & CTCGCCTGAACCTAGACTGG & & \\
\hline \multirow[t]{2}{*}{ Exon $12-13$} & Primer 08. F & GAGGAGGGTTGTCAGCATC & 401 & $56.2-60.6$ \\
\hline & Primer 08. R & СССTGTGGTACTCTCTCACTA & & \\
\hline \multirow[t]{2}{*}{ Exon $12-13$} & Primer 09. F & GGGACTTCAGGCTCCTTC & 219 & $53-56.2$ \\
\hline & Primer 09. R & CGAATCCACAAAGGCTCATTC & & \\
\hline \multirow[t]{2}{*}{ Exon 14} & Primer $10 . \mathrm{F}$ & GCAGGCACTGGGCACACTAGG & 235 & $60-65.1$ \\
\hline & Primer $10 . \mathrm{R}$ & GACCTGCTAGGGGAGTGAAGC & & \\
\hline \multirow[t]{2}{*}{ Exon $15-16$} & Primer $11 . \mathrm{F}$ & ATTCCCTGTCTTCCCTGGTGTA & 235 & $53-60.6$ \\
\hline & Primer $11 . \mathrm{R}$ & CATCGGCGCAACACCCT & & \\
\hline \multirow[t]{2}{*}{ Exon 17} & Primer 12. F & TCCTGTCTTTGCACACCTATG & 409 & $54.6-61$ \\
\hline & Primer $12 . \mathrm{R}$ & GAGTGCTCTCAGGGCAAATTA & & \\
\hline \multirow[t]{2}{*}{ Exon 18} & Primer 13. F & СССАААСССТСАAАGСТС & 207 & $56-61$ \\
\hline & Primer $13 . \mathrm{R}$ & AAAGTATCCTACССТСТTCCС & & \\
\hline \multirow[t]{2}{*}{ Exon 19} & Primer $14 . \mathrm{F}$ & GGAGTTGAGTTCCTAGAGGTTC & 321 & $53-61$ \\
\hline & Primer $14 . \mathrm{R}$ & CATGGCCACCAGGAAAGA & & \\
\hline \multirow[t]{2}{*}{ Exon 20} & Primer $15 . \mathrm{F}$ & TCTTTGGATAAAGCTGTTCTAGGG & 200 & $57-58.6$ \\
\hline & Primer $15 . \mathrm{R}$ & GGGACTCCTGGGTAGCA & & \\
\hline \multirow[t]{2}{*}{ Exon 21} & Primer $16 \mathrm{~F}$ & TCAATGAGACAGCCAGAGATGC & 620 & $57-61$ \\
\hline & Primer $16 \mathrm{R}$ & CATTCAACAGCTTCACCACCAC & & \\
\hline
\end{tabular}

pathogenic variants were found. We sequenced 21 exons of SLC26A6 (Fig. 2.) [22]. We found four common variants: a missense variant c.616G > A (p.V206M; rs13324142) in exon 6 and three intronic variants: c.23 + 78_110del in intron 1 (rs556322139); c.1834C > A in intron 2 (rs34368826); and c.1134 + 32C > A in intron 9 ( $r$ 3821876) in complete linkage disequilibrium, indicating a conserved haplotype. One homozygous and heterozygous patients were identified with the haplotype (allele frequency 15.8\%). One patient carried a synonymous mutation c.1191C > A (p.P397=) in exon 10 (rs369278809). Subsequently, we determined the distribution of the p.V206M associated haplotype in the Hungarian cohort by genotyping the p.V206M variant in 46 subjects with alcoholic CP and 99 control subjects using RFLP. When genotypefrequencies were compared, the distribution of the p.V206M variant did not show a statistically significant difference between patients and controls. The Hungarian cohorts were also genotyped for the c.1191C > A (p.P397=) variant but beyond the single case identified by sequencing no additional carriers were found.

We performed a replication study in a German cohort consisting of 202 subjects with non-alcoholic CP, 159 subjects with alcoholic

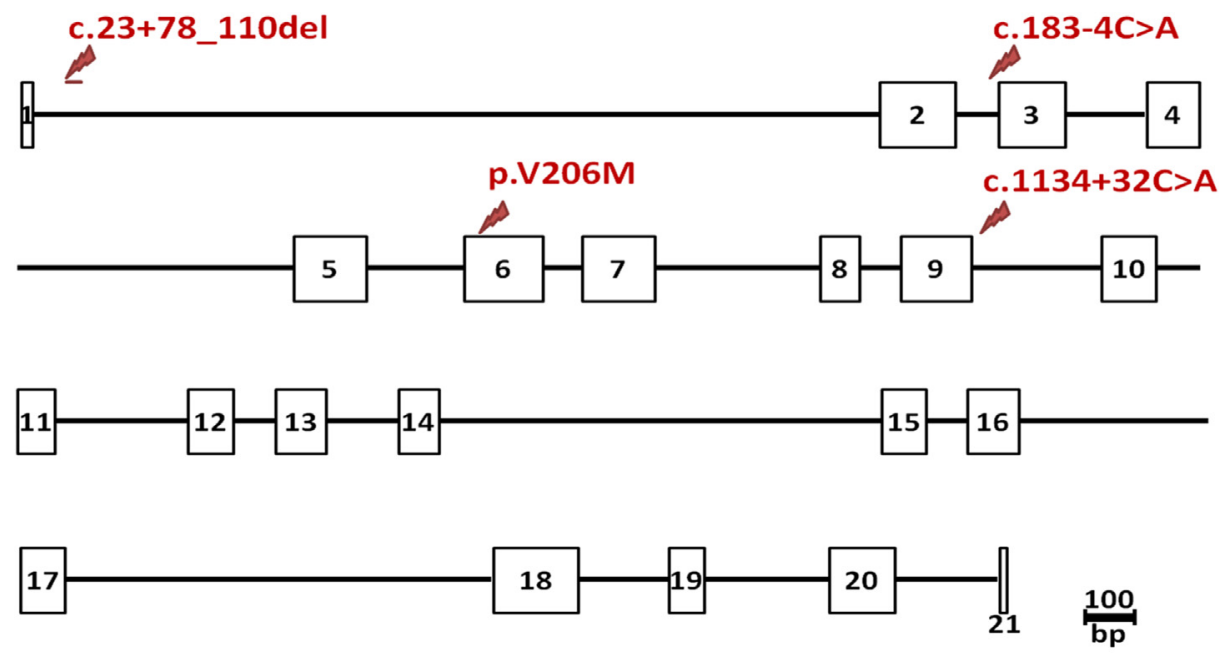

Fig. 2. Schematic overview of the human SLC26A6 gene. Squares represent exons. The p.V206M associated haplotype is indicated by red arrows. 
$\mathrm{CP}$ and 171 controls. In 40 non-alcoholic $\mathrm{CP}$ cases the coding region was sequenced and the p.V206M associated haplotype was detected in five patients (three heterozygous and two homozygous). Additionally, two intronic variants c.1248 + 9_20del and c.-10C > T ( $r$ 150438742) were detected in single cases. The rest of the German cohort was genotyped for variant p.V206M by sequencing. In agreement with our findings in the Hungarian cohort, the distribution of the p.V206M variant did not show a statistically significant difference between cases with alcoholic or non-alcoholic etiology and controls (Table 3a and b). In order to exclude the possibility of interactions between pancreatitis susceptibility genes, one of the cohorts (German patients) were screened for risk variants in PRSS1, CFTR, SPINK1, and CPA1 genes. Importantly, no variants were detected in linkage disequilibrium with p.V206M (data not shown).

\section{Discussion}

Pancreatic ductal $\mathrm{HCO}_{3}^{-}$secretion is essential for the maintenance of tissue integrity, and is impaired in CP. In the present study we investigated the association of SLC26A6 variants with CP, based on the crucial role of this candidate gene in the maintenance of ductal fluid and bicarbonate secretion. However, the SLC26A6 variants we identified did not alter the risk for development of either alcoholic or non-alcoholic CP. Smoking represents an independent risk factor for the development of $\mathrm{CP}$ [23], possibly by impairing $\mathrm{HCO}_{3}^{-}$transport $[24,25]$ Therefore, we compared the occurrence of the p.V206M variant in patients where data on smoking habits were available. It is conceivable, that mutations of the SLC26A6 anion transporter could influence the effects of smoking, however, we did not find a significant difference between genotype frequencies of smokers and non-smokers (data not shown). Previously, Amato et al. (2012) examined SLC26 anion transporter and epithelial $\mathrm{Na}^{+}$channel genes in 39 patients with CFTR related disorders, and found no association [26]. They described the SLC26A6 variants which we also identified as the p.V206M associated haplotype, however, they did not report linkage of these variants.

Studies on native pancreatic ducts isolated from Slc26a6 $6^{-1-}$ mice have been controversial regarding the effect on ductal fluid and bicarbonate secretion $[27,28]$. Our group investigated two acute pancreatitis models in Slc26a6 $6^{-1-}$ mice, and we did not detect a difference in disease severity compared to the wild type animals (unpublished observations).

On the other hand, Slc26a6 $6^{-1-}$ mice exhibit a high incidence of oxalate nephrolithiasis [29], due to defective intestinal oxalate secretion and urinary excretion [30]. In an attempt to identify association with nephrolithiasis, SLC26A6 variants were screened in familiar hyperoxaluria and primary hyperparathyroidism, but none of the variants increased disease risk [31,32] Notably, the authors also reported co-segregation of 3 intronic variations with p.V206M. Functional analysis of the p.V206M mutation in Xenopus oocyte expression studies revealed a $30 \%$ decrease of oxalate transport activity. However, the variant did not influence oxalate excretion in heterozygous carrier subjects [31]. Surmising that heterozygosity would result in a $15 \%$ reduction in transport, this defect may not be sufficient to alter oxalate homeostasis.

The STAS domain of SLC26A6 plays a key role in the functional interaction with CFTR [18]. The p.V206M mutation is located outside the STAS domain, and therefore, most likely does not have a substantial effect on bicarbonate transport.

In conclusion, in this study we tested the hypothesis that pancreatitis-associated mutations may be located in the SLC26A6 gene encoding a pancreatic $\mathrm{Cl}^{-} / \mathrm{HCO}_{3}^{-}$transporter, which interacts with CFTR. We did not find association between genetic variants of SLC26A6 and CP in Hungarian and German cohorts.

Table 3

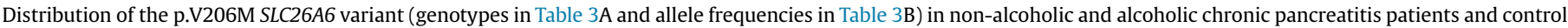

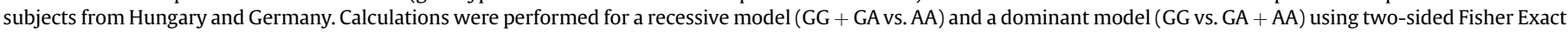
test. $P$-values are displayed for the dominant model (no significant $p$-value was obtained for the recessive model).

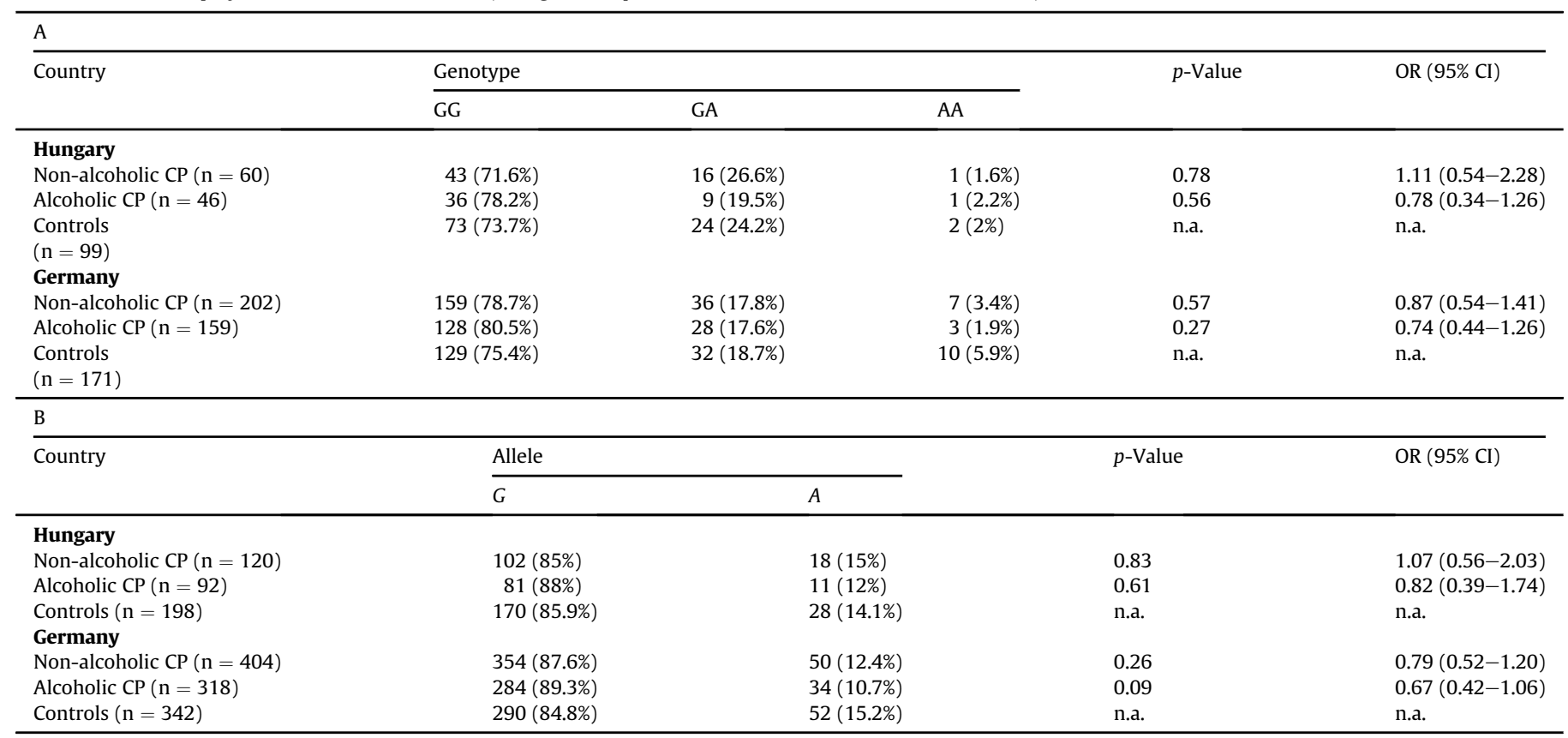

Recessive model.

$\mathrm{p}$-value $=0.87 ;$ OR $=0.82 ; 95 \% \mathrm{CI}=0.73-9.27$

$\mathrm{p}$-value $=0.95 ; \mathrm{OR}=1.08 ; 95 \% \mathrm{CI}=0.09-12.2$

$\mathrm{p}$-value $=0.28 ; \mathrm{OR}=0.58 ; 95 \% \mathrm{CI}=0.22-1.56$.

$\mathrm{p}$-value $=0.08 ; \mathrm{OR}=0.31 ; 95 \% \mathrm{CI}=0.08-1.15$ 


\section{Acknowledgments}

This study was supported by the Hungarian National Development Agency grants (TÁMOP-4.2.2.A-11/1/KONV-2012-0035, TÁMOP-4.2.2-A-11/1/KONV-2012-0052, TÁMOP-4.2.2.A-11/1/ KONV-2012-0073), the Hungarian Scientific Research Fund (OTKA NF105758, NF100677, K109756, PD105948), the Hungarian Academy of Sciences (BO/00531/11/5, BO/00632/14/5), the European Union and the State of Hungary, co-financed by the European Social Fund in the framework of TÁMOP 4.2.4.A/2-11-1-2012-0001 and TÁMOP-4.2.4.A2- 710-SZJÖ-TOK-13-0017 'National Excellence Program' and the MTA-SZTE Momentum Grant (LP2014-10/2014), the Deutsche Forschungsgemeinschaft (DFG) grants RO 3929/1-1 \& RO 3939/2-1 (to J.R.), and a grant of the Colora Stiftung gGmbH (to J.R.).

\section{References}

[1] Whitcomb DC, Gorry MC, Preston RA, Furey W, Sossenheimer MJ, Ulrich CD, et al. Hereditary pancreatitis is caused by a mutation in the cationic trypsinogen gene. Nat Genet 1996;14:141-5. http://dx.doi.org/10.1038/ng1096-141.

[2] Witt H, Luck W, Hennies HC, Classen M, Kage A, Lass U, et al. Mutations in the gene encoding the serine protease inhibitor, Kazal type 1 are associated with chronic pancreatitis. Nat Genet 2000;25:213-6. http://dx.doi.org/10.1038/ 76088.

[3] Rosendahl J, Witt H, Szmola R, Bhatia E, Ozsvári B, Landt O, et al. Chymotrypsin C (CTRC) variants that diminish activity or secretion are associated with chronic pancreatitis. Nat Genet 2008;40:78-82. http://dx.doi.org/10.1038/ ng.2007.44.

[4] Cohn JA, Friedman KJ, Noone PG, Knowles MR, Silverman LM, Jowell PS. Relation between mutations of the cystic fibrosis gene and idiopathic pancreatitis. N Engl J Med 1998;339:653-8. http://dx.doi.org/10.1056/ NEJM199809033391002.

[5] Domschke S, Domschke W, Rösch W, Konturek SJ, Sprügel W, Mitznegg P, et al. Inhibition by somatostatin of secretin-stimulated pancreatic secretion in man: a study with pure pancreatic juice. Scand J Gastroenterol 1977;12: 59-63.

[6] Denyer ME, Cotton PB. Pure pancreatic juice studies in normal subjects and patients with chronic pancreatitis. Gut 1979;20:89-97.

[7] Hegyi P, Petersen $\mathrm{OH}$. The exocrine pancreas: the acinar-ductal tango in physiology and pathophysiology. Rev Physiol Biochem Pharmacol 2013;165: 1-30. http://dx.doi.org/10.1007/112_2013_14.

[8] Maléth J, Balázs A, Pallagi P, Balla Z, Kui B, Katona M, et al. Alcohol disrupts levels and function of the cystic fibrosis transmembrane conductance regulator to promote development of pancreatitis. Gastroenterology 2015;148: 427-39. http://dx.doi.org/10.1053/j.gastro.2014.11.002. e16.

[9] Venglovecz V, Rakonczay Jr Z, Ozsvári B, Takács T, Lonovics J, Varró A, et al Effects of bile acids on pancreatic ductal bicarbonate secretion in guinea pig. Gut 2008;57:1102-12. http://dx.doi.org/10.1136/gut.2007.134361.

[10] Pallagi P, Venglovecz V, Rakonczay Jr Z, Borka K, Korompay A, Ozsvári B, et al. Trypsin reduces pancreatic ductal bicarbonate secretion by inhibiting CFTR $\mathrm{Cl}^{-}$channels and luminal anion exchangers. Gastroenterology 2011;141: 2228-39. http://dx.doi.org/10.1053/j.gastro.2011.08.039. e6.

[11] Raju SV, Jackson PL, Courville CA, McNicholas CM, Sloane PA, Sabbatini G et al. Cigarette smoke induces systemic defects in cystic fibrosis transmembrane conductance regulator function. Am J Respir Crit Care Med 2013;188: 1321-30. http://dx.doi.org/10.1164/rccm.201304-07330C.

[12] LaRusch J, Jung J, General IJ, Lewis MD, Park HW, Brand RE, et al. Mechanisms of CFTR functional variants that impair regulated bicarbonate permeation and increase risk for pancreatitis but not for cystic fibrosis. PLoS Genet 2014;10. http://dx.doi.org/10.1371/journal.pgen.1004376.

[13] Bishop MD, Freedman SD, Zielenski J, Ahmed N, Dupuis A, Martin S, et al. The cystic fibrosis transmembrane conductance regulator gene and ion channel function in patients with idiopathic pancreatitis. Hum Genet 2005;118: 372-81. http://dx.doi.org/10.1007/s00439-005-0059-z.
[14] Cavestro GM, Zuppardo RA, Bertolini S, Sereni G, Frulloni L, Okolicsanyi S, et al. Connections between genetics and clinical data: role of MCP-1, CFTR and SPINK-1 in the setting of acute, acute recurrent, and chronic pancreatitis. Am J Gastroenterol 2010;105:199-206. http://dx.doi.org/10.1038/ajg.2009.611.

[15] Rosendahl J, Landt O, Bernadova J, Kovacs P, Teich N, Bödeker H, et al. CFTR SPINK1, CTRC and PRSS1 variants in chronic pancreatitis: is the role of mutated CFTR overestimated? Gut 2013;62:582-92. http://dx.doi.org/ 10.1136/gutjnl-2011-300645.

[16] Anagnostopoulou P, Riederer B, Duerr J, Michel S, Binia A, Agrawal R, et al. SLC26A9-mediated chloride secretion prevents mucus obstruction in airway inflammation. J Clin Invest 2012;122:3629-34. http://dx.doi.org/10.1172/ JCI60429.

[17] Mount DB, Romero MF. The SLC26 gene family of multifunctional anion exchangers. Pflüg Arch Eur J Physiol 2004;447:710-21. http://dx.doi.org/ 10.1007/s00424-003-1090-3.

[18] Ko SBH, Zeng W, Dorwart MR, Luo X, Kim KH, Millen L, et al. Gating of CFTR by the STAS domain of SLC26 transporters. Nat Cell Biol 2004;6:343-50. http:// dx.doi.org/10.1038/ncb1115.

[19] Choi JY, Muallem D, Kiselyov K, Lee MG, Thomas PJ, Muallem S. Aberrant CFTR-dependent HCO3- transport inmutations associated with cystic fibrosis. Nature 2001;410:94-7. http://dx.doi.org/10.1038/35065099.

[20] Steward MC, Ishiguro H. Molecular and cellular regulation of pancreatic duct cell function. Curr Opin Gastroenterol 2009;25:447-53. http://dx.doi.org/ 10.1097/MOG.0b013e32832e06ce.

[21] Lohi H, Lamprecht G, Markovich D, Heil A, Kujala M, Seidler U, et al. Isoforms of SLC26A6 mediate anion transport and have functional PDZ interaction domains. Am J Physiol - Cell Physiol 2003;284:C769-79. http://dx.doi.org/ 10.1152/ajpcell.00270.2002.

[22] Waldegger S, Moschen I, Ramirez A, Smith RJ, Ayadi H, Lang F, et al. Cloning and characterization of SLC26A6, a novel member of the solute carrier 26 gene family. Genomics 2001;72:43-50. http://dx.doi.org/10.1006/geno.2000.6445.

[23] Maisonneuve P, Lowenfels AB, Müllhaupt B, Cavallini G, Lankisch PG, Andersen JR, et al. Cigarette smoking accelerates progression of alcoholic chronic pancreatitis. Gut 2005;54:510-4. http://dx.doi.org/10.1136/ gut.2004.039263.

[24] Kadiyala V, Lee LS, Banks PA, Suleiman S, Paulo JA, Wang W, et al. Cigarette smoking impairs pancreatic duct cell bicarbonate secretion. JOP J Pancreas 2013;14:31-8.

[25] Kreindler JL, Jackson AD, Kemp PA, Bridges RJ, Danahay H. Inhibition of chloride secretion in human bronchial epithelial cells by cigarette smoke extract. Am J Physiol Lung Cell Mol Physiol 2005;288:L894-902. http:// dx.doi.org/10.1152/ajplung.00376.2004.

[26] Amato F, Bellia C, Cardillo G, Castaldo G, Ciaccio M, Elce A, et al. Extensive molecular analysis of patients bearing CFTR-related disorders. J Mol Diagn 2012;14:81-9. http://dx.doi.org/10.1016/j.jmoldx.2011.09.001.

[27] Wang Y, Soyombo AA, Shcheynikov N, Zeng W, Dorwart M, Marino CR, et al. Slc26a6 regulates CFTR activity in vivo to determine pancreatic duct $\mathrm{HCO} 3$ secretion: relevance to cystic fibrosis. EMBO J 2006;25:5049-57. http:// dx.doi.org/10.1038/sj.emboj.7601387.

[28] Song Y, Ishiguro H, Yamamoto A, Jin CX, Kondo T. Effects of Slc26a6 deletion and CFTR inhibition on HCO3- secretion by mouse pancreatic duct. J Med Investig JMI 2009;56(Suppl. 332-5).

[29] Jiang Z, Asplin JR, Evan AP, Rajendran VM, Velazquez H, Nottoli TP, et al. Calcium oxalate urolithiasis in mice lacking anion transporter Slc26a6. Na Genet 2006;38:474-8. http://dx.doi.org/10.1038/ng1762.

[30] Freel RW, Hatch M, Green M, Soleimani M. Ileal oxalate absorption and urinary oxalate excretion are enhanced in Slc26a6 null mice. Am J Physiol Gastrointest Liver Physiol 2006;290:G719-28. http://dx.doi.org/10.1152/ ajpgi.00481.2005.

[31] Monico CG, Weinstein A, Jiang Z, Rohlinger AL, Cogal AG, Bjornson BB, et al Phenotypic and functional analysis of human SLC26A6 variants in patients with familial hyperoxaluria and Calcium oxalate nephrolithiasis. Am J Kidney Dis Off J Natl Kidney Found 2008;52:1096-103. http://dx.doi.org/10.1053/ j.ajkd.2008.07.041.

[32] Corbetta S, Eller-Vainicher C, Frigerio M, Valaperta R, Costa E, Vicentini L, et al. Analysis of the 206M polymorphic variant of the SLC26A6 gene encoding a Cloxalate transporter in patients with primary hyperparathyroidism. Eur J Endocrinol Eur Fed Endocr Soc 2009;160:283-8. http://dx.doi.org/10.1530/ EJE-08-0623. 
II. 


\section{View Letter}

\section{Close}

Date: $\quad$ 08/07/2015

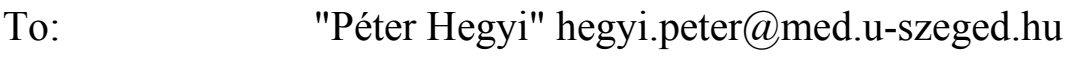

From: $\quad$ "Pancreas Editorial Office" pancreasofc@ucla.edu

Subject: $\quad$ Pancreas journal - PANCREAS 15236R1

Pancreas - Official Journal of the American Pancreatic Association, Japan Pancreas Society, and the North American NeuroEndocrine Tumor Society

$08 / 06 / 2015$

Péter Hegyi, MD, PhD

University of Szeged

First Department of Medicine

Koranyi fasor 8-10

Szeged H-6720

HUNGARY

Re: Manuscript Number PANCREAS 15236R1

Dear Dr. Hegyi,

We are pleased to inform you we have accepted your paper titled:

"A common CCK-B receptor intronic variant in pancreatic adenocarcinoma in a Hungarian cohort," for publication in Pancreas as a Full Manuscript.

However, some changes need to be made to the manuscript to meet publication requirements:

1. Reformat your abstract to only include four sections labeled, Objectives, Methods, Results, and Conclusions. Limit the abstract to 200 words or fewer. Expand all abbreviations at first mention and the abstract length should not be reduced by eliminating fully spelled out terms in favor of using only abbreviations.

2. Table 3 is titled Table 2. Change the title.

3. Reformat figures 1 and 2 as separate TIFF or EPS format files in at least $300 \mathrm{ppi} / \mathrm{dpi}$ resolution in CMYK color or Grayscale. Submit line art at $1200 \mathrm{ppi} / \mathrm{dpi}$.

Figures 1 and 2 have a resolution of 96 dpi.

-Check the quality and clarity of all images before uploading because our office cannot fix pixelated 
or blurry images. Please see our publisher's PDF guide to formatting pictures by visiting http://edmgr.ovid.com/lww-final/accounts/5StepsforArt.pdf. If you cannot make the resolution and/or color changes yourself or if picture quality cannot be retained after increasing resolution, submit the figures as PowerPoint files.

4. Rename Figures 1 and 2 to match the convention outlined in the Instruction for Authors. For example, Hegyi_Figure_1.tif.

5. Reformat references according to our journal's Instruction for Authors.

(http://journals.lww.com/pancreasjournal/Pages/InstructionsforAuthors.aspx)

a) Remove issue numbers. The journal's style only uses volume numbers.

b) Insert a period after each journal title.

c) Some journal titles contain periods after each abbreviation. Only include one period at the end of the journal titles.

d) For references that are websites, such as Ref 19, include the date the site was first accessed. For example, Accessed August 7, 2015.

-Keep the rest of the formatting the same.

Example: Journal Article [follow AMA style, but use et al after the first 3 authors] Farkas LG, Tompson B, Phillips JH, et al. Comparison of anthropometric and cephalometric measurements of the adult face. J Craniofacial Surg. 1999;10:18-25.

6. Copyright transfer agreement forms were not submitted for Adrienn Csiszko, Andrea Parniczky, and Ferenc Izbeki. Please have each author download and individually complete a LWW Copyright Transfer and Disclosure form available at http://inks.lww.com/MPA/A249 and upload the signed CTAFs along with your revision. This is a new form that can be signed electronically. (For detailed help with electronically signing this form, go to http://links.lww.com/ZUAT/A106.) Forms that are filled out or signed by hand should be scanned and saved as a pdf. Each copyright transfer file name should include the manuscript number and the signing author's name. For example: copyright 15236 Izbeki, Ferenc.pdf.

Note: Only 1 name should appear in the Author section and it should be the name of the author who signs the form. Make sure to complete all sections including manuscript title otherwise the CTAF will have to be redone.

Please send the revisions and CTAFs to chnguyen@mednet.ucla.edu.

Once complete, your materials will be forwarded to our publisher for copyediting and typesetting, and you will receive electronic page proofs directly from them within the next several weeks. Our Editorial Office will send you a publication notice by email when your article has been assigned to an upcoming volume and issue of the journal.

We look forward to the appearance of your article in Pancreas and hope you will continue to submit your original articles to us for publication consideration.

http://pancreas.edmgr.com/ 
Your username is: $* * * * * * * *$

Your password is:

Sincerely,

Christine Nguyen

Managing Editor, Pancreas

Close 


\section{ARTICLE COVERSHEET}

\section{LWW_CONDENSED(7.75X10.75) SERVER-BASED}

Article : MPA50179

Creator : dpc_lww

Date : Thursday September 3rd 2015

Time : 09:15:05

Number of Pages (including this page) $: 7$ 


\title{
A Common CCK-B Receptor Intronic Variant in Pancreatic Adenocarcinoma in a Hungarian Cohort
}

\author{
Anita Balázs, MD, * Balázs Csaba Németh, MD, PhD, † Balázs Ördög, PhD, Eszter Hegyi, MD, *\$ \\ István Hritz, MD, PhD, * László Czakó, MD, PhD, * József Czimmer, MD, PhD,// Szilárd Gódi, MD,// \\ Adrienn Csiszkó, MD, $₫$ Zoltán Rakonczay, Jr, MD, PhD, * Andrea Párniczky, MD, \# Ferenc Izbéki, MD, PhD, ** \\ Adrienn Halász, MD, ** Zsuzsanna Kahán, MD, PhD, †† Péter Hegyi, MD, PhD, DSc, *t+ \\ Miklós Sahin-Tóth, MD, PhD, † and on behalf of the Hungarian Pancreatic Study Group
}

\begin{abstract}
Objectives: Variant c. $811+32 \mathrm{C}>\mathrm{A}$ in intron 4 of the cholecystokinin- $\mathrm{B}$ receptor gene $(C C K B R)$ was reported to correlate with higher pancreatic cancer risk and poorer survival. The variant was suggested to induce retention of intron 4, resulting in a new splice form with enhanced receptor activity. Our objective was to validate the $\mathrm{c} .811+32 \mathrm{C}>\mathrm{A}$ variant as an emerging biomarker for pancreatic cancer risk and prognosis.

Methods: We genotyped variant c. $811+32 \mathrm{C}>\mathrm{A}$ in 122 pancreatic adenocarcinoma case patients and 106 control subjects by sequencing and examined its association with cancer risk and patient survival. We tested the functional effect of variant c. $811+32 \mathrm{C}>\mathrm{A}$ on pre-messenger RNA splicing in human embryonic kidney 293T and Capan-1 cells transfected with $C C K B R$ minigenes.
\end{abstract}

Results: The allele frequency of the variant was similar between patients and control subjects (18.4\% and $17.9 \%$, respectively). Survival analysis showed no significant difference between median survival of patients with the $\mathrm{C} / \mathrm{C}$ genotype (266 days) and patients with the $\mathrm{A} / \mathrm{C}$ or $\mathrm{A} / \mathrm{A}$ genotypes (257 days). CCKBR minigenes with or without variant c. $811+32 \mathrm{C}>\mathrm{A}$ exhibited no difference in expression of the intron-retaining splice variant.

Conclusion: These data indicate that variant c. $811+32 \mathrm{C}>\mathrm{A}$ in $C C K B R$ does not have a significant impact on pancreatic cancer risk or survival in a Hungarian cohort.

From the *First Department of Medicine, University of Szeged, Szeged, Hungary; $\dagger$ Department of Molecular and Cell Biology, Boston University Henry M. Goldman School of Dental Medicine, Boston, MA; $\$$ Department of Pharmacology and Pharmacotherapy, Faculty of Medicine, University of Szeged, Szeged, Hungary; \$2nd Department of Pediatrics, Comenius University Medical School, University Children's Hospital, Bratislava, Slovakia; ||First Department of Internal Medicine, University of Pécs, Hungary; $\uparrow$ Institute of Surgery, University of Debrecen, Clinical Center, Debrecen, Hungary; \#Heim Pál Children's Hospital, Budapest, Hungary; **First Department of Medicine, Szent György Teaching Hospital of County Fejér, Székesfehérvár, Hungary; $\dagger$ Department of Oncotherapy, University of Szeged, Szeged, Hungary; and \#\$MTA-SZTE Translational Gastroenterology Research Group, Szeged, Hungary. Received for publication March 11, 2015; accepted August 7, 2015.

Reprints: Péter Hegyi, MD, PhD, DSc, First Department of Medicine,

University of Szeged, Koranyi fasor 8-10, H-6720 Szeged, Hungary (e-mail: hegyi.peter@med.u-szeged.hu).

This study was supported by Hungarian National Development Agency grants (TÁMOP-4.2.2.A-11/1/KONV-2012-0035, TÁMOP-4.2.2-A-11/1/KONV2012-0052, and TÁMOP-4.2.2.A-11/1/KONV-2012-0073) and the

Hungarian Scientific Research Fund (OTKA K101521 and NF100677) This study was also supported by the European Union and the State of Hungary, cofinanced by the European Social Fund in the framework of TÁMOP-4.2.4.A2-710-SZJÖ-TOK-13-0017 and TÁMOP-4.2.4.-A/2-111-2012-0001 "National Excellence Program" and MTA-SZTE Momentum Grant (LP2014-10/2014). Functional studies in the laboratory of M.S.-T. were supported by National Institutes of Health grants R01DK058088, R01DK082412, and R01DK095753.

The authors declare no conflict of interest.

Supplemental digital contents are available for this article. Direct URL citations appear in the printed text and are provided in the HTML and PDF versions of this article on the journal's Web site (www.pancreasjournal.com).

Copyright $(\subseteq 2015$ Wolters Kluwer Health, Inc. All rights reserved.
Key Words: pancreatic adenocarcinoma, CCK-B receptor, alternative splicing, survival, genetic risk factor

(Pancreas 2015;00: 00-00)

$P$ ancreatic ductal adenocarcinoma (PDAC) has the highest mortality rate of all malignancies. There is no effective screening available and advanced disease is commonly present at initial diagnosis. ${ }^{1}$ Established risk factors are cigarette smoking, chronic pancreatitis, diabetes mellitus, and increased body mass. ${ }^{2}$ Inherited genetic factors also play an important role in familiar and sporadic occurrences of pancreatic cancer. Several highly penetrant susceptibility genes have been identified, including $B R C A 1, B R C A 2, p 16 /$ CDKN2A, STK11/LKB, TP53, APC, PRSS1, SPINK1, PALLD, and $P A L B 2$, which are mainly associated with familial cancer syndromes and familial pancreatic cancer. ${ }^{3,4}$ In sporadic case patients, more common genetic variants are implicated, which represent a minor risk for the disease, such as variants in the ABO blood group gene. ${ }^{5,6}$ To date, 5 genome-wide association studies have described multiple susceptibility loci associated with the risk of pancreatic cancer. ${ }^{5-9}$ Smith et $\mathrm{al}^{10}$ reported a common single nucleotide polymorphism in the cholecystokinin-B receptor gene $(C C K B R)$ as a risk factor for PDAC, which has not been observed in prior genome-wide association studies. The authors showed in a small cohort (51 case patients and 39 control subjects) that variant c.811+32C $>\mathrm{A}$ (rs1800843) located in intron 4 of $C C K B R$ increased PDAC risk and was also associated with poorer survival. In a more recent follow-up study, Smith et al ${ }^{11}$ replicated their results in a larger North American multicenter cohort (931 case patients and 59 control subjects) and confirmed both increased PDAC risk (odds ratio [OR], 2.28; CC vs. AC plus AA genotypes) and shorter survival (hazard ratio, 1.56) associated with variant c. $811+32 \mathrm{C}>\mathrm{A}$. The gastrin/CCK-B receptor is a member of the $G$ protein-coupled receptor superfamily, physiologically expressed in the human pancreas. ${ }^{12}$ Binding of gastrin or CCK triggers activation of multiple signal transduction pathways that relay mitogenic signals to the nucleus and promote cell proliferation. Numerous studies have shown that the CCK-B receptor plays a significant role in carcinogenesis and tumor progression. ${ }^{13,14}$ An alternatively spliced messenger RNA (mRNA) form of the receptor generated by retention of intron 4 (designated CCK-BRi4sv for intron 4-containing splice variant, also referred to as CCK-C receptor) was reported in various tumors, ${ }^{15}$ including pancreatic cancer. ${ }^{16}$ The resulting CCK-BRi4sv receptor protein exhibits constitutive (agonist independent) activation of cell proliferation pathways. ${ }^{17}$ Using immunohistochemistry, Smith et al found that tumors with variant c. $811+32 \mathrm{C}>\mathrm{A}$ expressed CCK-BRi4sv receptor protein, suggesting that the variant might be directly responsible for intron retention. The authors speculated that binding of the splicing factor SRp5 5 might be reduced by the intronic variant resulting in enhanced retention of intron $4 .{ }^{12,13}$ 
TABLE 1. Characteristics of Patients and Control Subjects

\begin{tabular}{lcc}
\hline & PDAC Patients & Control Subjects \\
\hline $\mathrm{n}$ & 122 & 106 \\
Sex & & \\
$\quad$ Female & 59 & 61 \\
$\quad$ Male & 63 & 45 \\
Age at diagnosis/recruitment, y & & \\
$\quad$ Mean (SD) & $65.6(10.4)$ & $51.5(18.8)$ \\
$\quad$ Range & $31-89$ & $18-89$ \\
Survival days & & \\
$\quad$ Mean (SD) & $336(251.8)$ & \\
$\quad$ Median (25\%-75\%) & $260(118-465)$ & \\
\hline
\end{tabular}

There are few known risk factors in pancreatic adenocarcinoma, and a better understanding of the molecular pathogenesis is urgently needed. Therefore, we aimed to reevaluate the role of variant c. $811+32 \mathrm{C}>\mathrm{A}$ as a novel genetic prognostic marker. In this study, we had 3 objectives: (1) to replicate the association between $C C K B R$ variant c. $811+32 \mathrm{C}>\mathrm{A}$ and the risk for developing pancreatic cancer in an independent population, (2) to evaluate the impact of the variant on patient survival, and (3) to examine the functional effect of the variant on pre-mRNA splicing.

\section{METHODS}

\section{Study Population}

The study protocol has been approved by the Regional and Institutional Committee of Science and Research Ethics. All participants gave written informed consent for genetic analysis. A total of 122 case patients with a confirmed diagnosis of PDAC were recruited from the Hungarian National Pancreas Registry. For each patient, information about sex, age at diagnosis, method of diagnosis, and date of death or date of last follow-up was collected. Two patients had synchronous or metachronous cancer suggestive of inherited cancer syndromes. Other case patients were sporadic; no patients fulfilled the criteria for familial pancreatic cancer ( 2 or more first-degree relatives with pancreatic cancer). A total of 106 control subjects were recruited from adult volunteers who considered themselves generally healthy and from inpatients who had no history of pancreatic diseases. Characteristics of case T1 T2 patients and control subjects are described in Tables 1 and 2.

\section{DNA Extraction and Genotyping}

Genomic DNA was isolated from $300 \mu \mathrm{L}$ of EDTA blood using a QIAamp DNA Blood mini kit (Qiagen, Hilden, Germany). Primers were designed according to the genomic sequence of CCKBR on chromosome 11 (GenBank NC_000011.10) (see T3 primer sequences in Table 3). Polymerase chain reaction (PCR)

TABLE 2. Tumor Stage and Survival of Patients

\begin{tabular}{lcc}
\hline & No. Patients & Survival, Median (SD), Days \\
\hline Localized & 9 & $480(312)$ \\
Locally advanced & 78 & $321(267)$ \\
Metastasized & 29 & $222(204)$ \\
Unknown & 5 & \\
\hline
\end{tabular}

was performed in a total volume of $30 \mu \mathrm{L}$, which contained $0.5 \mathrm{U}$ HotStarTaq DNA Polymerase (Qiagen), $1.5 \mathrm{mM} \mathrm{MgCl}_{2}$, $0.2 \mathrm{mM}$ dNTP, $0.5 \mu \mathrm{M}$ of each primer, and 10-50 ng of genomic DNA. Amplification was performed under the following cycle conditions: $95^{\circ} \mathrm{C}$ for 15 minutes to activate the enzyme, followed by 40 cycles of 30 -second denaturation at $94^{\circ} \mathrm{C}, 30$-second annealing at $58^{\circ} \mathrm{C}$, and 1 -minute extension at $72^{\circ} \mathrm{C}$, with a final extension of 5 minutes. Before sequencing, PCR products were purified with a QIAquick PCR Purification Kit (Qiagen). Nucleotide sequence analysis was carried out in a commercial laboratory (Delta Bio 2000 Ltd, Szeged, Hungary) using a 3500 Genetic Analyser (Applied Biosystems) automatic dye-terminator sequencing machine. The reverse PCR primer was used as sequencing primer. Chromatograms were analyzed with ChromasPro software (Technelysium, South Brisbane, Australia).

\section{Construction of Expression Plasmids Harboring CCKBR Minigenes}

We designed $C C K B R$ minigenes that contain intron 4 placed in the appropriate context of the full-length coding DNA (Fig. 1). F1 CCKBR coding DNA (GenBank NM_176875.3) was custom synthesized (GenScript) and cloned into the pcDNA3.1(-) plasmid using $X h o \mathrm{I}$ and EcoRI restriction sites. To create CCKBR minigenes, a 584-nucleotide-long fragment containing intron 4 with or without the c. $811+32 \mathrm{C}>\mathrm{A}$ variant was custom synthesized and cloned into the pcDNA3.1(-) CCKBR plasmid using BsrGI and BamHI restriction sites. Full sequences of $C C K B R$ minigenes are provided in the Supplementary Material, http://links.lww.com/MPA/A453.

\section{Construction of Lentiviral Vectors}

The pWPI lentivirus vector plasmid and the packaging plasmids (psPAX2 and pMD2.G) were obtained from Didier Trono's laboratory (http://tronolab.epfl.ch/; Ecole Polytechnique Federale de Lausanne, Lausanne, Switzerland) through Addgene (Addgene plasmids 12254, 12260, and 12259). First, CCKBR minigene templates were PCR amplified with Phusion Flash High-Fidelity PCR Master Mix (Thermo Scientific) using the following primers: 5'-GCTTAATTAACCATGGAGCTGCTAAAGCTGAACC-3' containing a $P a c$ I restriction site and $5^{\prime}$ phosphorylated $5^{\prime}$ CTCAGCCAGGGCCCAGTGTG-3'. CCKBR minigene inserts were then subcloned into the pWPI plasmid between PmeI and $P a c I$ restriction sites. The lentivirus production in human embryonic kidney (HEK) $293 \mathrm{~T}$ packaging cells was performed as described previously. ${ }^{18}$ Briefly, 293T cells were cotransfected with the pWPI expression plasmids, the packaging plasmid psPAX2, and the envelope vector pMD2.G. Transfection medium was changed after 16 hours, and the lentivirus-containing medium

TABLE 3. Oligonucleotide Primers Used in This Study

Primers Used for Genotyping

Forward 5'-CTGTGTTGCCTTCAGGTCCG-3'

Reverse 5'-ATCACCAGCAACATTCGCAC-3'

Primers Used for RT-PCR

CCKBR-total Forward 5'-TCTCCTCAACAGCAGCAGTG-3'

Reverse 5'-CCCAGGACCACGATGATGAG-3'

CCKB-Ri4sv Forward 5'-AATGGAGTTGAGCTGGGAGC-3'

Reverse 5'-TGGGCGGTCAGAGAAAAAGG-3'

GAPDH Forward 5'-CACCATCTTCCAGGAGCGAG-3

Reverse 5'- GACTCCACGACGTACTCAGC-3' 
CCKBR CDNA

Minigene wild type

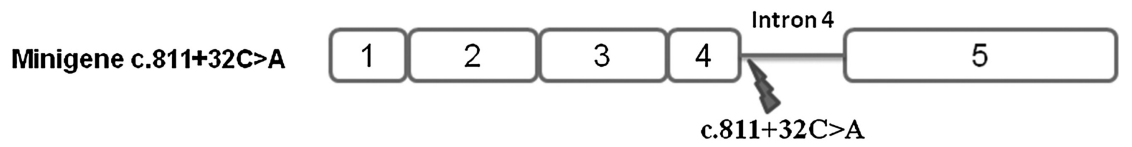

\begin{abstract}
$250 \mathrm{bp}$
FIGURE 1. Minigene constructs used to analyze the effect of the c.811+32C $>$ A variant on pre-mRNA splicing. Intron 4 was placed in the appropriate context of the CCKBR CDNA. Numbers indicate exons.
\end{abstract}

was subsequently harvested after 48 hours and frozen at $-80^{\circ} \mathrm{C}$. Viral preparations were titrated on HEK 293T cells.

\section{Cell Culture, Transfection, and Viral Transduction}

Human embryonic kidney 293T cells were cultured in 6-well plates in Dulbecco Modified Eagle Medium (Sigma, Budapest, Hungary) supplemented with $10 \%$ fetal bovine serum, $4 \mathrm{mM}$ glutamine, and $1 \%$ penicillin/streptomycin at $37^{\circ} \mathrm{C}$ in a humidified atmosphere containing $5 \% \mathrm{CO}_{2}$. Transfections of HEK 293T cells were performed at $70 \%-80 \%$ confluence using $2 \mu \mathrm{g}$ of plasmid DNA and $10 \mu \mathrm{L}$ of Lipofectamine 2000 (Life Technologies, Carlsbad, Calif) in $2 \mathrm{~mL}$ of Opti-MEM Reduced Serum Medium (Life Technologies). After 4 hours of incubation, cells were washed and the transfection medium was replaced with $2 \mathrm{~mL}$ of Dulbecco Modified Eagle Medium. Cells were harvested 24 hours after this medium change. Capan-1 pancreatic adenocarcinoma cells were maintained in RPMI-1640 Medium (Sigma) supplemented with $15 \%$ fetal bovine serum, $4 \mathrm{mM}$ glutamine, and $1 \%$ penicillin/ streptomycin at $37^{\circ} \mathrm{C}$. To establish stable cell lines, a total number of $10^{5}$ cells were plated in 6-well plates and transduced with viral supernatant at multiplicities of infection of 4 . Expression analysis was performed at the first, second, and third passage.

\section{RNA Extraction and Reverse Transcription}

Total RNA was isolated from transfected cells using an RNeasy Mini Kit (Qiagen). To avoid plasmid and genomic DNA contamination, an additional on-column DNase digestion step was applied with RNase-Free DNAse (Qiagen). Two micrograms of RNA was reverse transcribed using a High Capacity cDNA Reverse Transcription Kit (Applied Biosystems, Foster City, Calif) in the presence of RNase inhibitor RNasin Plus (Promega, Fitchburg, Wis).

\section{Quantification of CCKBR Expression and Splicing}

Real-time PCR reactions were performed with Maxima SYBR Green/ROX qPCR Master Mix $(2 \times)$ (Fermentas) on an ABI PRISM 7000 Sequence Detection System (Applied Biosystems) platform with the following conditions: 10 minutes initial denaturation at $95^{\circ} \mathrm{C}$, followed by 40 two-step cycles: 15 seconds at $95^{\circ} \mathrm{C}$ and 1 minute at $60^{\circ} \mathrm{C}$. Primer sequences are given in Table 3. Threshold cycle (CT) values were determined using the 7000 Sequence Detection System Software V.1.2.3. Relative expression was calculated using the comparative CT method $(\Delta \Delta \mathrm{CT}$ method). Expression level of $C C K B R$ was first normalized to the glyceraldehyde-3-phosphate dehydrogenase $(G A P D H)$ internal control gene $(\triangle \mathrm{CT})$ and then to expression levels measured in cells transfected with empty vector $(\Delta \Delta \mathrm{CT})$. Results were expressed as fold changes calculated with the formula $2^{-\Delta \Delta C T}$. Relative expression of splice variants was studied by using 2 different primer sets, one amplifying both the spliced and unspliced forms of CCKBR and the other amplifying the intron 4-retaining splice variant $(C C K B-R i 4 s v)$ only. For absolute quantification of total CCKBR and $C C K-B R i 4 s v$ expression, we generated external calibration curves using serial dilutions of minigene plasmid templates. Using the calibration curves, copy numbers of total $C C K B R$ and unspliced $C C K-B R i 4 s v$ were determined and expressed as percentage of total (spliced plus unspliced) $C C K B R$ expression. All reactions were performed in duplicate.

\section{Statistical Analysis}

Quantitative variables were described as mean \pm SE. Observed genotype frequencies in the study population were compared with the expected Hardy-Weinberg equilibrium. To test the association between pancreatic cancer and genotype/allele frequencies, we used 2-tailed Fisher exact test. Additional ORs with $95 \%$ confidence interval were estimated. Overall survival was defined as the time interval between diagnosis and death (uncensored observation) or the last date when the patient was still known to be alive (censored observation). Survival curves were calculated for overall survival of patients according to KaplanMeier. Two-sided log rank test was used to compare the difference between survival of pancreatic cancer patients harboring the A-allele (A/A or $\mathrm{A} / \mathrm{C})$ with survival of those patients with the $\mathrm{C} / \mathrm{C}$ genotype. Median survival time was calculated using data from all patients; median follow-up time was computed with censored observations. All the analyses were performed with

TABLE 4. Genotype and Allele Frequencies of Variant c.811 $+32 \mathrm{C}>\mathrm{A}$ in PDAC Patients and Control Subjects

\begin{tabular}{lrrcc}
\hline & $\begin{array}{c}\text { PDAC } \\
\text { Patients }\end{array}$ & $\begin{array}{c}\text { Control } \\
\text { Subjects }\end{array}$ & $\begin{array}{c}\text { Genotypic } \\
\text { OR (95\% CI) }\end{array}$ & $\boldsymbol{P}$ \\
\hline $\mathrm{CC}$ & $82 / 122$ & $71 / 106$ & Reference & - \\
$\mathrm{AC}$ & $35 / 122$ & $32 / 106$ & $0.947(0.5328-1.683)$ & 0.884 \\
$\mathrm{AA}$ & $5 / 122$ & $3 / 106$ & $1.443(0.339-6.255)$ & 0.7271 \\
$\mathrm{AC}+\mathrm{AA}$ & $40 / 122$ & $35 / 106$ & $0.9895(0.5686-1.722)$ & 1 \\
& & & Allelic OR (95\% CI) & \\
Minor allele & $18.4 \%$ & $17.9 \%$ & $1.01(0.58-1.76)$ & 1 \\
frequency & & & & \\
\hline
\end{tabular}

CI indicates confidence interval. 


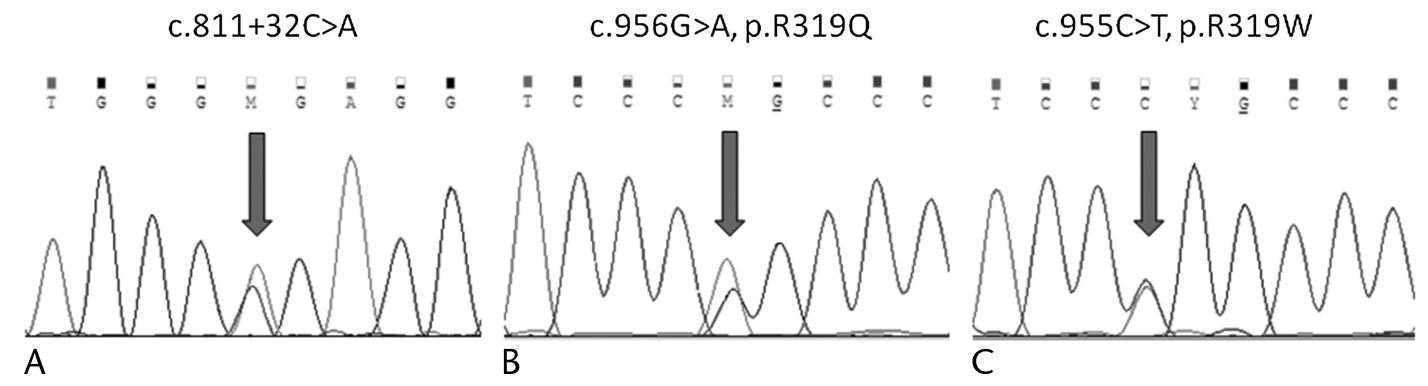

FIGURE 2. Sequence electropherograms of CCKBR gene variants found in our cohort.

GraphPad Prism (San Diego, Calif). For sample size calculation, we used Quanto v.1.2.4. ${ }^{19}$

\section{RESULTS}

\section{Variant c.811+32C >A Does Not Predict Risk for PDAC}

First, we attempted to replicate the published association between variant c. $811+32 \mathrm{C}>\mathrm{A}$ in intron 4 of $C C K B R$ and the risk for developing pancreatic cancer. To this end, we sequenced this region of $C C K B R$ in our Hungarian cohort and detected variant c. $811+32 \mathrm{C}>\mathrm{A}$ in 35 heterozygous and 5 homozygous case patients (allele frequency, 18.4\%) and in 32 heterozygous and 3 homozygous control subjects (allele frequency, 17.9\%). Similar to allele frequencies, genotype frequencies did not show a statistically significant difference between case patients and control subjects

T4 either (Table 4). Genotype frequencies in case patients and control subjects were found to conform to the Hardy-Weinberg equilibrium. Additionally, we identified 2 variants in exon 5: c. $955 \mathrm{C}>\mathrm{T}$ (p.R319W, rs113168010) in 1 control subject and c.956G $>A$

F2 (p.R319Q, rs1805001) in a single patient (Fig. 2).

\section{Variant c.811+32C $>$ A Does Not Predict Survival in PDAC}

To address the hypothesis that variant c. $811+32 \mathrm{C}>\mathrm{A}$ may have a prognostic relevance, we analyzed this variant in relation

F3 to patient survival (Fig. 3). Median follow-up time was 334 days; $12.3 \%$ of the observations were censored. Median survival of case patients with $\mathrm{A} / \mathrm{C}$ and $\mathrm{A} / \mathrm{A}$ genotypes was not significantly different from those with the CC genotype (257 days and 266 days, respectively; $P=0.45$ ), indicating that this variant does not modify survival of PDAC patients.

\section{Variant c.811+32C $>$ A Does Not Affect Splicing of Intron 4 in CCKBR}

To determine whether variant c. $811+32 \mathrm{C}>\mathrm{A}$ has an effect on pre-mRNA splicing; we have tested 2 different cell lines. Human embryonic kidney $293 \mathrm{~T}$ cells were transfected with expression plasmids carrying $C C K B R$ minigenes with or without the intron 4 variant and examined mRNA expression. CCKBR expression in transfected HEK 293 T cells was about 6 orders of magnitude

F4 higher than endogenously expressed levels (Fig. 4A). Interestingly, CCKBR mRNA was expressed at 1.5-fold higher levels when cells were transfected with intron-containing minigenes compared with cells transfected with the intronless $C C K B R$ cDNA construct. This phenomenon is in agreement with published observations that the presence of introns can enhance gene expression. ${ }^{20,21}$ For absolute quantification of different splice forms, we generated calibration curves using minigene plasmids as template. We found that expression of the CCK-BRi4sv intron 4-retaining splice variant corresponded to approximately $10 \%$ of total CCKBR mRNA and was not different between cells transfected with minigenes with or without the c.811+32C $>$ A variant (Fig. 4C). Because splicing factors can be differently expressed in carcinoma cells, we have analyzed CCKBR splicing in Capan-1 pancreatic adenocarcinoma cells as well. In line with the data on HEK 293T cells, splicing was not affected by the variant c. $811+32 \mathrm{C}>\mathrm{A}$ (Figs. 4B, D).

\section{DISCUSSION}

Identification of pancreatic cancer susceptibility genes is of outmost importance to define high-risk populations who may benefit from early detection by screening tests. Based on its role in pancreatic carcinogenesis and regulation of tumor growth, $C C K B R$ is a promising candidate for a susceptibility gene. Indeed, several somatic mutations were identified in colorectal and gastric cancers that alter receptor activity, sensitization, and localization. ${ }^{22,23}$ Some of these mutations are located in the third intracellular loop of the receptor, which plays a critical role in signal transduction. The same loop is altered by the tumor-associated $C C K-B R i 4 s v$ splice variant, which retains intron 4 and codes for an insertion of 69 additional amino acid residues that enhances receptor activity. ${ }^{17}$ The molecular basis for this alternative splicing has been explained by aberrant expression of certain auxiliary splicing factors in carcinoma cells that are necessary for the spliceosome assembly. ${ }^{24}$ Alternatively, Smith et al ${ }^{10,14}$ proposed AQ1 that the c. $811+32 \mathrm{C}>\mathrm{A}$ intronic variant in $C C K B R$ can induce retention of intron 4 and thereby increase risk for the development of PDAC and also lead to poorer survival in carriers. ${ }^{12,13}$ In contrast, here we demonstrated that variant $\mathrm{c} .811+32 \mathrm{C}>\mathrm{A}$ has no effect on CCKBR mRNA splicing, and it is not associated with increased risk for pancreatic cancer or with shorter survival in PDAC. Although we had more than $85 \%$ statistical power to replicate the previously described $\mathrm{OR}$ of 2.28 , we detected no

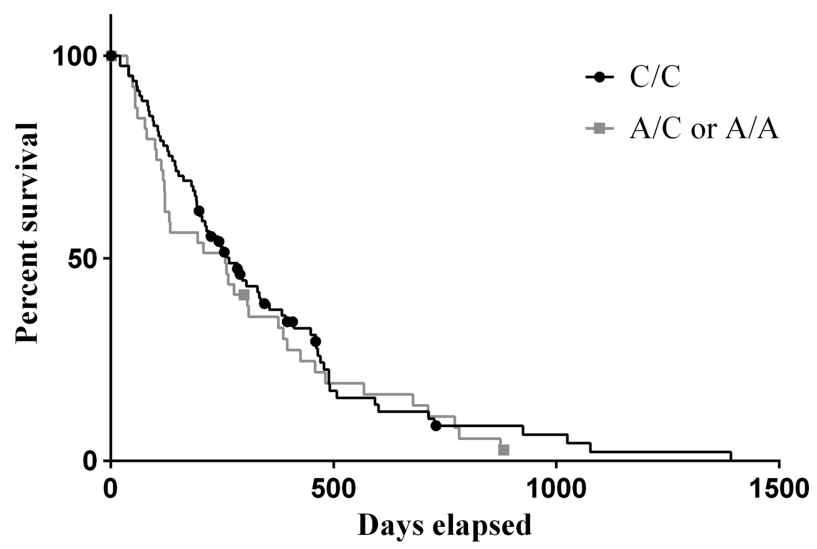

FIGURE 3. Kaplan-Meier survival curves according to genotype. Censored case patients are shown as dots and squares. 


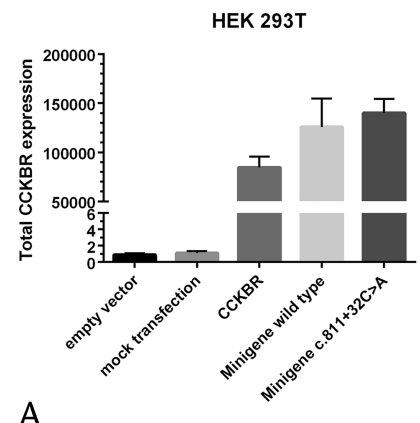

A

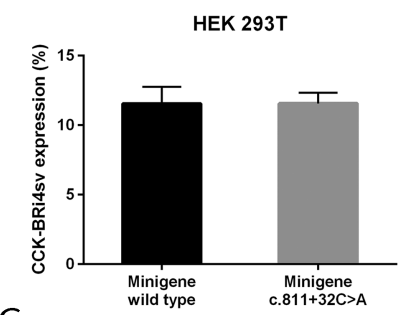

C

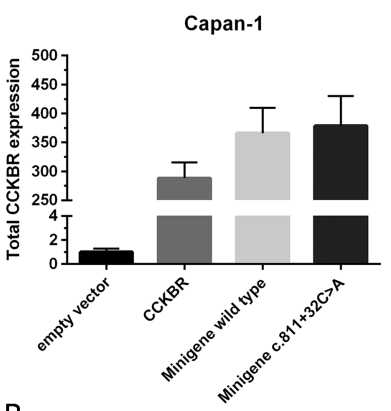

B

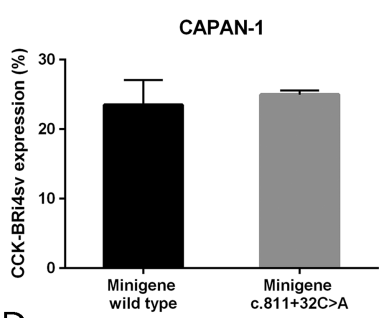

D

3. Marcus DM. The ABO and Lewis blood-group system. Immunochemistry, genetics and relation to human disease. N Engl J Med. 1969;280:994-1006.

4. Wolpin BM, Chan AT, Hartge P, et al. ABO blood group and the risk of pancreatic cancer. J Natl Cancer Inst. 2009;101:424-431.

5. Amundadottir L, Kraft P, Stolzenberg-Solomon RZ, et al. Genome-wide association study identifies variants in the ABO locus associated with susceptibility to pancreatic cancer. Nat Genet. 2009;41:986-990.

6. Low SK, Kuchiba A, Zembutsu H, et al. Genome-wide association study of pancreatic cancer in Japanese population. PLoS One. 2010;5:e11824.

7. Wu C, Miao X, Huang L, et al. Genome-wide association study identifies five loci associated with susceptibility to pancreatic cancer in Chinese populations. Nat Genet. 2011;44:62-66.

8. Petersen GM, Amundadottir L, Fuchs CS, et al. A genome-wide association study identifies pancreatic cancer susceptibility loci on chromosomes 13q22.1, 1q32.1 and 5p15.33. Nat Genet. 2010;42:224-228.

9. Wolpin BM, Rizzato C, Kraft P, et al. Genome-wide association study identifies multiple susceptibility loci for pancreatic cancer. Nat Genet. 2014;46:994-1000.

10. Smith JP, Harms JF, Matters GL, et al. A single nucleotide polymorphism of the cholecystokinin-B receptor predicts risk for pancreatic cancer. Cancer Biol Ther. 2012;13:164-174.

11. Smith JP, Whitcomb DC, Matters GL, et al. Distribution of cholecystokinin-B receptor genotype between patients with pancreatic cancer and controls and its impact on survival. Pancreas. 2015;44: 236-242.

HEK 293 T cells (A) and transduced Capan- 1 cells (B) with the indicated constructs. Expression of the intron-retaining splice variant relative to the total amount of CCKBR mRNA in HEK 293T cells (C) and Capan- 1 cells (D).

enrichment of the variant in our PDAC cohort. The reasons for the discrepancy between our results and those of Smith et al ${ }^{10,14}$ are not readily apparent but may be related to ethnic and geographic variability of the frequency of the $c .811+32 \mathrm{C}>\mathrm{A}$ variant and the admixed nature of the US cohort. Association studies in ethnically admixed populations are potentially vulnerable to spurious association because of the ethnic variability of the single nucleotide polymorphism frequency studied. Indeed, data retrieved from the 1000 Genome Project database (www.1000genomes.org) show that the allele frequency of variant c. $811+32 \mathrm{C}>\mathrm{A}$ is $18.4 \%$ in subjects of European origin, whereas it is $2 \%$ in subjects of Asian descent and $23 \%$ in subjects of African descent. We also note that

AQ2 the control group in the study by Smith and Solomon ${ }^{14}$ was unusually small (59 subjects), which might result in the incorrect determination of control genotype frequencies. Indeed, the reported minor allele frequency (11.8\%) for this control cohort is appreciably smaller than the incidence found in our control subjects (17.9\%), which compares well with the 1000 Genomes data.

In conclusion, data presented here argue that the intronic variant c. $811+32 \mathrm{C}>\mathrm{A}$ in $C C K B R$ is not associated with PDAC risk or survival in a Hungarian cohort and does not alter splicing of the $C C K B R$ pre-mRNA. Despite the fact that our study was not designed to detect a potentially small effect of variant c.811 $+32 \mathrm{C}>\mathrm{A}$ on cancer risk and we did not take into account age and tumor stage at diagnosis when analyzing survival, our findings are convincingly self-consistent. Therefore, we propose that variant c. $811+32 \mathrm{C}>\mathrm{A}$ is functionally harmless and it should be considered a common polymorphism with no clinical significance. Finally, our results highlight the necessity for replication studies and the importance of functional testing of new genetic risk markers.

\section{REFERENCES}

1. Hidalgo M. Pancreatic cancer. N Engl J Med. 2010;362:1605-1617.

2. Lowenfels AB, Maisonneuve P. Epidemiology and risk factors for pancreatic cancer. Best Pract Res Clin Gastroenterol. 2006;20:197-209.

12. Rozengurt E, Walsh JH. Gastrin, CCK, signaling, and cancer. Annu Rev Physiol. 2001;63:49-76.

13. Aly A, Shulkes A, Baldwin GS. Gastrins, cholecystokinins and gastrointestinal cancer. Biochim Biophys Acta. 2004;1704:1-10.

14. Smith JP, Solomon TE. Cholecystokinin and pancreatic cancer: the chicken or the egg? Am J Physiol Gastrointest Liver Physiol. 2014;306:G91-G101.

15. Körner M, Waser B, Reubi JC, et al. CCK(2) receptor splice variant with intron 4 retention in human gastrointestinal and lung tumours. J Cell Mol Med. 2010;14:933-943.

16. Smith JP, Verderame MF, McLaughlin P, et al. Characterization of the CCK-C (cancer) receptor in human pancreatic cancer. Int J Mol Med. 2002; 10:689-694.

17. Hellmich MR, Rui XL, Hellmich HL, et al. Human colorectal cancers express a constitutively active cholecystokinin-B/gastrin receptor that stimulates cell growth. J Biol Chem. 2000;275:32122-32128.

18. Dawson K, Wakili R, Ördög B, et al. MicroRNA29: a mechanistic contributor and potential biomarker in atrial fibrillation. Circulation. 2013; 127:1466-1475, 1475e1-28

19. Gauderman WJ, Morrison JM. QUANTO 1.1: a computer program for power and sample size calculations for genetic-epidemiology studies. http://hydra.usc.edu/gxe/ Accessed May 4, 2009.

20. Wiegand HL, Lu S, Cullen BR. Exon junction complexes mediate the enhancing effect of splicing on mRNA expression. Proc Natl Acad Sci U S A. 2003;100:11327-11332.

21. Kereszturi E, Király O, Sahin-Tóth M. Minigene analysis of intronic variants in common SPINK1 haplotypes associated with chronic pancreatitis. Gut. 2009;58:545-549.

22. Willard MD, Lajiness ME, Wulur IH, et al. Somatic mutations in CCK2R alter receptor activity that promote oncogenic phenotypes. Mol Cancer Res. 2012;10:739-749

23. Schmitz F, Otte JM, Stechele HU, et al. CCK-B/gastrin receptors in human colorectal cancer. Eur J Clin Invest. 2001;31:812-820.

24. Ding W-Q, Kuntz SM, Miller LJ. A misspliced form of the cholecystokinin-B/gastrin receptor in pancreatic carcinoma: role of reduced cellular U2AF35 and a suboptimal 3'-splicing site leading to retention of the fourth intron. Cancer Res. 2002;62:947-952. 


\section{AUTHOR QUERIES}

\section{AUTHOR PLEASE ANSWER ALL QUERIES}

AQ1 = Both occurrences of "Smith et al. (2012, 2014)" were changed to "Smith et al. ${ }^{10,14 " ~(t h e ~ s u p e r s c r i p t ~} 10$ and 14 being the corresponding reference citations). Is this correct?

AQ2 = "Smith et al (2014) was changed to "Smith and Solomon" ${ }^{14 " ~(t h e ~ s u p e r s c r i p t ~} 14$ being the corresponding reference citation). Is this correct?

\section{END OF AUTHOR QUERIES}

